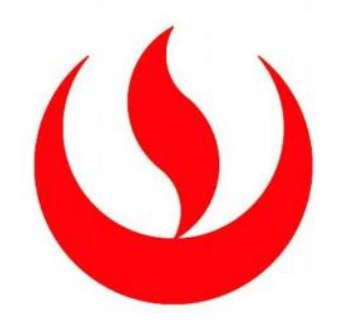

UNIVERSIDAD PERUANA DE CIENCIAS APLICADAS

\author{
FACULTAD DE NEGOCIOS
}

CARRERA DE ADMINISTRACIÓN DE EMPRESAS

\title{
Análisis de la gestión administrativa del Hospital Guillermo Almenara Irigoyen y su impacto en el manejo de la lista única de oportunidad quirúrgica
}

\author{
TESIS
}

Para optar el título profesional de Licenciado en Administración de Empresas

\author{
AUTOR
}

Palma Meyhuey, Diana Cecilia (0000-0002-4852-3797)

Ruiz Barrios, Leyla Lisett (0000-0002-6864-1539)

ASESOR DE TESIS

Jorge Ruiz, Marisol (0000000309492876) 
“... La administración es la consecución de metas organizacionales en forma adecuada y eficaz planeando, organizando, dirigiendo y controlando los recursos."

Richard L. Daft. Administración 


\section{DEDICATORIA}

\section{A : Dios y a la Virgen:}

Por permitirnos estar presentes con buena salud, por las bendiciones que nos otorga día a día, entre ellas la bendición de llegar a esta etapa importante en nuestras vidas y protegernos en todo el camino para lograr nuestros objetivos.

A : Nuestros Padres:

Quienes son el motor de nuestra vida y mediante su apoyo incondicional nos hacen saber siempre su amor. De igual forma a todas las personas que nos ayudaron en esta etapa, nuestro eterno agradecimiento. 


\section{AGRADECIMIENTOS}

A Dios, por estar siempre presente en cada etapa de nuestras vidas, guiándonos y dándonos las fuerzas necesarias para afrontar cualquier adversidad; él nos guarda y nos guía siempre.

Agradecemos de manera especial a nuestra asesora, Licenciada Marisol Jorge, quien fue guía y apoyo incondicional a lo largo del desarrollo de esta tesis. 


\section{RESUMEN}

El presente trabajo de tesis tiene como objetivo brindar un diagnóstico situacional a través de un análisis de contexto de la gestión administrativa y de las herramientas de gestión vinculadas al manejo de la lista de espera de oportunidad quirúrgica del Hospital Guillermo Almenara Irigoyen. En el primer capítulo, se presenta el marco teórico necesario para el desarrollo de la propuesta, tratándose temas de la Seguridad Social de Salud, Sistema de Salud en Perú, Red Asistencial Almenara, Hospital Guillermo Almenara, Plan Operativo Institucional, Normas para la gestión de la oportunidad quirúrgica y conceptos de administración. En el segundo capítulo, se realiza el análisis y diagnóstico de la situación actual del Hospital Guillermo Almenara Irigoyen, a través del uso de diversas herramientas metodológicas de investigación como la bitácora de contexto y matriz de procesamiento, dando a conocer los elementos que intervienen en el tema de investigación. Es así que, en el tercer capítulo se procede al análisis e interpretación de la información obtenida con el objetivo de responder a la pregunta de investigación y los objetivos de este trabajo. En el cuarto capítulo, identificamos algunas situaciones no consideradas que aparecieron en el desarrollo del trabajo. Finalmente, en el quinto capítulo se brindan las conclusiones y recomendaciones basadas en la investigación desarrollada.

Palabras clave :

Herramientas de gestion, Lista de espera, Gestion administrativa, Oportunidad quirugica. 


\begin{abstract}
This thesis work aims to provide a situational diagnosis through a contextual analysis of the administrative management and management tools linked to the management of the hold status of surgical opportunity of Guillermo Almenara Irigoyen Hospital. In the first chapter, the theoretical framework necessary for the development of the proposal is presented, dealing with issues of Social Health Insurance, Health System in Peru, Almenara Social Network Service, Guillermo Almenara Hospital, Institutional Operational Plan, Management of Surgical Opportunity Standards and Administration concepts. In the second chapter, the analysis and diagnosis of the current situation of the Guillermo Almenara Irigoyen Hospital are made, through the use of various methodological tools of investigation, such as the context log and the processing matrix, making known the elements that are involved in the research topic. Thus, in the third chapter, we proceed to the analysis and interpretation of the information obtained in order to answer the research question and the objectives of this work. In the fourth chapter, we identified some situations that appeared during the development of the work that we had not considered. Finally, in the fifth chapter, the conclusions and recommendations based on the research developed are provided.
\end{abstract}

Keywords:

Management tools, Waiting list, Administrative management, Surgical opportunity. 
TABLA DE CONTENIDO

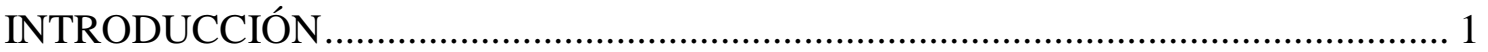

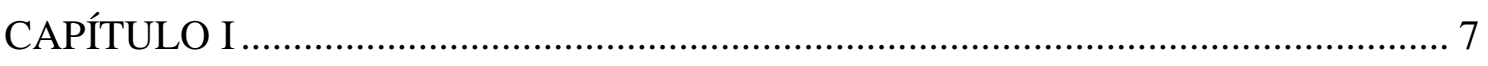

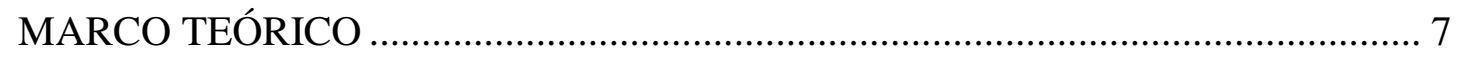

1.1. El sistema de salud en el Perú ………....................................................... 7

1.1.1. Breve reseña histórica del Seguro Social de Salud.................................... 15

1.1.2. Servicios de ESSALUD en Perú al año 2017 ............................................. 17

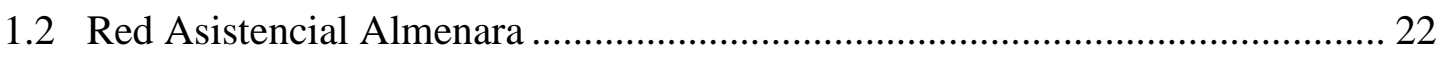

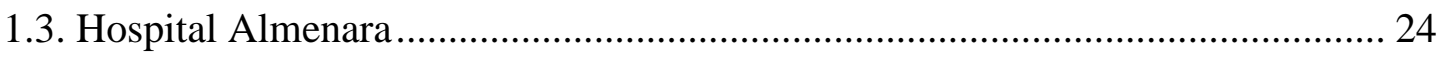

1.3.1 Breve Reseña Histórica del Hospital Almenara ............................................ 24

1.3.2. Gerencia Quirúrgica del Hospital Almenara .............................................. 26

1.3.3. Normas para la gestión de la oportunidad quirúrgica en el Seguro Social de

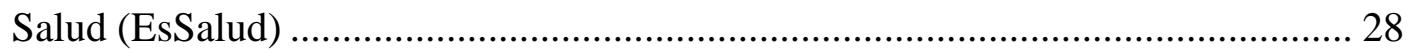

1.3.4. Plan Operativo Institucional 2017 Hospital Almenara............................... 31

1.4. Conceptos generales de la Administración......................................................... 32

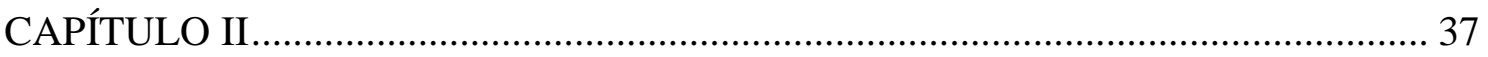

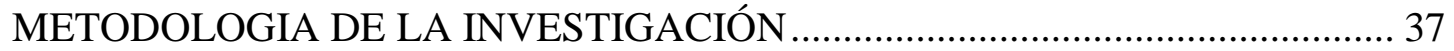

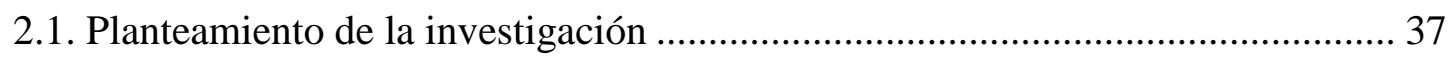

2.1.1. Propósito de la investigación ................................................................. 37

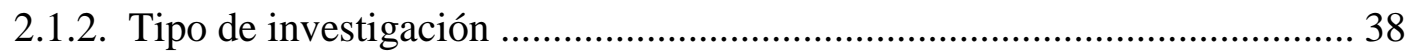

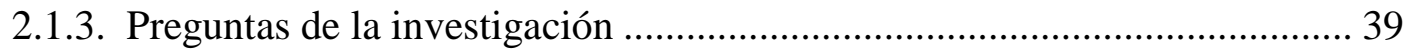

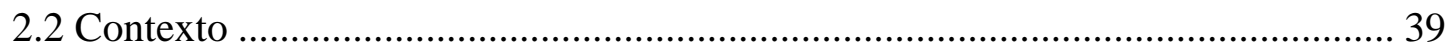

2.2.1. Descripción del contexto interno y externo:............................................... 39

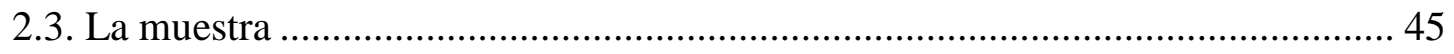

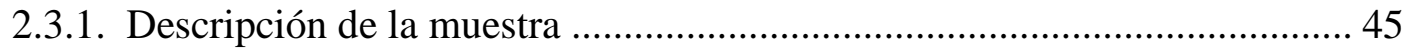




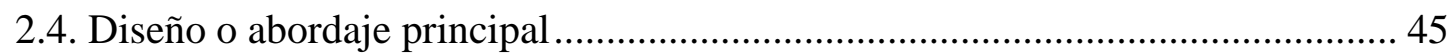

2.4.1. Identificación de la estructura de la entrevista .......................................... 45

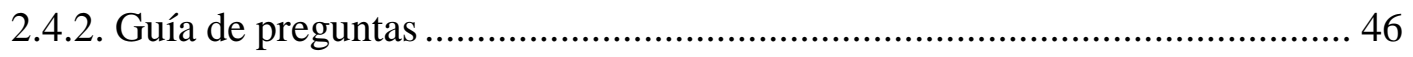

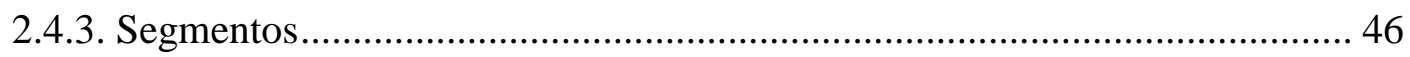

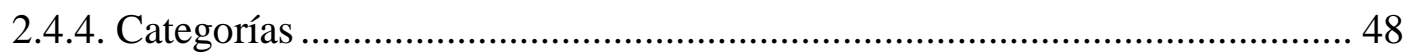

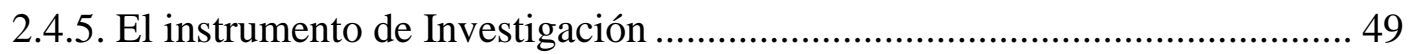

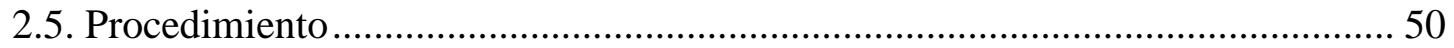

2.5.1. Matriz de procesamiento - codificación:.................................................. 50

2.5.2. Procesamiento de la información .......................................................... 55

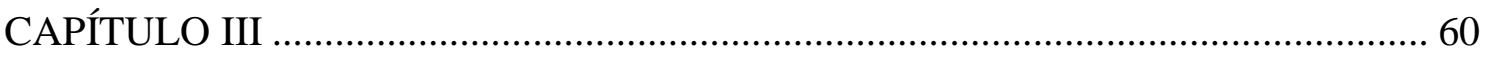

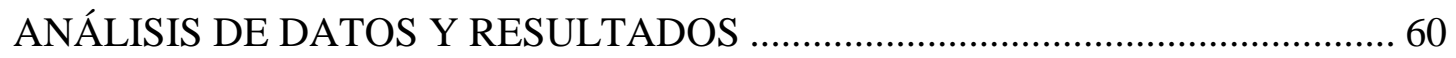

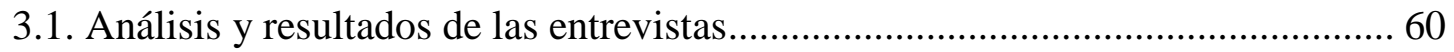

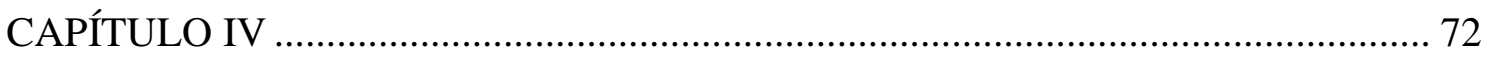

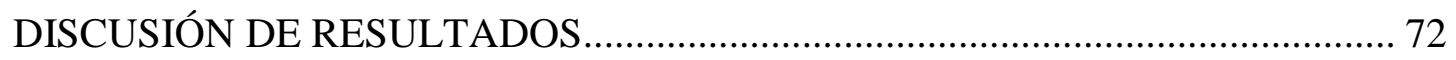

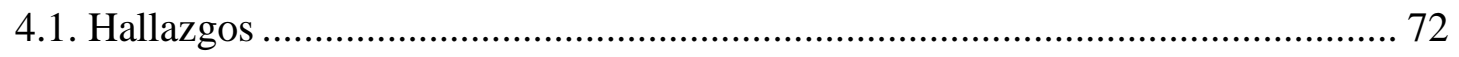

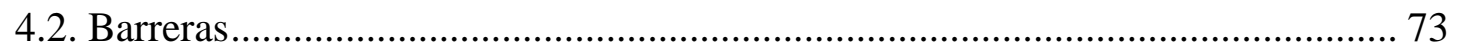

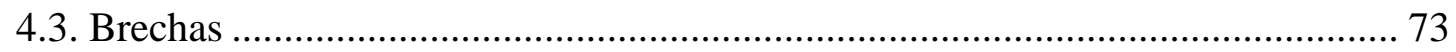

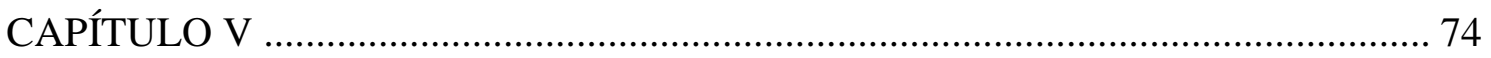

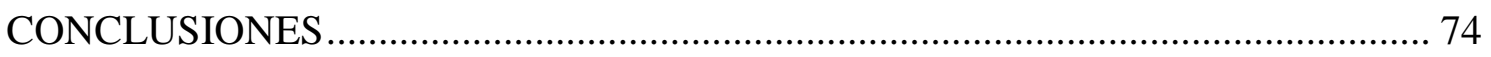

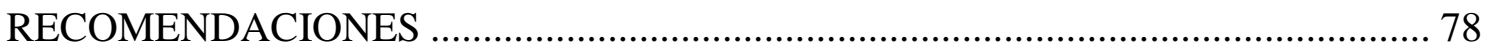

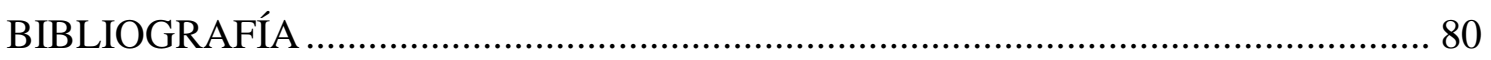

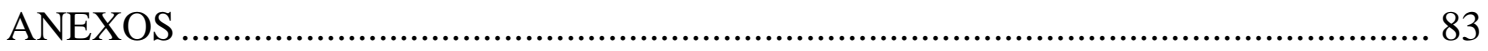




\section{ÍNDICE DE FIGURAS}

Figura 1. Mapa del Sistema de Salud, Perú 2016. Adaptado de "El Sistema de Salud en Perú-situación y desafíos”, por ESSALUD, 2017, según Lazo, Alcalde y Espinoza, 2016.

Figura 2. Cobertura según Instituciones administradoras de fondos para el aseguramiento en salud (Iafas). Adaptado de "El Sistema de Salud en Perú-situación y desafíos", por Lazo, Alcalde y Espinoza, 2016 9

Figura 3. Norma Técnica de Salud "Categorías de Establecimientos del Sector Salud", según información del MINSA 2006. Adaptado del portal MINSA. Elaboración Propia.

Figura 4. Distribución de la población de asegurados en ESSALUD, según estadísticas recientes. Adaptado de "Población Asegurada Activa 2017”, por ESSALUD, 2017"

Figura 5. Evolución de la Producción de Consulta Externa en ESSALUD, según estadísticas recientes. Adaptado de "Memoria Institucional 2016", por ESSALUD, $2017 "$ 18

Figura 6. Evolución de la Producción de Egresos Hospitalarios en ESSALUD, según estadísticas recientes. Adaptado de "Memoria Institucional 2016", por ESSALUD, $2017 "$

Figura 7. Evolución de la Producción de Emergencias en ESSALUD, según estadísticas recientes. Adaptado de "Memoria Institucional 2016”, por ESSALUD, 2017” .... 19

Figura 8. Evolución de Sesiones de Hemodiálisis en ESSALUD, según estadísticas recientes. Adaptado de "Memoria Institucional 2016”, por ESSALUD, 2017” .... 20 
Figura 9. Evolución de Sesiones de Intervenciones Quirúrgicas en ESSALUD, según estadísticas recientes. Adaptado de "Memoria Institucional 2016", por ESSALUD, $2017 "$ 20

Figura 10. Variación de Producción de Intervenciones Quirúrgicas en Hospitales a Nivel Nacional en ESSALUD, según estadísticas recientes. Adaptado de "Información gerencial de principales prestaciones de salud a setiembre 2017”, por ESSALUD, $2017 "$ 22

Figura 11. Organigrama Gerencia de Red Asistencial “Estructura Orgánica Hospital Nacional Guillermo Almenara Irigoyen”, según información del Reglamento de Organización y Funciones de la Red Asistencial Almenara 2011. Adaptado del portal ESSALUD. Elaboración Propia. 24

Figura 12. Organigrama de la Gerencia Quirúrgica del Hospital Almenara, según información de EsSalud 2018. Adaptado del Reglamento de Organización y Funciones Red Prestacional Almenara 2018. 


\section{ÍNDICE DE TABLAS}

Tabla 1. Bitácora del contexto donde se desarrolló la investigación de campo. ............ 40

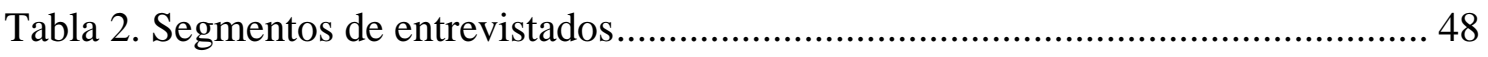

Tabla 3. Tabla de procesamiento de codificación de las entrevistas realizadas ............. 50

Tabla 4. Procesamiento de aspectos positivos y negativos de las entrevistas a los Gerentes Quirúrgicos. 55

Tabla 5. Procesamiento de aspectos positivos y negativos de las entrevistas a los Jefes Administrativos 56

Tabla 6. Procesamiento de aspectos positivos y negativos de las entrevistas a los Jefes de Departamento 56

Tabla 7. Procesamiento de aspectos positivos y negativos de las entrevistas a los Jefes de Servicio 57

Tabla 8. Procesamiento de aspectos positivos y negativos de las entrevistas al personal Personal Administrativo 57

Tabla 9. Procesamiento de aspectos positivos y negativos de las entrevistas al personal Personal Médico 58

Tabla 10. Procesamiento de aspectos positivos y negativos de las entrevistas al personal Personal Administrativo 59 


\section{INTRODUCCIÓN}

El Seguro Social de Salud (EsSalud) se creó bajo la Ley Nº 27056 del año 1999, como un organismo público descentralizado con personalidad jurídica de derecho público interno, adscrito al sector Trabajo y Promoción del Empleo, con autonomía técnica, administrativa, económica, financiera, presupuestal y contable. Su finalidad es brindar cobertura a los asegurados y sus derechohabientes a través del otorgamiento de prestaciones de prevención, promoción, recuperación y rehabilitación; y prestaciones económicas y sociales que corresponden al régimen contributivo de la Seguridad Social en Salud.

EsSalud es una institución que integra funciones de administración de fondos (rol asegurador - financiador) y provisión de servicios de salud en sus instituciones especializadas y dentro de una red de hospitales y centros de salud.

Entre ellas, está el Hospital Guillermo Almenara Irigoyen, en adelante Hospital Almenara, el cual es responsable de otorgar atención integral de salud a la población asegurada en el ámbito geográfico asignado, mediante la articulación de los centros asistenciales con diferente nivel de complejidad que la conforman; no obstante, se presentan muchos reclamos que reflejan la insatisfacción del asegurado.

En la Encuesta Nacional Socioeconómica de acceso a la salud de los asegurados de EsSalud, realizada el primer trimestre del año 2015 a una muestra de 25000 viviendas, con un nivel de confianza del 95\%, se indica que a dicha fecha el $22.6 \%$ de una población de 1,009,513 asegurados con alguna enfermedad vigente, no se atendieron porque no consiguieron citas. El $12.5 \%$ señala problemas con las referencias, el 10.9\% refirió la mala atención, el $6.1 \%$ de los reclamos se debieron a la postergación quirúrgica y un $1.1 \%$ a negligencia médica. 
Como muestra de los problemas mencionados, podemos especificar medidas que EsSalud implementó, dichas medidas fueron tomadas durante el periodo del 13 de mayo al 03 de junio del 2014, en el cual se llevó a cabo la huelga nacional convocada por el Sindicato Nacional de Médicos del Seguro Social de Salud del Perú (SINAMSSOP), con un ausentismo laboral del 30\% del personal médico, generando una baja producción quirúrgica, aumentando el número de pacientes con diferimiento quirúrgico e incrementando la lista de espera.

EsSalud a fin de garantizar la atención a los asegurados aprobó mediante resolución General N 862 GG-ESSALUD - 2014 el Plan de acción "Plan Confianza Fase II - Super Plan Confianza 2014”, el cual tenía como objetivo general garantizar al paciente asegurado de EsSalud la oportunidad quirúrgica, ampliando la cobertura de los servicios a nivel intra y extra institucional, es decir, atenciones dentro de la misma red de IPRESS y también clínicas privadas.

Dicha norma tuvo como objetivo estratégico contribuir a la disminución del número de pacientes con diferimiento quirúrgico operando con oferta propia, derivando y operando pacientes en IPRESS públicas y privadas, de esta manera EsSalud se proponía recuperar el control e incrementar la capacidad operativa en los centros quirúrgicos.

En el presente "Plan Confianza Fase II - Super Plan Confianza 2014", el número de cirugías con diferimiento quirúrgico en EsSalud durante huelgas en el año 2014 de la Red Asistencial Almenara fueron 4,851 y el tiempo de espera promedio fue 194 días en el mismo periodo.

Asimismo, Virginia Baffigo, ex presidente ejecutivo de EsSalud durante el período setiembre 2012 -agosto 2016, recordó que al iniciar su gestión encontró alrededor de 10 mil cirugías postergadas por la huelga médica del año 2012 y que en menos de un año se logró revertir la lista de espera de pacientes quirúrgicos, gracias al trabajo esforzado de 
los trabajadores de EsSalud y el apoyo de las clínicas contratadas. Acciones como estas propiciaron que EsSalud buscara una medida de apalear los problemas que ocasionaban las huelgas y de esta manera hacer frente al número de cirugías postergadas; Sin embargo, de acuerdo con la "Información gerencial de principales prestaciones de salud a setiembre del año 2017”, emitida en diciembre del año 2017 por la Gerencia Central de Planeamiento y Presupuesto de EsSalud, se han realizado 152 mil 360 cirugías a nivel nacional. En promedio se registraron 30 mil 472 cirugías mensuales a nivel nacional. Las intervenciones quirúrgicas registraron una leve disminución de 1,824 cirugías menos, respecto al mismo periodo del año 2016, representando una baja del $-1.2 \%$ de las intervenciones quirúrgicas. (Seguro Social de Salud ESSALUD (2017))

Respecto al Hospital Almenara, en una entrevista realizada el 06 de marzo del 2017 a Marco Argandoña Dueñas, gerente de control del Gobierno Nacional de la Contraloría, se indica que dicho órgano presenta problemas de excesivo tiempo de espera para que un paciente sea atendido quirúrgicamente, plazos largos para la programación de citas e incumplimiento en la programación para atención quirúrgica.

Según informa el "Plan Estratégico Institucional 2017 - 2021" de EsSalud, existe una ausencia efectiva frente a la demanda de atención; EsSalud presenta un prolongado tiempo de espera quirúrgico de 81.7 días promedio; sin embargo, lo más resaltante es la cifra que muestran los hospitales de alta capacidad resolutiva, el Hospital Almenara cuyo tiempo de espera es 211 días, siendo el primer hospital con excesivo tiempo de espera seguido por el Hospital Rebagliati con 138 días.

Por otro lado, es importante mencionar que en EsSalud se establecen objetivos y metas, mediante herramientas de gestión administrativas, con la finalidad de alcanzar los resultados deseados de sus distintas y variadas actividades en determinados tiempos. Dichos lineamientos están estipulados en directivas, normadas por el Seguro Social de 
Salud, y son de uso obligatorio para los funcionarios y colaboradores que conforman la estructura organizacional de EsSalud.

El presente trabajo se enfoca en analizar la gestión administrativa que realiza el Hospital Almenara, así como conocer y analizar las herramientas de gestión aplicadas para la administración de este, las cuales intervienen en el manejo de la lista única de oportunidad quirúrgica, en adelante lista de espera. Por ello, nos planteamos como pregunta de investigación lo siguiente: ¿Qué herramientas de gestión administrativa que se aplican en el Hospital Almenara aportan a una mejor gestión de la lista única de oportunidad quirúrgica?

La hipótesis a partir de la cual se genera esta investigación es que el cumplimiento de los lineamientos establecidos en las herramientas de gestión tales como i) el Plan Operativo Institucional 2017, en adelante POI 2017 y ii) Normas para la gestión de la oportunidad quirúrgica en el Seguro Social de Salud, aprobado mediante Directiva N ${ }^{\circ}$ 015-GGESSALUD-2016, en adelante Norma 015, aportan en una mejor gestión administrativa para el manejo de la lista única de oportunidad quirúrgica.

El objetivo general de esta investigación es conocer el contexto en el cual el Hospital Almenara desarrolla su administración, a través de la aplicación de las herramientas de gestión que intervienen en la lista de espera para la atención del paciente quirúrgico.

Entre los objetivos específicos se encuentran los siguientes:

- Conocer la gestión administrativa que se realiza dentro del Hospital Almenara y describir que acciones realizan los colaboradores para mejorar el manejo de la lista de espera de oportunidad quirúrgica.

- Conocer las acciones que realizan los colaboradores del Hospital Almenara para lograr el cumplimiento de las metas estipuladas en las herramientas de gestión 
administrativa tales como: POI 2017 y Normas para la gestión de la oportunidad quirúrgica en el Seguro social de Salud 2015.

- Identificar el proceso que sigue el Hospital Almenara para el manejo de la lista de espera en la atención del paciente quirúrgico.

- Analizar la importancia de las herramientas de gestión administrativa normadas por la entidad EsSalud: Norma 015 y POI 2017 y su aplicación en la gestión administrativa para el manejo de la lista de espera de oportunidad quirúrgica.

La justificación de la presente investigación está basada en conocer la gestión administrativa y evaluar la aplicación de las herramientas de gestión que se utilizan en el Hospital Almenara relacionadas al manejo de la lista de espera para la atención del paciente quirúrgico. Esto debido a los distintos problemas que se presentan vinculados a las intervenciones quirúrgicas que repercuten en quejas, reclamos y observaciones; esto facilitará información importante a funcionarios y trabajadores de las diferentes áreas del Hospital Almenara que necesiten tener un diagnóstico situacional de cómo se maneja la lista de espera; lo cual contribuirá a que tomen acciones para lograr una gestión óptima de la lista de espera que finalmente aportará en obtener resultados positivos en la Institución EsSalud, así como para los pacientes asegurados.

Por lo tanto, nuestra investigación tiene un aporte académico y práctico, ya que proporciona información para que el Hospital Almenara evalué su gestión administrativa dado que las investigaciones en estos temas son escasas y puede contribuir a futuros estudios. 


\section{CAPÍTULO I}

\section{MARCO TEÓRICO}

\subsection{El sistema de salud en el Perú}

El Sistema de Salud en el Perú comprende dos subsistemas, el público y el privado. El primero busca expresar la lógica del derecho ciudadano a la salud y el segundo se funda en la lógica de mercado. El Ministerio de Salud (MINSA), en su rol de autoridad sanitaria nacional, gobierna el sistema. Recientemente, se creó la Superintendencia de Salud (SUSALUD), entidad supervisora del conjunto de organizaciones del sistema, con quien comparte importantes responsabilidades en la gestión de la política de salud.

La segmentación del sistema se hace explícita en los regímenes de financiamiento, según Lazo, Alcalde \& Espinoza (2016).

- El régimen contributivo indirecto (subsidiado) se financia con recursos fiscales, el aporte de hogares y ocasionales donaciones de la cooperación intergubernamental.

- El régimen contributivo directo se financia mediante contribuciones directas y obligatorias de los empleadores. Comprende dos modalidades, que juntas conforman el Sistema de Seguridad Social en Salud: Seguro Social de Salud (EsSalud) y seguro social privado, constituido por organizaciones de intermediación financiera, las entidades prestadoras de salud (EPS) y las dependencias de salud de los ministerios de Defensa y del Interior, financiadas por el Estado, con el aporte complementario de sus miembros.

- El régimen privado es financiado por las familias (gasto de bolsillo) a través del pago directo de honorarios profesionales o mediante la adquisición de planes de atención a seguros privados (empresas de seguros, auto seguros y prepagas). (p.15) 
Acontinuación se muestra un gráfico que explica cómo está conformado el Sistema de

Salud en Perú y que organismos e instituciones se encuentran contenidas en el mismo.

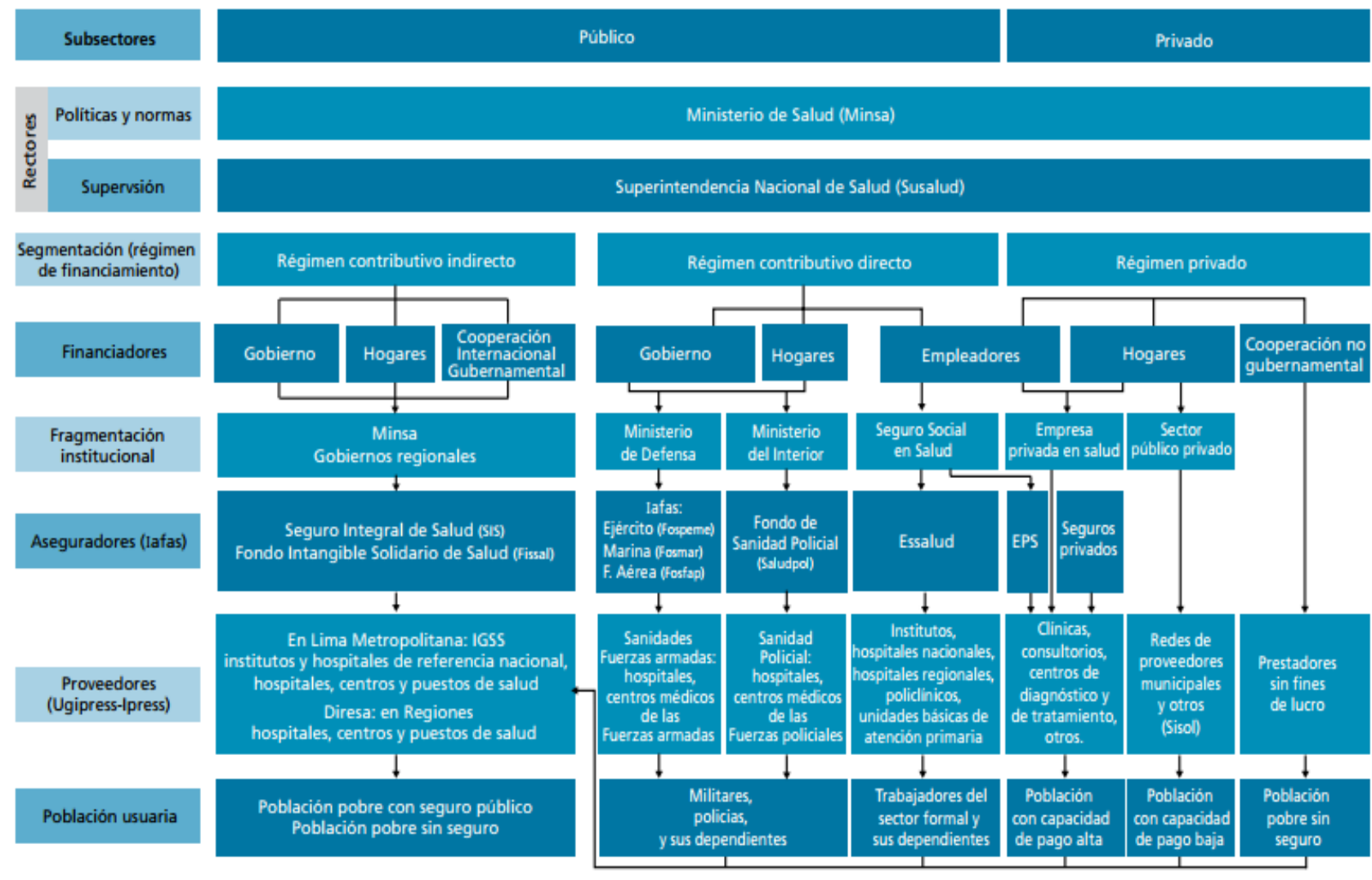

Figura 1. Mapa del Sistema de Salud, Perú 2016. Adaptado de "El Sistema de Salud en Perú-situación y desafíos”, por ESSALUD, 2017, según Lazo, Alcalde y Espinoza, 2016.

Como se aprecia en la figura 1, el sistema de salud en Perú está compuesto por un conjunto de entidades aseguradoras, son las instituciones Administradoras de Fondos para el Aseguramiento en Salud (Iafas), que fueron introducidas para favorecer el proceso de aseguramiento. (p.18) 


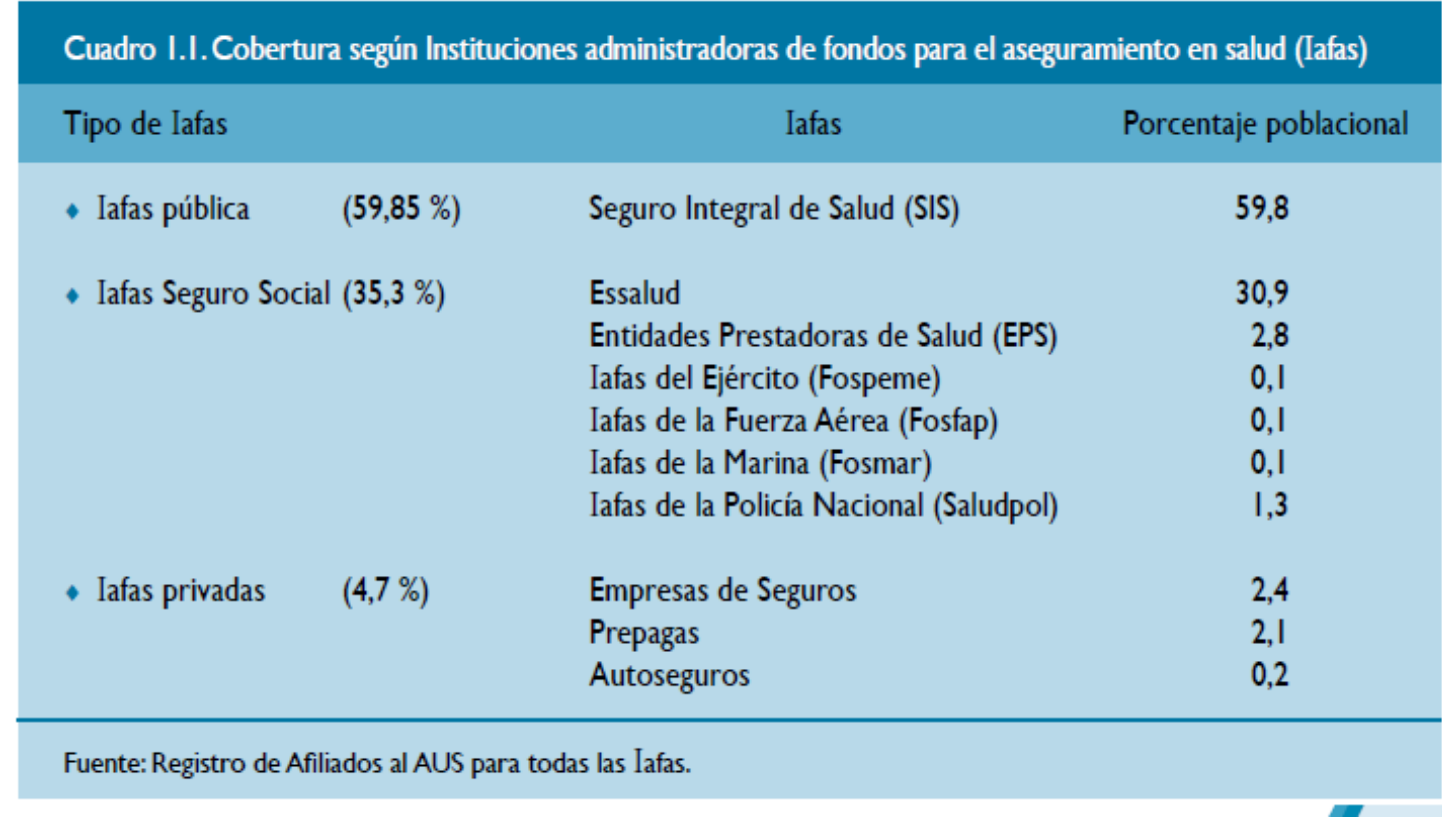

Figura 2. Cobertura según Instituciones administradoras de fondos para el aseguramiento en salud (Iafas). Adaptado de "El Sistema de Salud en Perú-situación y desafíos”, por Lazo, Alcalde y Espinoza, 2016.

Las Iafas están legalmente obligadas a ofertar al menos el Plan Esencial de Atenciones en Salud (PEAS). El PEAS y otros planes complementarios son provistos por las instituciones prestadoras de servicios de salud (Ipress); todas ellas de diversa naturaleza legal, capacidad resolutiva, costos de operación y calidad de atención. En teoría, las Iafas podrían contratar los servicios de aquellas Ipress que ofrezcan mejor atención a sus afiliados; sin embargo, esto ocurre excepcionalmente, pese a la suscripción de múltiples convenios para su operatividad. Lo usual es que cada segmento social reciba atención exclusivamente en los servicios de salud vinculados a la Iafas que lo afilió. (p.19)

Según definición del artículo 7 del Texto Único Ordenado (TUO) de la Ley Nº 29344, Ley Marco de Aseguramiento Universal en Salud, aprobado por Decreto Supremo DS 020-2014SA, el mes de julio de 2014, define a las IAFAS como "aquellas entidades o empresas públicas, privadas o mixtas, creadas o por crearse, que reciban, capten y/o 
gestionen fondos para la cobertura de las atenciones de salud o que oferten cobertura de riesgos de salud, bajo cualquier modalidad".

Entidades como el SIS, EsSalud, el Fondo Intangible Solidario de Salud (FISSAL), las Sanidades de las Fuerzas Armadas, la Sanidad de la Policía Nacional del Perú son IAFAS públicas. Son IAFAS privadas las EPS, las empresas privadas de seguros de salud, la mayoría de auto seguros y las prepagas. Estas organizaciones reciben, captan o gestionan fondos para la cobertura de atenciones de salud de los asegurados en nuestro país.

La Superintendencia Nacional de Salud - SUSALUD es el órgano que registra, supervisa, regula y fiscaliza a las IAFAS, quienes pueden contratar prestaciones libremente con los prestadores de servicios de salud, sean privados, públicos o mixtos; así como contratar entre ellas planes de aseguramiento, o de reaseguros.

El artículo 8 del Texto Único Ordenado (TUO) de la Ley $\mathrm{N}^{\circ}$ 29344, Ley Marco de Aseguramiento Universal en Salud, define a las IPRESS como: "aquellos establecimientos de salud y servicios médicos de apoyo, públicos, privados o mixtos, creados o por crearse, que realizan atención de salud con fines de prevención, promoción, diagnóstico, tratamiento y/o rehabilitación; así como aquellos servicios complementarios o auxiliares de la atención médica, que tienen por finalidad coadyuvar en la prevención, promoción, diagnóstico, tratamiento y/o rehabilitación de la salud"

Para poder ejercer esta función están obligadas a registrarse ante SUSALUD.

Las IPRESS están facultadas para vender sus servicios a las IAFAS e intercambiar servicios entre sí, haciéndose responsables por la calidad y oportunidad de la prestación de servicios de salud acordes a su nivel resolutivo. Por esta razón, sus parámetros de operación (recursos de infraestructura, humanos, tecnológicos, procesos etc.) deberán cumplir con los estándares de calidad exigidos por SUSALUD. 
Así mismo, el reglamento del Decreto Legislativo $\mathrm{N}^{\circ}$ 1159, que aprueba disposiciones para la implementación y desarrollo del intercambio prestacional en el sector público, en su capítulo 1, artículo 3, contempla el intercambio prestacional o de servicios entre las IAFAS e IPRESS de manera obligatoria para las entidades públicas, con el fin de garantizar una mayor oferta y oportuna accesibilidad a las prestaciones de salud de los afiliados a lo largo de todo el país, de acuerdo con sus coberturas y planes de salud.

Del mismo modo, Centrángolo, O., Bertranou, F., Casanova, L. \& Casalí, P., señalan que el sistema nacional coordinado y descentralizado de salud comprende proveedores de servicios públicos y privados, cada uno de los cuales incorpora un conjunto de mecanismos de financiamiento y suministros de servicio integrados verticalmente.

El prestador de servicio público se organiza en cinco segmentos con financiamiento contributivo o de rentas generales.

En el primer subsistema, el gobierno ofrece servicios de salud a la población no asegurada a cambio del pago de una cuota de recuperación de montos variables, a través del Seguro Integral de Salud (SIS) que subsidia la provisión de servicios a la población en situación de pobreza. La prestación de servicios, tanto para el régimen subsidiado de población abierta como para la población afiliada al SIS se realiza mediante la red de establecimientos de los Gobiernos regionales y MINSA, que están ubicados en las regiones y en la capital de la República. Este subsistema está estructurado en tres niveles: nacional conformado por el MINSA, regional representado por las Direcciones Regionales de Salud (DIRESA) pertenecientes a los gobiernos regionales y el nivel local, por algunas municipalidades encargadas de la administración y el presupuesto de los establecimientos de salud de sus jurisdicciones.

Los otros cuatro subsistemas que brindan servicios de salud son: i) el Seguro Social de Salud - EsSalud adscrito al Ministerio de Trabajo y Promoción del Empleo, que opera 
con su propia red de hospitales y centros de salud,; ii) las Sanidades de las fuerzas armadas (Marina, Aviación y Ejército), adscritas al Ministerio de Defensa, que cuenta con sus propias instalaciones; iii) la Sanidad de la policía nacional del Perú (PNP), adscrita al Ministerio del Interior, que también cuenta con sus propias instalaciones; y iv) las instituciones del sector privado: entidades prestadoras de salud (EPS), aseguradoras privadas, clínicas y organizaciones de la sociedad civil (OSC).

En consecuencia, el sistema peruano se caracteriza por una importante fragmentación y segmentación, operando cada uno de manera autónoma y sin articulación, con sus propias reglas y atendiendo poblaciones diferentes. (pp. 44)

En ese sentido, el MINSA, ente rector, ha dispuesto categorías de establecimientos para el sector salud, definiendo como categoría a la clasificación que caracteriza a los establecimientos de salud, en base al nivel de complejidad y a características funcionales comunes, para lo cual cuentan con unidades productoras de servicios de salud (UPSS), las cuales son unidades funcionales del establecimiento de salud constituidas por el conjunto de recursos humanos, tecnológicos, infraestructura entre otros, las unidades organizadas producen determinado servicios en relación directa a su nivel de complejidad.

Bajo este contexto, el MINSA define como categorización al proceso en el cual se clasifica a los diferentes establecimientos de salud en base a niveles de complejidad y a características funcionales que responden a las necesidades de salud de la población. Las categorías de establecimientos de salud por niveles de atención, consideradas en la norma técnica del MINSA son las siguientes: 


\begin{tabular}{|c|c|c|}
\hline \multirow{4}{*}{ PRIMER NIVEL DE ATENCION } & & Categoria I-1 \\
\hline & & Categoria I-2 \\
\hline & & Categoria I-3 \\
\hline & & Categoria I-4 \\
\hline \multirow{3}{*}{$\begin{array}{l}\text { SEGUNDO NIVEL DE } \\
\text { ATENCION }\end{array}$} & \multirow{2}{*}{$\begin{array}{c}\text { Establecimientos de salud de Atencion } \\
\text { General }\end{array}$} & Categoria II-1 \\
\hline & & Categoria II-2 \\
\hline & $\begin{array}{c}\text { Establecimientos de salud de Atencion } \\
\text { Especializada }\end{array}$ & Categoria II -E \\
\hline \multirow{3}{*}{ TERCER NIVEL DE ATENCION } & $\begin{array}{c}\text { Establecimientos de salud de Atencion } \\
\text { General }\end{array}$ & Categoria III -1 \\
\hline & \multirow{2}{*}{$\begin{array}{l}\text { Establecimientos de salud de Atencion } \\
\text { Especializada }\end{array}$} & Categoria III-E \\
\hline & & Categoria III-2 \\
\hline
\end{tabular}

Figura 3. Norma Técnica de Salud "Categorías de Establecimientos del Sector Salud", según información del MINSA 2006. Adaptado del portal MINSA. Elaboración Propia.

A continuación, situaremos puntos importantes de cada categoría.

Primer nivel de atención:

Categoría I-1, en esta categoría se encuentran los puestos de salud o postas de salud con profesionales de salud no médico, dentro de sus funciones generales brindan atención integral de salud a la persona por etapa de vida en el contexto de su familia y comunidad. Sus principales actividades son atención de urgencias y emergencias referencias y contrarreferencia, salud ocupacional, atención con medicamentos pruebas rápidas y toma de muestras entre otros.

Categoría I-2, esta categoría corresponde a puestos de salud o posta de salud con médico, consultorio médico con o sin especialidad.

Esta categoría brinda atención integral de salud a las personas, dentro de sus actividades se encuentra la atención de emergencia y urgencias, salud ocupacional, salud familiar y comunitaria, nutrición integral, prevención y diagnóstico, rehabilitación entre otras. 
Categoría I-3, corresponde a centro de salud, centro médico especializado, policlínico, además de todas las actividades que realiza un centro de salud de categorías inferiores, la categoría I-3, realiza intervenciones de cirugía de consultorio externo.

Categoría I-4, corresponde a centro de salud o centros médicos con camas de internamiento, en sus actividades adicionales en referencia a las demás categorías se encuentra las intervenciones quirúrgicas y rehabilitación basada en la comunidad.

Segundo nivel de atención:

Categoría II-1, corresponde a hospitales de atención general y clínicas de atención general, cuentan con centros quirúrgicos, hospitalización, banco de sangre entre otros.

Categoría II-2, corresponde a hospitales de atención general y clínicas de atención general, cuenta con cuidados intensivos, patología, entre otros.

Categoría II-E, corresponde a hospitales de atención especializada y clínicas de atención especializada, cuenta con hospitalización, centro quirúrgico, obligatorias según campo clínico.

Categoría III-1, corresponde a hospitales y clínicas de atención general, cuenta con radioterapia y medicina nuclear.

Categoría III-2, corresponde a institutos especializados, dentro de sus funciones se encuentra la docencia y la investigación, dentro de sus actividades se encuentra la hospitalización, docencia e investigación, centro quirúrgico, cuidados intensivos, radioterapia, medicina nuclear entre otros.

Categoría III -E, corresponde a hospitales y clínicas de atención especializada, dentro de sus actividades destacan: centro quirúrgico, cuidados intensivos, centro de esterilización, nutrición entre otros.

Por lo antes explicado, el presente trabajo de investigación se centra en el Seguro Social de Salud, por lo que, entenderemos su contexto. 


\subsubsection{Breve reseña histórica del Seguro Social de Salud.}

Según explica Bustios (2005), como se cita en el Plan Estratégico Institucional, 2012) la creación de la seguridad social en el Perú fue resultado de la confluencia de dos procesos: una fuerte corriente internacional de promoción de las primeras experiencias de seguros sociales en Europa, proceso que se aceleró luego de la Primera Guerra Mundial y la ocurrencia de la Gran Depresión de 1929. Jugó también un papel destacado la Organización Internacional del Trabajo (OIT), creada como consecuencia de la Conferencia de Paz de Versalles (1919), y que tiene como órgano supremo a la Conferencia Internacional del Trabajo, que promovió (en el período de 1919 a 1935) la implantación de sistemas de seguros sociales en el hemisferio occidental. Por otro lado, en el plano nacional, los movimientos sindicales y políticos emergentes durante la década del veinte introdujeron en la agenda pública la necesidad de contar con sistemas de protección social en el país, demanda que fue recogida en el artículo ${ }^{\circ} 48$ de la Constitución Política del Perú de 1933, que prescribía que: "la ley establecerá un régimen de previsión de las consecuencias económicas de la desocupación, edad, enfermedad, invalidez y muerte y fomentará las instituciones de solidaridad social, los establecimientos de ahorros y de seguros".

Por ello, el gobierno peruano, durante el año 1935, envió a Edgardo Rebagliati y Guillermo Almenara a estudiar la organización de los programas de seguridad social en Argentina, Chile y Uruguay. Seguro Social de Salud -ESSALUD. (2012).

\subsubsection{La Seguridad Social en Perú - ESSALUD}

Conforme señala Gutiérrez, W. (Dir.). (2005) la seguridad social es, qué duda cabe, un mecanismo de protección del ser humano frente a las situaciones que se presentan en la vida y que originan una disminución o, inclusive, la extinción de su capacidad para 
trabajar. Sin embargo, en la medida que presenta diversas acepciones dependiendo del análisis que se realice, se le considera un concepto complejo.

En efecto, cuando alguien se refiere a la seguridad social generalmente lo hace desde un ángulo concreto que personalmente se haya adoptado. Así, para el ciudadano común, será un derecho; para el Estado, una política; para la Ciencia Jurídica, una rama del Derecho; para la Sociedad, un factor de solidaridad; para la Administración, un servicio público; para la Economía, un factor de redistribución de la riqueza, etcétera. (p.432) Por lo antes expuesto, definiremos la finalidad del Seguro Social de Salud -ESSALUD en Perú y su contexto actual, según el Reglamento de Organización y Funciones de ESSALUD (2014), dicha institución tiene por finalidad la recepción, captación y gestión de los fondos de la seguridad social en salud para dar cobertura a los asegurados y sus derechohabientes, a través del otorgamiento de prestaciones de prevención, promoción, recuperación y rehabilitación de la salud; prestaciones económicas y sociales que corresponden al régimen contributivo de la Seguridad Social de Salud, así como otros seguros de riesgos humanos.

Según la Ley de Modernización de la Seguridad de Social en Salud [Ley N ${ }^{\circ}$ 26790], son asegurados del Seguro Social de Salud, los afiliados regulares o potestativos y sus derechohabientes.

Son afiliados regulares, los trabajadores activos que laboran bajo relación de dependencia o en calidad de socios de cooperativas de trabajadores. Los pensionistas que perciben pensión de jubilación, incapacidad o de sobrevivencia.

Son derechohabientes el cónyuge o el concubino a que se refiere el Art. 326o. del Código Civil, así como los hijos menores de edad o mayores incapacitados en forma total y permanente para el trabajo. La cobertura de los hijos se inicia desde la concepción, en la atención a la madre gestante. (Ley 26790, art. 3) 
Para los trabajadores en actividad la tasa aplicable es el 9\% sobre la remuneración y para los pensionistas la tasa aplicable es el $4 \%$ sobre su pensión. En el caso del trabajador activo, el empleador es responsable de la declaración y pago de su aporte ante la SUNAT, para el pensionista la entidad que paga su pensión es responsable de la retención de su aporte. SUNAT. (s.f)

\subsubsection{Servicios de ESSALUD en Perú al año 2017}

De acuerdo con las estadísticas del Seguro Social de Salud (ESSALUD, 2017) al mes de marzo 2017 el número de la población de asegurados en EsSalud es de 11,059, 014 los cuales se encuentran distribuidos a nivel nacional por Redes Asistenciales de la manera siguiente:

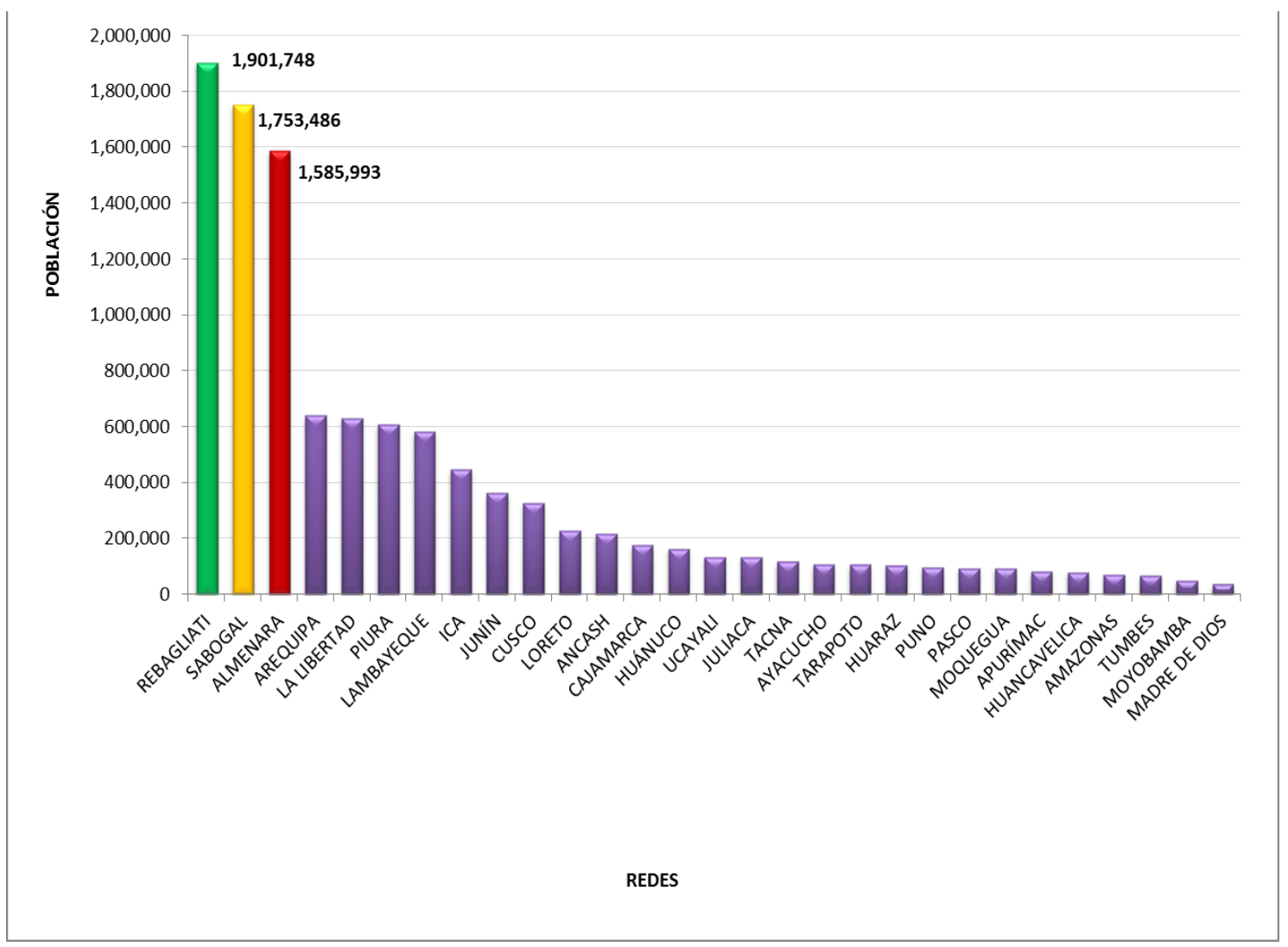

Figura 4. Distribución de la población de asegurados en ESSALUD, según estadísticas recientes. Adaptado de "Población Asegurada Activa 2017”, por ESSALUD, 2017" 
Durante el periodo 2011 - 2016 EsSalud brindó a la población asegurada servicios asistenciales tales como: consultas externas, egresos hospitalarios, emergencias y sesiones de hemodiálisis e intervenciones quirúrgicas. ESSALUD. (2017).

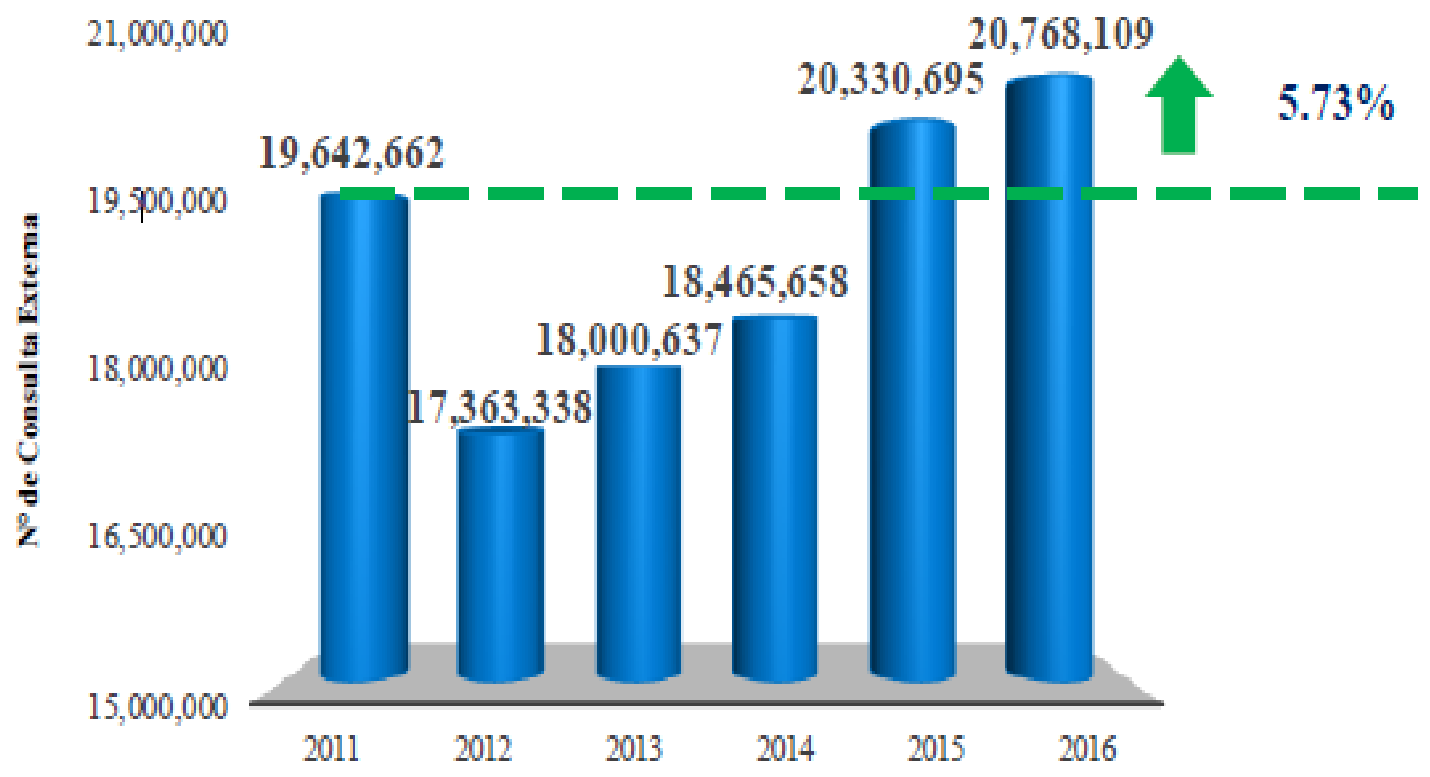

Figura 5. Evolución de la Producción de Consulta Externa en ESSALUD, según estadísticas recientes. Adaptado de "Memoria Institucional 2016", por ESSALUD, 2017" 


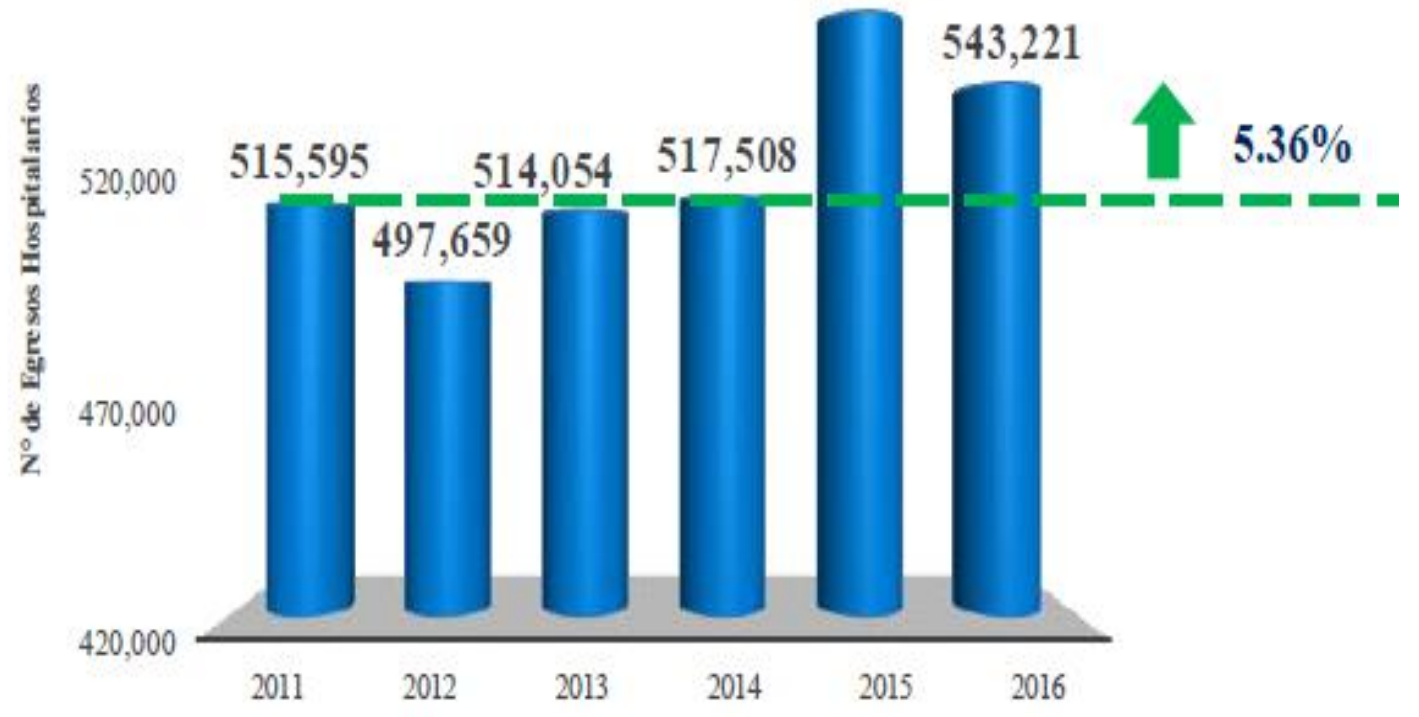

Figura 6. Evolución de la Producción de Egresos Hospitalarios en ESSALUD, según estadísticas recientes. Adaptado de "Memoria Institucional 2016", por ESSALUD, 2017"

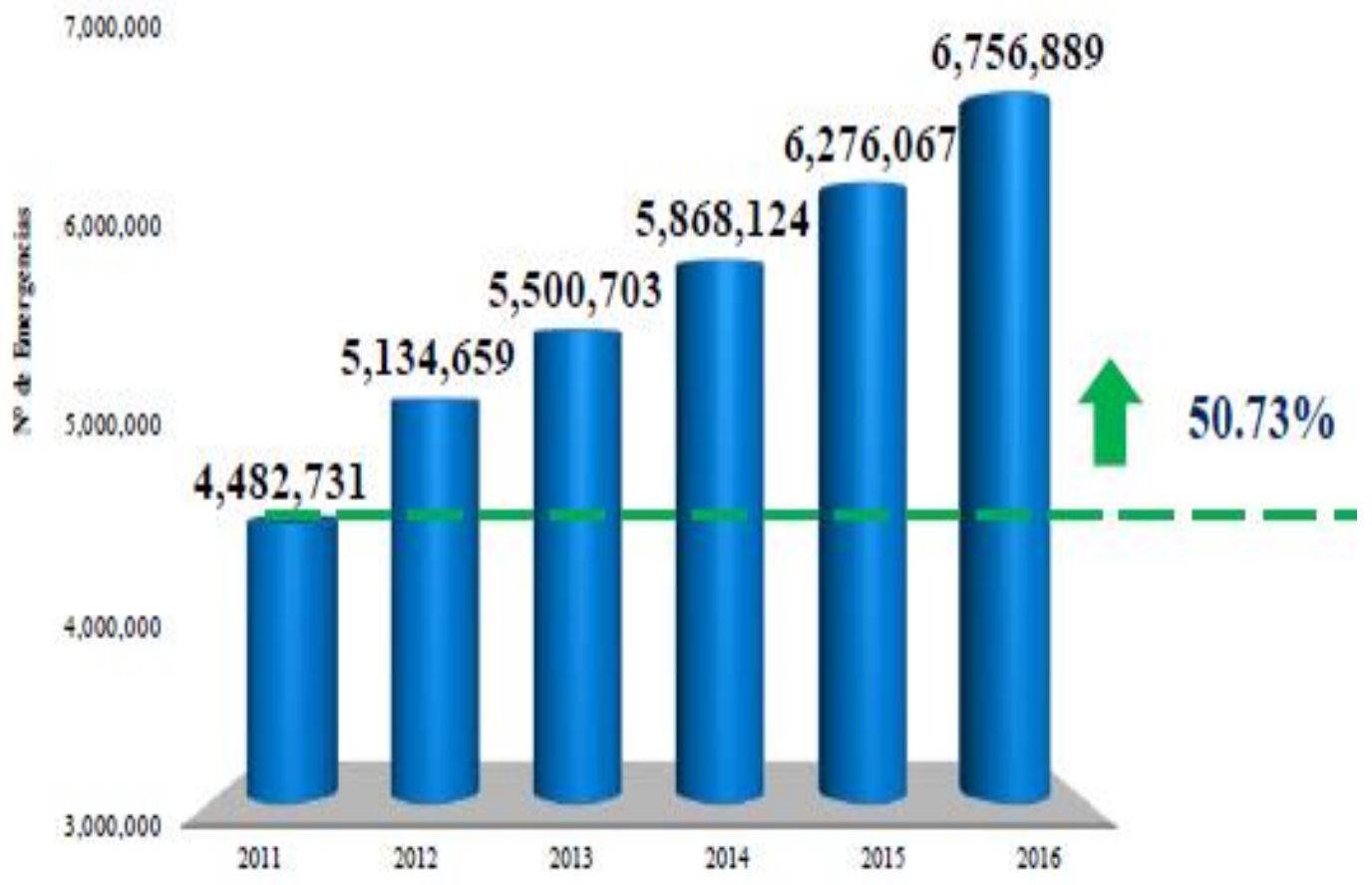

Figura 7. Evolución de la Producción de Emergencias en ESSALUD, según estadísticas recientes. Adaptado de "Memoria Institucional 2016", por ESSALUD, 2017" 


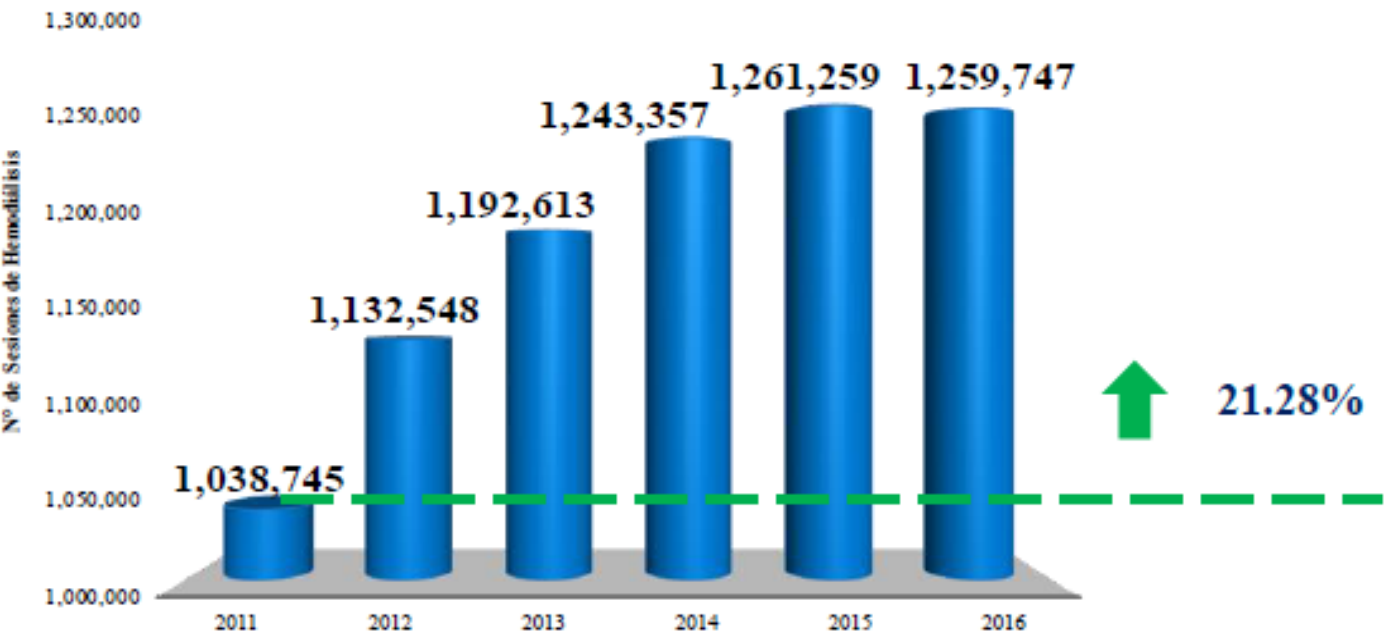

Figura 8. Evolución de Sesiones de Hemodiálisis en ESSALUD, según estadísticas recientes. Adaptado de "Memoria Institucional 2016", por ESSALUD, 2017"

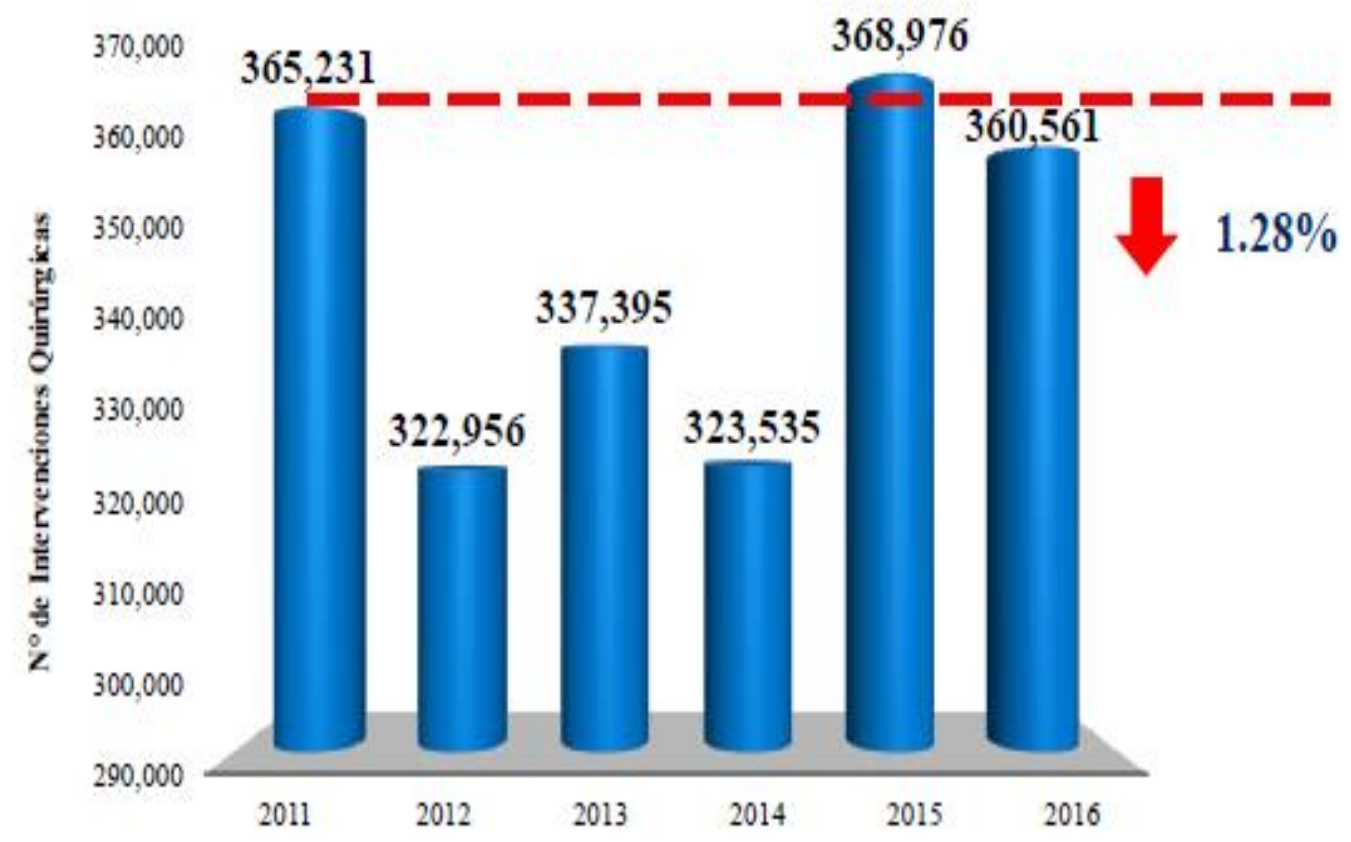

Figura 9. Evolución de Sesiones de Intervenciones Quirúrgicas en ESSALUD, según estadísticas recientes. Adaptado de "Memoria Institucional 2016", por ESSALUD, 2017" 
En EsSalud los servicios de consultas externas, egresos hospitalarios, emergencia y sesiones de hemodiálisis se han incrementado, caso contrario ha sucedido con las intervenciones quirúrgicas. ESSALUD (2017)

De acuerdo a la Información Gerencial de Principales Prestaciones de Salud de enero a setiembre 2017 en EsSalud se han realizado 152 mil 360 cirugías. En promedio se registraron 30 mil 472 cirugías mensuales. (ESSALUD, 2017).

Las Redes Asistenciales que mejor desempeño de producción tuvieron en el periodo 2017, fueron las redes: Sabogal con 1,108 cirugías adicionales, Loreto con 580 cirugías adicionales y Tarapoto con 398 cirugías adicionales a lo efectuado en el mismo periodo del año 2016. (ESSALUD, 2017).

Por otro lado, se comparó el desarrollo de las intervenciones quirúrgicas, determinando que los hospitales que redujeron dichas actividades del año 2017 respecto al año anterior fueron: hospital III Iquitos quien disminuyó en -676 cirugías menos, Hospital Nacional Carlos Seguín con -517 cirugías menos y el Hospital Nacional Guillermo Almenara con 10 cirugías menos a lo realizado en el año 2016.

\begin{tabular}{|c|c|c|c|c|c|}
\hline $\begin{array}{c}\text { ESTABLECIMIENTOS DE } \\
\text { SALUD } \\
\end{array}$ & $\begin{array}{c}2015 \\
\text { Ene - Set }\end{array}$ & $\begin{array}{c}2016 \\
\text { Ene - Set }\end{array}$ & $\begin{array}{c}2017 \\
\text { Ene - Set }\end{array}$ & $\begin{array}{c}\text { VAR \% } \\
2016-2015 \\
\end{array}$ & $\begin{array}{c}\text { VAR \% } \\
2017-2016 \\
\end{array}$ \\
\hline Total general & 67,918 & 67,905 & 71,802 & $-0.02 \%$ & $5.7 \%$ \\
\hline H.N. GUILLERMO ALMENARA & 19,449 & 18,903 & 18,893 & $-2.8 \%$ & $-0.1 \%$ \\
\hline H.N. ALBERTO SABOGAL & 12,920 & 11,024 & 11,465 & $-14.7 \%$ & $4.0 \%$ \\
\hline H.N. CARLOS SEGUIN & 9,388 & 9,544 & 9,027 & $1.7 \%$ & $-5.4 \%$ \\
\hline H.IILIMANORTE-CALLAO & 6,744 & 6,240 & 7,563 & $-7.5 \%$ & $21.2 \%$ \\
\hline H.II GUILLERMO KAELIN & 6,495 & 8,312 & 9,250 & $28.0 \%$ & $11.3 \%$ \\
\hline H.IIALBERTO BARTON & 6,847 & 7,025 & 8,654 & $2.6 \%$ & $23.2 \%$ \\
\hline H.IIIIQUITOS & 3,178 & 3,224 & 2,548 & $1.4 \%$ & $-21.0 \%$ \\
\hline H.II GUSTAVO LANATTA & 2,897 & 3,633 & 4,402 & $25.4 \%$ & $21.2 \%$ \\
\hline
\end{tabular}


Figura 10. Variación de Producción de Intervenciones Quirúrgicas en Hospitales a Nivel Nacional en ESSALUD, según estadísticas recientes. Adaptado de "Información gerencial de principales prestaciones de salud a setiembre 2017”, por ESSALUD, 2017”. Es necesario mencionar que en el periodo de evaluación 2017 ESSALUD tiene registrado un total de 250 salas de operaciones a nivel nacional, ambientes donde se realizan los procedimientos quirúrgicos en condiciones de máxima seguridad. (ESSALUD, 2017) El indicador promedio que midió el grado de cumplimiento de las actividades quirúrgicas programadas a nivel nacional en el periodo evaluado fue de $6.2 \%$, ligeramente inferior en 0.7\% respecto al registrado el mismo período del año anterior. (ESSALUD, 2017).

Por lo antes mencionado, nos centraremos en conocer la gestión administrativa y analizar todo lo concerniente al manejo de la lista de espera para la atención del paciente quirúrgico del Hospital Almenara, por lo que comprenderemos su contexto.

\subsection{Red Asistencial Almenara}

La Red Asistencial Almenara es un órgano de EsSalud que tiene como base al Hospital Nacional Guillermo Almenara, que es responsable de otorgar atención integral de salud a la población asegurada en el ámbito geográfico asignado mediante la articulación de los centros asistenciales.

Estructura Orgánica de la Red Asistencial Almenara.

La estructura orgánica es la siguiente:

- Unidad Orgánica de Dirección.

Gerencia de Red Asistencial.

- Unidades Orgánicas de Asesoramiento. 
- Unidades Orgánicas de Apoyo.

- Unidades Orgánicas de Línea.

Gerencia de Clínica.

Gerencia Quirúrgica.

Gerencia de Ayuda al Diagnóstico y Tratamiento.

Departamento de Enfermería.

- Unidades Prestadoras.

Hospital III Grau.

Hospital II Vitarte.

Hospital II Clínica Geriátrica San Isidro Labrador.

Hospital I Aurelio Diaz Ufano y Peral.

Hospital I Juan Voto Bernales Corpancho.

Policlínico Ramón Castilla.

Policlínico Chosica.

Policlínico Francisco Pizarro.

Policlínico San Luis.

Centro de Atención Primaria III Huaycán.

Centro de Atención Primaria III El Agustino.

Centro de Atención Primaria III San Borja.

Centro de Atención Primaria III Independencia.

Centro de Atención Primaria III Alfredo Piazza Roberts.

Centro de Atención Primaria III Manco Cápac.

Centro de Atención Primaria III Zarate.

Centro de Atención Primaria III Gamarra.

Centro Médico Ancije. 
Centro Médico Casapalca.

Posta Medica Construcción Civil.

A continuación, se presenta el organigrama de la Gerencia de Red Asistencial del Hospital Almenara, donde tiene como hospital base al Hospital Almenara.

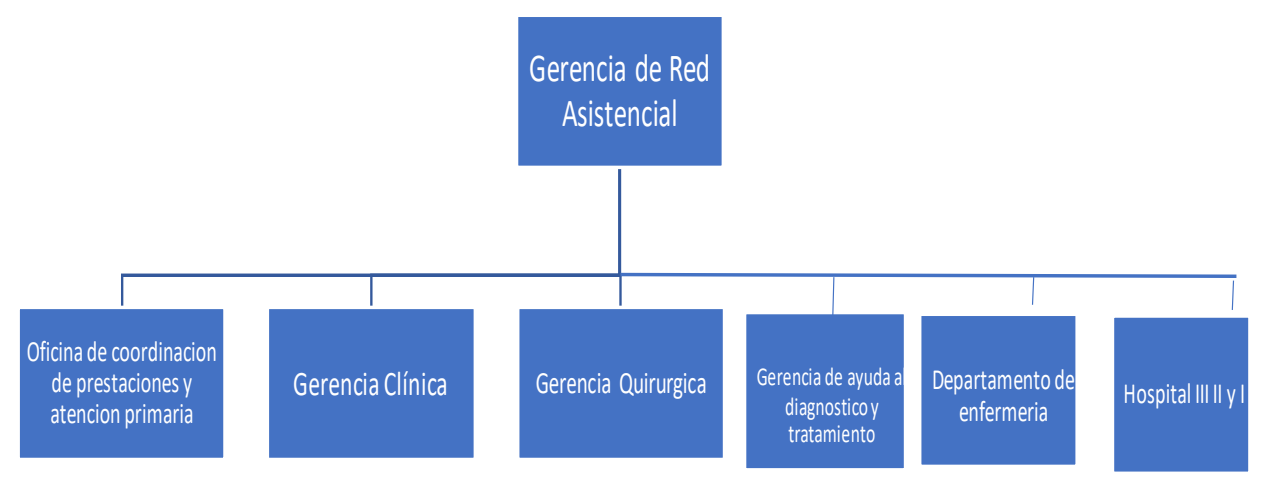

Figura 11. Organigrama Gerencia de Red Asistencial “Estructura Orgánica Hospital Nacional Guillermo Almenara Irigoyen”, según información del Reglamento de Organización y Funciones de la Red Asistencial Almenara 2011. Adaptado del portal ESSALUD. Elaboración Propia.

\subsection{Hospital Almenara}

\subsubsection{Breve Reseña Histórica del Hospital Almenara}

El 15 de marzo de 1938, el doctor Edgardo Rebagliati Martins, colocó la primera piedra que dio inicio a la construcción del Hospital Mixto, tiempo después se dio el nombre de Hospital Nacional Guillermo Almenara Irigoyen.

El funcionamiento del hospital se inició en el año 1941 y produjo un impacto favorable a la sociedad ya que decenas de personas y familias se vieron interesadas y asistieron a las modernas instalaciones del hospital recién inaugurado. 
Con el inicio de operación se brindó acceso a la salud a la población obrera asegurada quien tenía inconveniente en ser atendidos en otros hospitales.

El Hospital Almenara tiene una población adscrita de 1,491,451 asegurados que son atendidos en los diferentes establecimientos de salud, de los cuales el $70 \%$ representa el nivel de atención I, 22\% de los establecimientos de salud son nivel de atención II y el 9\% representa al nivel de atención III.

El Plan Confianza, es un plan Institucional aprobado por la Presidencia Ejecutiva del Seguro Social en el año 2013 con la finalidad de garantizar la oportunidad de la atención de los asegurados, bajo lineamientos de calidad y calidez.

El propósito del plan es que el Seguro Social de Salud cuente con más operaciones y menos tiempo de espera, para ello se ampliaron dos salas de operaciones en el centro quirúrgico del Hospital Guillermo Almenara y se establecieron turnos quirúrgicos adicionales en cirugía de día; 851 pacientes fueron intervenidos quirúrgicamente mediante operativos de reducción para el número de pacientes en lista de espera, esto se logró con turnos adicionales en el mes de enero y marzo del año 2013.

En el año 2014, la Gerencia General del Seguro Social de Salud aprueba el Plan Confianza Fase II denominado Super Plan Confianza 2014 que ha permitido al Seguro Social de Salud orientarse a una mejora en la atención del asegurado con calidad y calidez.

Según información reportada por el Seguro Social en el plan confianza 2013, en diciembre del 2012 el Seguro Social de Salud enfrentaba un número de pacientes con diferimiento quirúrgico en la programación de cirugías, en promedio eran 32,103 pacientes con un promedio aproximado de más de 432 días de espera, las causas de este número de pacientes con diferimiento quirúrgico, se resumían en la limitada capacidad operativa de las Redes Asistenciales a nivel nacional, la falta de recursos humanos y salas de operaciones entre otros factores. 
Bajo este contexto la ex presidenta ejecutiva, Dra. Virginia Baffigo de Pinillos, aprobó, el 04 de enero del 2013 la resolución de la presidencia ejecutiva $N^{\circ} 008$-PE-ESSALUD donde se aprueba el Plan Institucional para la mejora en la atención del asegurado denominado "Plan Confianza”. ESSALUD (2018).

Por otro lado, luego de un rigoroso proceso de clasificación en abril del 2015, el Hospital Almenara fue categorizado como Instituto de Salud Especializado III 2, máximo nivel otorgado por el Ministerio de Salud, la categorización implica haber superado la evaluación de los componentes y estándares de infraestructura, equipamiento y recursos humanos.

Según las categorías de establecimientos del sector salud normados por el MINSA, la categoría III 2, Instituto especializado, logra alcanzar dicho reconocimiento por contar con equipo de profesionales altamente especializados que garantizan y fomentan la investigación. Así mismo, los establecimientos que correspondan a esta categoría contarán con unidades productoras comunes y exclusivas entre ellos se destaca el centro quirúrgico.

\subsubsection{Gerencia Quirúrgica del Hospital Almenara}

La actual Gerencia Quirúrgica cuenta con ocho departamentos: Departamento de Cirugía Especializada I, Departamento de Cirugía Especializada II, Departamento de Ortopedia y Traumatología, Departamento de Neurocirugía, Departamento de Trasplantes, Departamento de Oftalmología, Departamento Gineco Obstetricia y Departamento de Anestesiología y Reanimación.

Todos los jefes de Departamentos reportan directamente a la Gerencia Quirúrgica.

Así mismo, cada Departamento cuenta con servicios médicos, los cuales tienen un jefe de servicio, en total son 31 servicios en la Gerencia Quirúrgica. 


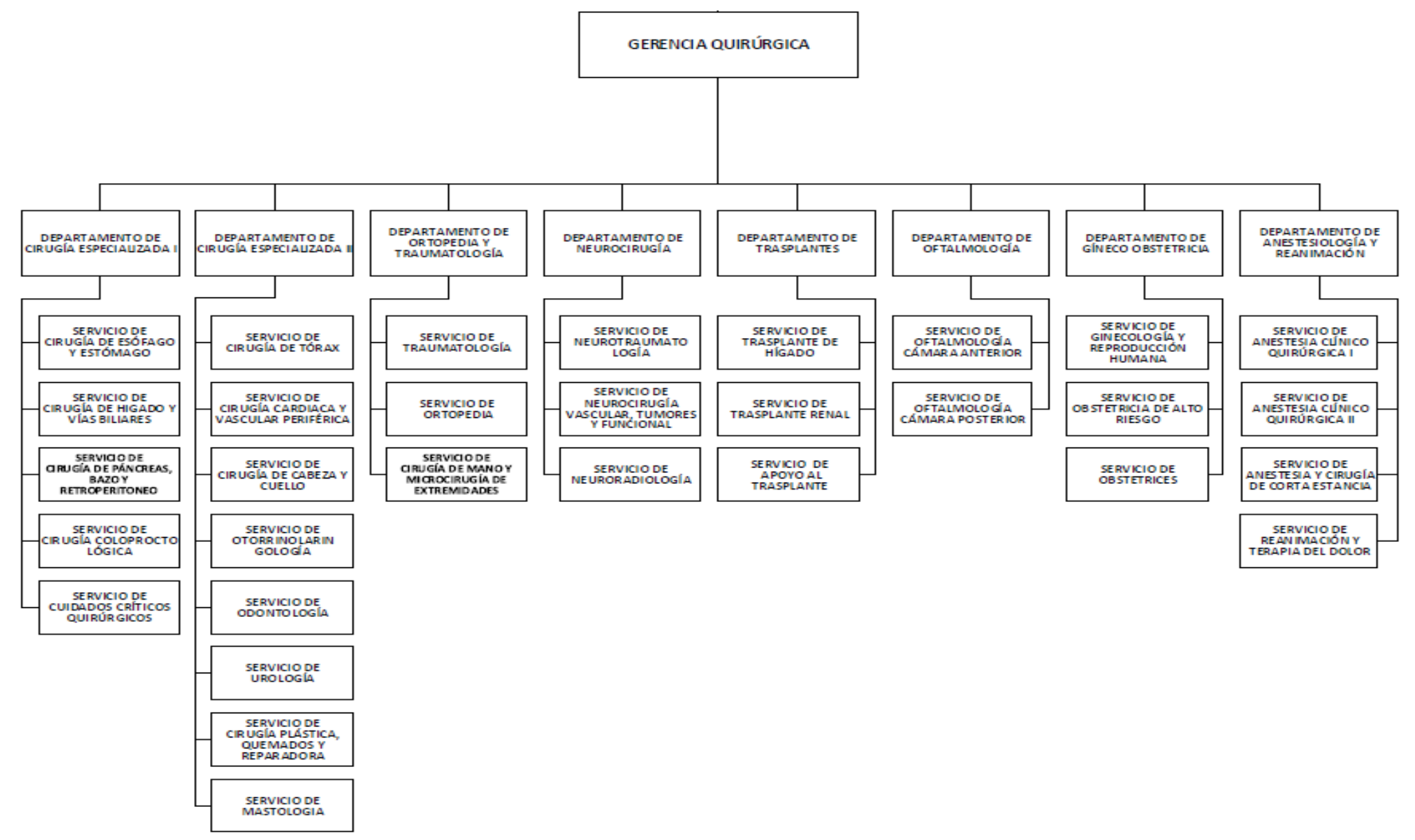

Figura 12. Organigrama de la Gerencia Quirúrgica del Hospital Almenara, según información de EsSalud 2018. Adaptado del Reglamento de Organización y Funciones Red Prestacional Almenara 2018. 


\subsubsection{Normas para la gestión de la oportunidad quirúrgica en el Seguro Social de Salud (EsSalud)}

El Seguro Social de Salud mediante su Gerencia General establece la Directiva de Gerencia General N015-GG-ESSALUD-2015 "Normas para la Gestión de la Oportunidad Quirúrgica en el Seguro Social de Salud - ESSALUD”, aprobada mediante Resolución de Gerencia General N 1518 - GG - ESSALUD - 2015, la cual tiene como finalidad establecer las normas técnico-administrativas para la gestión de la oportunidad quirúrgica en el Hospital Almenara y demás Órganos Desconcentrados e IPRESS, estandarizando los procedimientos para la gestión de la lista de oportunidad quirúrgica. Según se menciona en la Norma 015 , dicha directiva es de aplicación y de cumplimiento obligatorio en todo EsSalud. (pp.11)

La Lista Única de Oportunidad Quirúrgica es el instrumento de gestión informatizado para la atención del paciente quirúrgico que tiene como meta mantener el promedio de tiempo de espera en 45 días o menos. (pp.12)

A su vez, por medio de la Lista Única de Oportunidad Quirúrgica se realiza el seguimiento del otorgamiento de prestaciones quirúrgicas electivas, cuyos componentes son:

- Lista de pacientes con indicación quirúrgica.

- Lista de pacientes con solicitud de exámenes pre quirúrgicos e interconsultas.

- Lista de pacientes aptos para cirugía y que han completado la evaluación pre quirúrgico y riesgo anestesiológico. Existen dos tipos:

- $\quad$ Espera mayor de 45 días

- $\quad$ Espera menor o igual de 45 días

- Lista de pacientes para ser intervenidos por IPRESS intrainstitucionales o extrainstitucionales.

- Lista de pacientes intervenidos. 
- Registro de complicaciones.

- Lista de pacientes dados de baja del registro. Existen dos tipos:

- Defunción

- Cirugía ya realizada

Por otro lado, las Unidades de Gestión de Oportunidad Quirúrgica, son instancias funcionales que se encuentran en el nivel central y que se encuentran a cargo del Gerente de Operaciones Territoriales de la Gerencia Central de Operaciones y es responsable de la dirección, conducción supervisión y control de las actividades para la gestión de la oportunidad quirúrgica. (pp.9).

Del mismo modo, la gestión de la oportunidad quirúrgica en el Hospital Almenara está a cargo del Gerente Quirúrgico, quien finalmente reporta a la Unidad Central de Gestión de Oportunidad Quirúrgica el cumplimiento de los indicadores e informes según se requiera. (pp.10).

Ahora bien, para que un paciente sea programado a una intervención quirúrgica, debe tener en cuenta los siguientes criterios:

- Prioridad: según gravedad de la patología del paciente.

- Capacidad: capacidad en las instalaciones, salas de operaciones, insumos y material quirúrgico, camas hospitalarias entre otros.

- $\quad$ Antigüedad: Según el tiempo de espera que tiene el paciente.

- Proximidad a la mayoría de edad en el caso de derecho habientes. (pp.20).

Por consiguiente, se identificó el procedimiento de intervenciones quirúrgicas.

- El médico cirujano especialista, realiza la atención al paciente en consulta externa, hospitalización o emergencia, determina la necesidad de intervención quirúrgica, revisa la lista de espera y determina la prioridad de intervención quirúrgica del paciente, en base a la lista de pacientes aptos y registra la información en el sistema 
Informático Institucional vigente. - SIIV, solicitando la sala de operaciones. (pp.39).

- El jefe de servicio programa la disponibilidad de salas de operaciones y recursos necesarios para intervención quirúrgica. (pp.20).

- Cada jefatura de servicio administra la lista única de oportunidad quirúrgica en el Sistema Informático Institucional vigente, comunica al paciente la fecha probable de su intervención quirúrgica y brinda información de los pasos a seguir. (pp.37)

- El jefe de servicio programa la disponibilidad de sala de operaciones y recursos necesarios para la intervención quirúrgica. (pp.16)

- Los pacientes que no han sido programados o los que habiéndolo sido no hubieran sido operados en su oportunidad, tienen prioridad en la programación subsiguiente. (pp.20)

- El cirujano especialista determina el alta definitiva del paciente luego de los controles post quirúrgicos y de ser el caso se realiza la contrarreferencia. (pp.21)

- El Sistema Informático Institucional vigente, permite la depuración en la lista única de oportunidad quirúrgica una vez operado el paciente, que es verificado permanentemente por el Jefe de Servicio o Departamento Quirúrgico.

- El Sistema Informático Institucional vigente, permite identificar a los pacientes de la lista única de oportunidad quirúrgica que son registrados en la consulta externa, así como los pacientes que ingresan por emergencia y hospitalización, de igual modo, cuando el paciente es atendido quirúrgicamente, es depurado de la lista única de oportunidad quirúrgica y pasa a una lista de seguimiento y control. (pp.17)

De manera complementaria, es necesario mencionar el proceso de las referencias y contrarreferencias para que un paciente sea atendido quirúrgicamente en el Hospital Almenara. 
La Norma 015, menciona que la Oficina de Referencia de cada IPRESS Institucional, utilizando el aplicativo vigente, procede a la designación, de la IPRESS destino.

- El médico cirujano especialista deriva al paciente a la Oficina de Referencias del IPRESS.

- El responsable de la Oficina de Referencias genera la primera cita en la IPRESS y entrega al paciente copia de los documentos, a fin de que lo lleve a la IPRESS.

- El responsable de la Oficina de Referencias recibe al paciente, verifica los documentos y deriva con el nuevo médico tratante.

- El médico tratante en IPRESS genera las consultas especializadas, análisis prequirúrgicos, programa la intervención.

- El responsable de la lista única de oportunidad quirúrgica de la IPRESS ingresa la información en el aplicativo informático SIVI

- El responsable de la IPRESS, remite a la Red Asistencial de procedencia del paciente, vía la Oficina de Referencias todos los documentos pertinentes.

- Si el paciente es contrarreferido, el responsable de la IPRESS, envía al jefe de Servicio el documento indicando la causa. (pp.39)

\subsubsection{Plan Operativo Institucional 2017 Hospital Almenara}

El Seguro Social de Salud enmarca sus líneas de intervención en ejes de gestión impulsados por la alta dirección, esto como resultado del análisis del diagnóstico Institucional elaborado como parte del proceso de formulación del Plan Estratégico Institucional 2017-2021.

El Plan Operativo Institucional 2017 del Hospital Almenara, tiene como objetivo estratégico brindar a los asegurados un cuidado humanizado con calidad, oportunidad, con mayor nivel de compromiso y satisfacción de los colaboradores. 
Según se estipula en el Plan Operativo Institucional 2017 en referencia a la programación de metas físicas del Hospital Almenara, el número de intervenciones quirúrgicas que el Hospital debería alcanzar por trimestre es 6,067 cirugías para el primer, segundo y tercer trimestre, en el cuarto trimestre el número cirugías a alcanzar es 6,068 en lo que respecta al año 2017, siendo en total 24269 operaciones quirúrgicas para el año 2017.

En cuanto al tiempo de espera para intervención quirúrgica, el número de días de espera en el Hospital Almenara para el año 2017 es 60 días para todos los trimestres, como tiempo de espera máximo para que un paciente espere ser intervenido quirúrgicamente. Además, el Plan Operativo Institucional 2017 de EsSalud estipula las metas a alcanzar para todo el año en mención de todos los organismos que conforman EsSalud. Se mencionan las siguientes metas en lo que respecta a intervenciones quirúrgicas del Hospital Almenara porque son los únicos lineamientos que indican el número de intervenciones y tiempo de espera a cumplir para que los colaboradores trabajen en función a alcanzar las metas.

\subsection{Conceptos generales de la Administración.}

La administración es un elemento esencial para cualquier organización:

Según, Koontz H., Weihrich H. \& Cannice M. (2012), los gerentes son responsables de actuar de manera que permitan a los individuos contribuir de la mejor forma al logro de los objetivos del grupo. Así, la administración se aplica a todo tipo de organizaciones, empresas lucrativas o no lucrativas, grandes y pequeñas, una dependencia gubernamental, un hospital (...)

El autor también señala que Michael Porter, catedrático de Harvard, mencionó que:

"En las empresas no lucrativas, como un departamento de policía, los gerentes tienen metas y deben buscar alcanzarlas con el mínimo de recursos, o lograr lo más posible con los ya disponibles" (pág. 4) 
Es así que, define organización a un grupo de personas que trabajan en conjunto para crear valor agregado. En organizaciones lucrativas dicho valor agregado se traduce en utilidades; en organizaciones no lucrativas, como las caritativas u hospitales, puede ser la satisfacción de necesidades o la satisfacción que un paciente reciba por el solo hecho de ser atendido.

Todas las nuevas ideas, los nuevos descubrimientos de investigación o técnicas pueden colocarse con facilidad en las clasificaciones de planear, organizar, integrar personal, dirigir o controlar. Koontz (2012)

Planear.

Planear incluye elegir objetivos, y las acciones para lograrlos. Hay varios tipos de planes que van desde los propósitos y objetivos generales hasta las acciones más detalladas a seguir, como ordenar un tornillo especial de acero inoxidable para un instrumento, o contratar y capacitar trabajadores para una línea de ensamblaje. El gerente debe asegurarse de que todos comprendan tanto el proyecto a realizar como los objetivos del grupo y los métodos para alcanzarlos. (pág. 108)

Los planes pueden clasificarse de varias maneras, pero para el presente trabajo se enfocará desde el punto de vista de objetivos y metas para la atención del paciente quirúrgico en el hospital Almenara.

Señala que ambos términos se usan indistintamente, pues son los fines, a las cuales se dirige la actividad; no solo representan el punto final de la planeación, sino el fin al que se dirige la organización.

Organizar.

Las personas que trabajan juntas en grupos para alcanzar una meta deben tener funciones que desempeñar, tal como los papeles que los actores desempeñan en una obra, ya sea que ellos mismos las desarrollen. El concepto de función supone que lo que las personas 
hacen tiene un propósito u objetivo definido: saben de qué manera se ajusta su objetivo de trabajo al esfuerzo del grupo. Esto puede verse en algo tan simple como el esfuerzo de un grupo para instalar el campamento en una expedición de pesca; todos podrían hacer lo que quisieran, pero seguro que la actividad sería más efectiva y se harían todas las tareas si se asigna una o dos personas a reunir leña para la fogata, otras a conseguir agua, una más a encender el fuego, varias a cocinar, etcétera.

Organizar, entonces, es esa parte de la administración que supone el establecimiento de una estructura intencional de funciones que las personas desempeñen en una organización; es intencional en el sentido de asegurarse que todas las tareas necesarias para lograr las metas se asignen, en el mejor de los casos, a las personas más aptas para realizarlas.

Integrar el personal.

Integrar el personal requiere cubrir y mantener cubiertos los puestos de la estructura organizacional. Esto se logra al identificar los requisitos de fuerza de trabajo; inventariar a las personas disponibles o, de otra forma, desarrollar candidatos u ocupantes actuales de puestos para que las tareas puedan cumplirse con efectividad y eficiencia.

\section{Dirigir.}

Dirigir es influir en las personas para que contribuyan a las metas organizacionales y de grupo; asimismo, tiene que ver sobre todo con el aspecto interpersonal de administrar. Todos los gerentes coinciden en que la mayoría de sus principales problemas surgen de las personas, sus deseos y actitudes, así como de su comportamiento individual y en grupo, y en que los gerentes efectivos también requieren ser líderes efectivos.

Como el liderazgo supone seguidores y las personas tienden a seguir a los que ofrecen medios para satisfacer sus necesidades, anhelos y deseos, es comprensible que dirigir suponga motivar, estilos y enfoques de liderazgo y comunicación. 
Controlar.

Controlar es medir y corregir el desempeño individual y organizacional para asegurar que los hechos se conformen a los planes. Incluye medir el desempeño respecto de las metas y los planes, mostrar dónde existen desviaciones de los estándares y ayudar a corregir las desviaciones. En suma, el control facilita el cumplimiento de los planes. Aun cuando planear debe preceder al control, los planes no se logran solos, sino que guían a los gerentes en el uso de recursos para alcanzar metas específicas; entonces las actividades son examinadas para determinar si se conforman a los planes. Las actividades de control casi siempre se relacionan con la medición del logro. Algunos de los medios de control, como el presupuesto de gastos, los registros de inspección y el registro de horas de trabajo perdidas, son bastante conocidos; cada uno de estos índices muestra si los planes funcionan, y si las desviaciones persisten deben tomarse medidas correctivas, por supuesto que éstas deben llevarse a cabo por personas de la organización, pero, ¿qué debe corregirse? Nada puede hacerse, por ejemplo, para reducir los sobrantes o comprar según las especificaciones, o gestionar las devoluciones de ventas, a menos que alguien sepa quién es el responsable de esas funciones.

Asegurarse de que los hechos se conformen a los planes significa localizar a las personas responsables de los resultados que difieren de la acción planeada y luego dar los pasos necesarios para mejorar el desempeño. Así, los resultados se controlan al llevar un registro de lo que las personas hacen.

Coordinación. La esencia del arte de administrar

Algunas autoridades consideran a la coordinación como una función aparte del gerente; sin embargo, parece más preciso considerarla como la esencia del arte de administrar, para lograr armonía entre los esfuerzos individuales hacia el cumplimiento de las metas 
de grupo; cada una de las funciones gerenciales es un ejercicio que contribuye a la coordinación.

Hasta en el caso de una iglesia u organización fraternal, los individuos a menudo interpretan intereses similares de diferentes maneras y sus esfuerzos hacia metas mutuas no se funden automáticamente con los de otros; así, reconciliar diferencias de enfoque, tiempo, esfuerzo o interés y armonizar las metas individuales para contribuir a las metas organizacionales se convierte en la tarea central del gerente.

La planeación y el control, son inseparables; cualquier intento por controlar sin una buena planeación no tiene sentido, pues no hay forma de que las personas sepan si van en la dirección que quieren (el resultado de la tarea del control), a menos de que primero estén seguros de adónde quieren ir (parte de la tarea de planeación); así, los planes aportan los estándares de control.

Por lo tanto, según lo antes expuesto, desde la perspectiva de Administración, el Hospital Almenara es una organización, que atiende al régimen contributivo de la Seguridad Social, como órgano de EsSalud, teniendo como una de sus misiones satisfacer la necesidad de los pacientes en cuanto a intervención quirúrgica que por su complejidad le son referidos de los centros asistenciales de menor nivel. 


\section{CAPÍTULO II}

\section{METODOLOGIA DE LA INVESTIGACIÓN}

\subsection{Planteamiento de la investigación}

\subsubsection{Propósito de la investigación}

La presente investigación tiene como propósito analizar el contexto en el cual el Hospital Guillermo Almenara Irigoyen desarrolla sus actividades de gestión administrativa a través de los lineamientos del Plan Operativo Institucional y Normas para la gestión de la oportunidad quirúrgica en el Seguro Social de Salud, los cuales intervienen en la programación de la lista única de oportunidad quirúrgica y que impactan en la atención del paciente quirúrgico.

Se entrevistó a segmentos potenciales involucrados en el proceso de atención de los pacientes que necesitan ser intervenidos quirúrgicamente en el Hospital Almenara. La investigación se llevó a cabo en Lima Perú y se utilizará entrevistas a profundidad para la recolección de datos deseable.

Por lo expuesto, determinamos que la investigación tiene un alcance descriptivo y explicativo del contexto en el cual el Hospital Almenara desarrolla su administración y su impacto en el manejo de la lista de espera, mediante la utilización de las herramientas de gestión, con la finalidad de brindar un diagnóstico situacional a los funcionarios y colaboradores inmersos en las actividades de la administración de la lista única de oportunidad quirúrgica en el mencionado hospital. 


\subsubsection{Tipo de investigación}

Según el enfoque de nuestro trabajo, desarrollaremos una investigación cualitativa, de tipo descriptiva y explicativa, porque se recolectarán datos, obteniendo información desde la perspectiva de los gerentes, jefes administrativos, jefes de departamento, jefes de servicios, personal administrativo, personal médico y asegurados, basándonos en su experiencia personal y profesional, desde el ámbito de las funciones de cada colaborador dentro de la organización, así como el conocimiento que tiene el paciente acerca del manejo de la lista de espera.

La investigación es descriptiva, ya que se realizará entrevistas a profundidad, mediante guía de preguntas semiestructuradas, orientadas a conocer la gestión administrativa, buscando describir los factores relevantes del uso de las herramientas de gestión administrativas tales como: POI 2017 y Norma 015, y su aplicación en el manejo de la lista de espera para que los pacientes sean atendidos quirúrgicamente en el Hospital Almenara. Del mismo modo, es explicativa, ya que tiene como finalidad analizar del uso de las herramientas y su efecto en la gestión administrativa dentro del Hospital.

Se utilizará la teoría fundamentada, pues las entrevistas en profundidad nos permitirán entender y explicar cómo en el Hospital Almenara, se utilizan las herramientas de gestión normadas por la institución EsSalud y el impacto que tienen en la lista de espera para la atención del paciente quirúrgico, tal como indica Hernández Sampieri:

"La teoría fundamentada, significa que la teoría (hallazgos) va emergiendo fundamentada en los datos."

Por esto, a través del presente trabajo de investigación se buscará responder las siguientes preguntas de investigación. 


\subsubsection{Preguntas de la investigación}

Las preguntas de investigación que vertebran el siguiente trabajo provienen de los objetivos específicos.

1. ¿Cuál es el proceso que sigue el Hospital Almenara para el manejo de la lista de espera en la atención del paciente quirúrgico?

2. ¿Cuál es la gestión administrativa que se realiza dentro del Hospital Almenara y cuáles son las acciones para mejorar el manejo de la lista de espera de oportunidad quirúrgica?

3. ¿Cuáles son las acciones que realizan los colaboradores del Hospital Almenara para lograr el cumplimiento de las metas estipuladas en las herramientas POI $2017 \mathrm{y}$ Normas 015 ?

4. ¿Cuál es la importancia del uso de la Norma 015 y POI 2017 vinculados a la lista de espera de la atención en pacientes quirúrgicos?

\subsection{Contexto}

\subsubsection{Descripción del contexto interno y externo:}

Las entrevistas a profundidad realizadas, así como las observaciones del contexto interno y externo en el que se desarrollaron permitieron obtener mayor información para su posterior análisis. A continuación, se muestra la bitácora de contexto interno y externo, donde se describen nuestras observaciones de los diversos escenarios antes, durante y después de cada entrevista efectuada. 
Tabla 1. Bitácora del contexto donde se desarrolló la investigación de campo.

\begin{tabular}{|c|c|c|c|c|c|c|c|c|c|}
\hline $\begin{array}{l}\text { Contexto } \\
\text { Segmento }\end{array}$ & \multicolumn{2}{|c|}{ Contexto/Segmento } & Gerente Quirúrgico & $\begin{array}{l}\text { Jefes de las oficinas } \\
\text { administrativas }\end{array}$ & Jefes de Servicios & Jefes de Departamento & $\begin{array}{l}\text { Personal } \\
\text { administrativo }\end{array}$ & Médicos & Pacientes \\
\hline $\begin{array}{l}\text { Observaciones } \\
\text { antes de la } \\
\text { entrevista }\end{array}$ & \begin{tabular}{|l} 
Contexto \\
Interno
\end{tabular} & 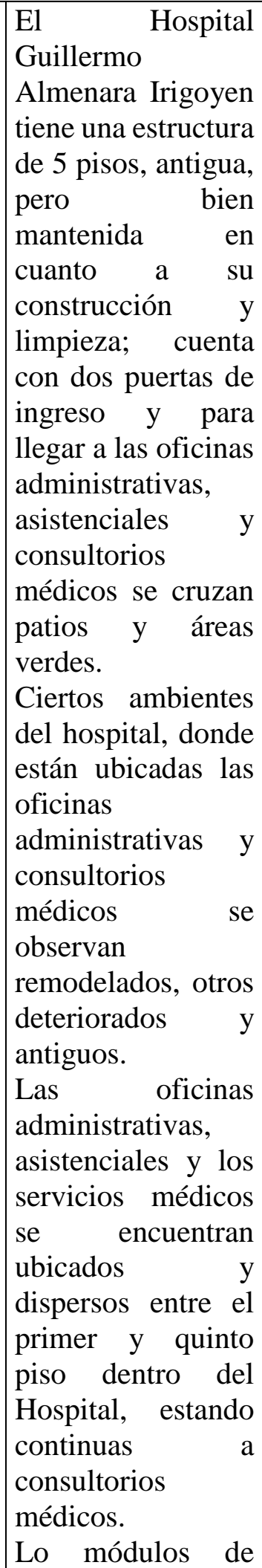 & $\begin{array}{l}\text { Mediante nuestro contacto, } \\
\text { Dra. Flor, quien nos ayudó } \\
\text { hablando con la secretaria del } \\
\text { Gerente Quirúrgico y } \\
\text { concretó una cita para que el } \\
\text { mismo nos pueda atender, } \\
\text { obtuvimos la entrevista. La } \\
\text { secretaria nos brindó una } \\
\text { fecha tentativa y se hacía } \\
\text { seguimiento los días que se } \\
\text { iba al Hospital, preguntando } \\
\text { y acercándonos a su oficina, } \\
\text { hasta que nos dieron fecha } \\
\text { para el 10 de abril a las 9.30 } \\
\text { am. Ese día nos acercamos } \\
\text { puntuales a la oficina del Dr. } \\
\text { su secretaria nos indicó que } \\
\text { esperemos, ya que el Dr. se } \\
\text { encontraba ocupado, } \\
\text { esperamos en los pasadizos } \\
\text { casi dos horas hasta que su } \\
\text { secretaria nos hizo pasar. }\end{array}$ & 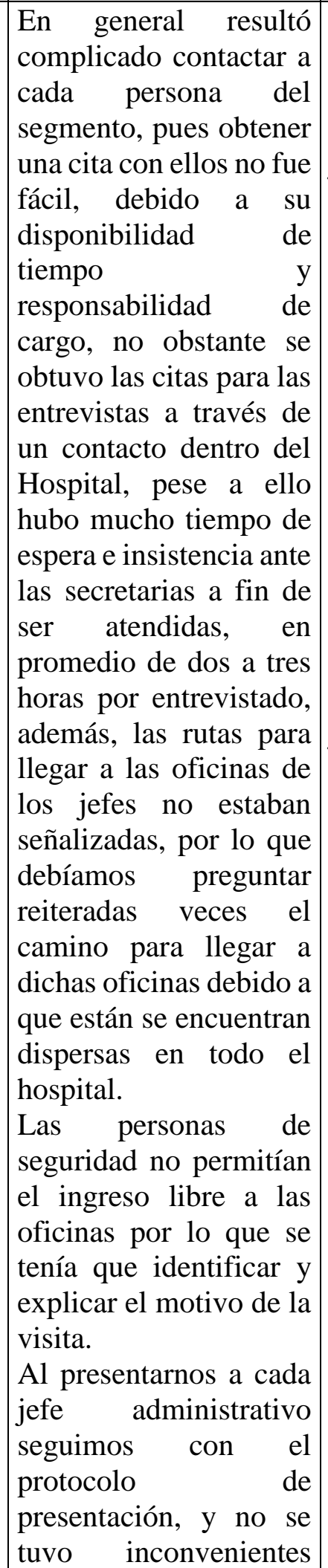 & $\begin{array}{l}\text { Las dificultades } \\
\text { que se presentaron } \\
\text { para realizar las } \\
\text { entrevistas a los } \\
\text { jefes de servicios en } \\
\text { su mayoría fueron } \\
\text { porque no se les } \\
\text { ubicaba en sus } \\
\text { oficinas, pese a las } \\
\text { reiteradas } \\
\text { búsquedas. } \\
\text { Además, en la } \\
\text { mayoría se siguió } \\
\text { con el protocolo de } \\
\text { la guíar de } \\
\text { preguntas, refes los } \\
\text { A todos los jefes } \\
\text { abordamos sin cita, } \\
\text { presentándonos en } \\
\text { sus oficinas de } \\
\text { jefatura de servicio, } \\
\text { pidiéndoles unos } \\
\text { minutos rya } \\
\text { entrevistarlos, para } \\
\text { explicándoles el } \\
\text { tema a investigar y } \\
\text { pidiéndoles } \\
\text { permiso para grabar } \\
\text { la entrevista, a lo } \\
\text { cual accedieron } \\
\text { amablemente. }\end{array}$ & 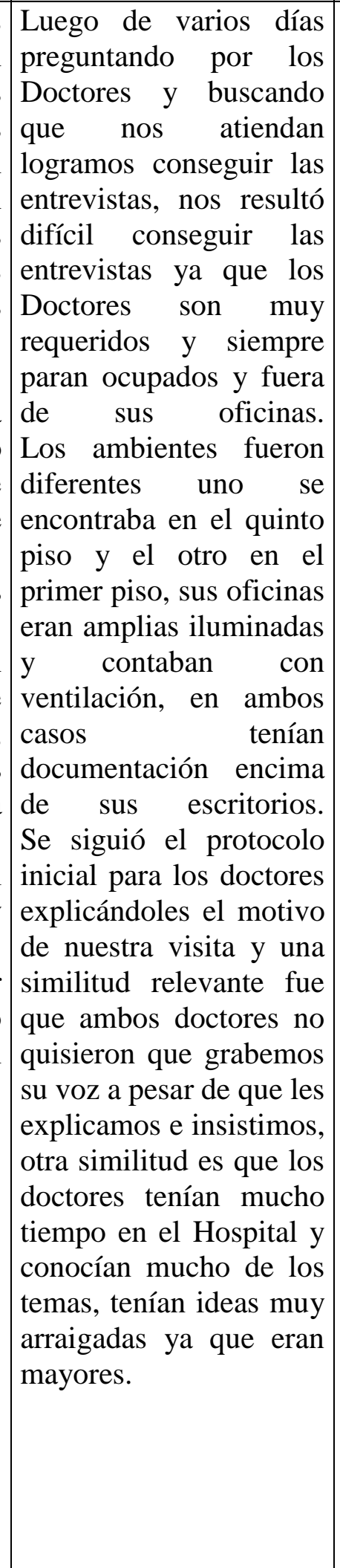 & 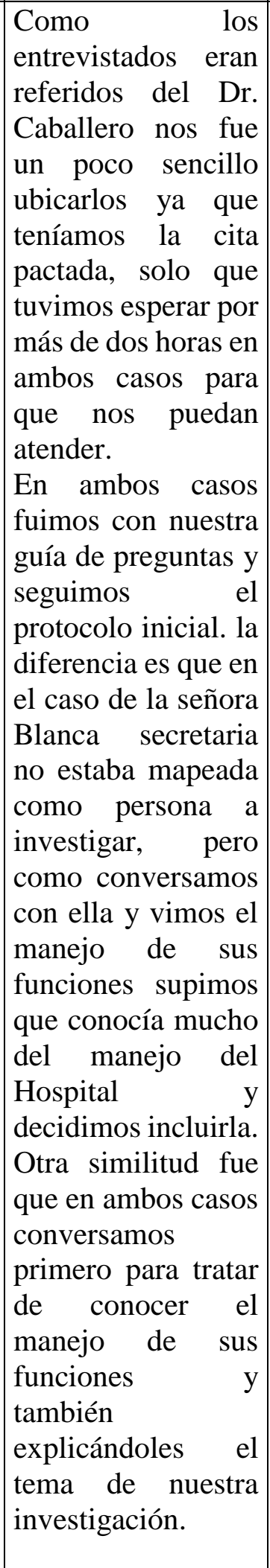 & 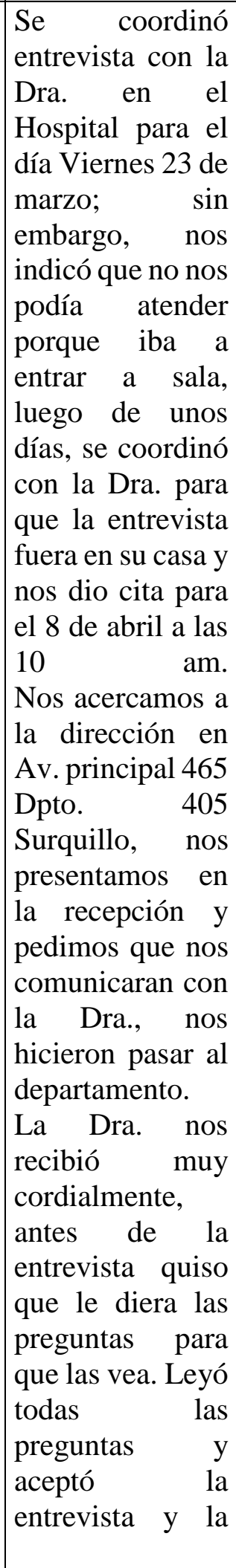 & $\begin{array}{l}\text { A la salida del hospital se } \\
\text { encontró sentada el muro } \\
\text { de la parte externa del } \\
\text { hospital, se escuchó a dos } \\
\text { señoras hablando una le } \\
\text { decía que su esposo había } \\
\text { sido operado } \\
\text { recientemente, } \\
\text { procedimos a preguntar a } \\
\text { la señora si nos podía } \\
\text { brindar unos minutos para } \\
\text { hacerle unas preguntas } \\
\text { sobre el proceso que } \\
\text { siguió para que su esposo } \\
\text { sea atendido por lo que } \\
\text { nos dijo que sí. }\end{array}$ \\
\hline
\end{tabular}




\begin{tabular}{|c|c|c|c|c|c|c|c|c|}
\hline \begin{tabular}{|l|}
$\begin{array}{l}\text { Contexto } \\
\text { Segmento }\end{array}$ \\
\end{tabular} & Contexto/Segmento & Gerente Quirúrgico & $\begin{array}{c}\text { Jefes de las oficinas } \\
\text { administrativas }\end{array}$ & Jefes de Servicios & Jefes de Departamento & \begin{tabular}{|l|}
$\begin{array}{l}\text { Personal } \\
\text { administrativo }\end{array}$ \\
\end{tabular} & Médicos & Pacientes \\
\hline & \begin{tabular}{|lr} 
atención & por \\
especialidad & $\mathrm{y}$
\end{tabular} & & $\begin{array}{l}\text { con la grabación de } \\
\text { voz. }\end{array}$ & & & & \begin{tabular}{|l} 
grabación de \\
voz.
\end{tabular} & \\
\hline \begin{tabular}{|l}
\multicolumn{2}{|l|}{ Observaciones } \\
durante la la \\
entrevista
\end{tabular} & 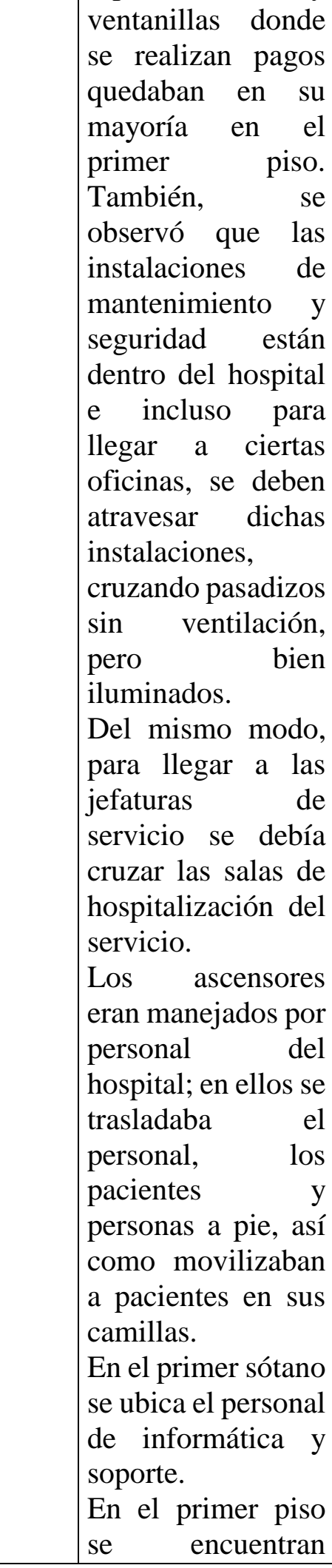 & 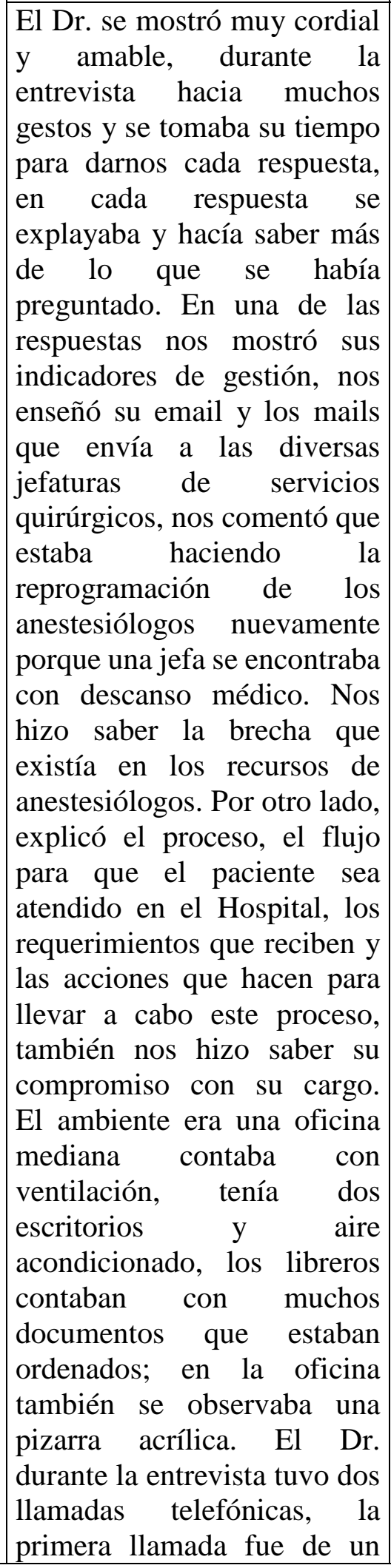 & 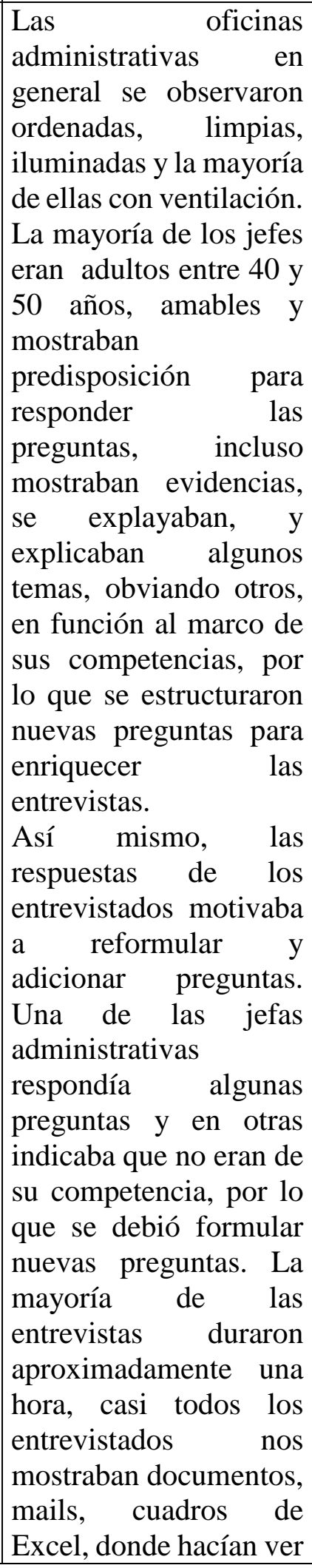 & 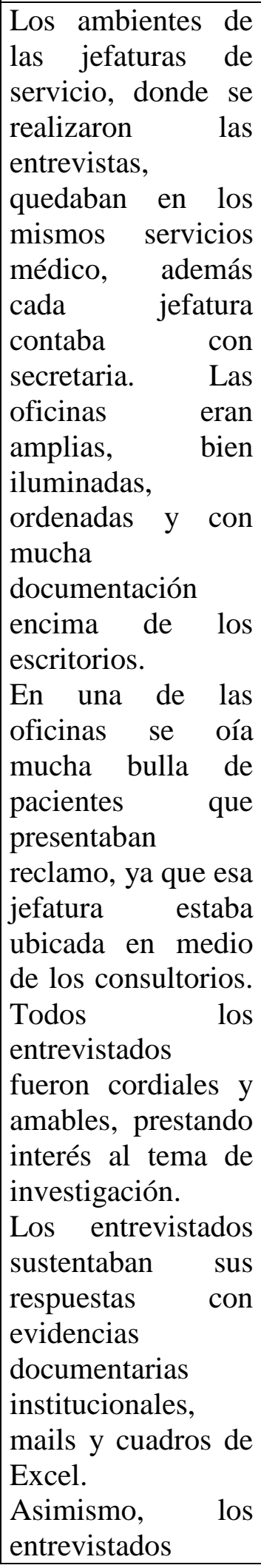 & 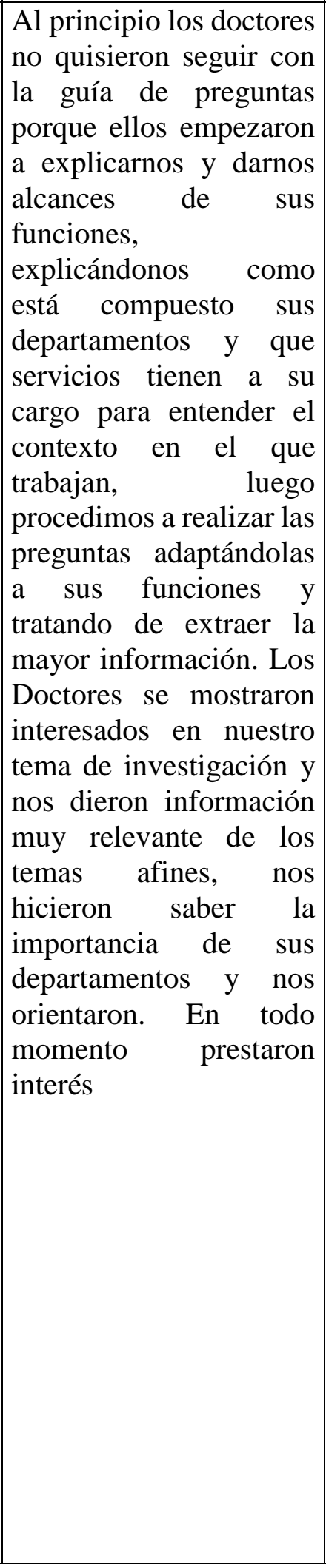 & 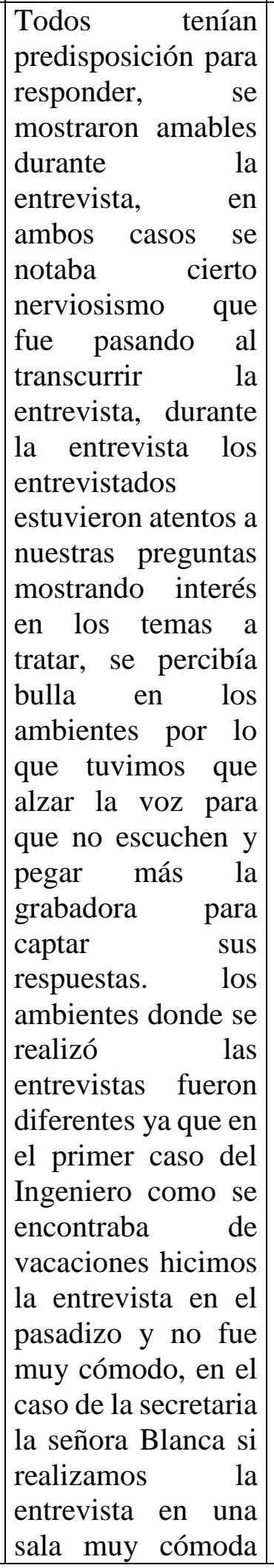 & 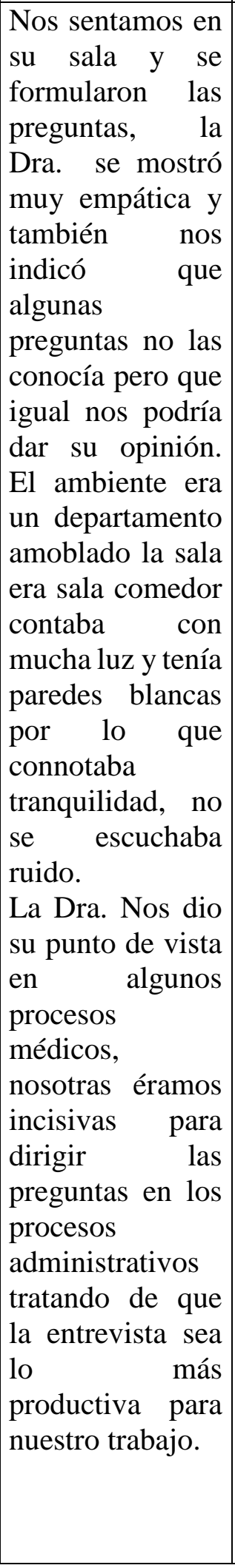 & $\begin{array}{l}\text { Nos sentamos en el } \\
\text { murito y seguidamente le } \\
\text { realizamos algunas } \\
\text { preguntas, era un día } \\
\text { caluroso por lo que nos } \\
\text { protegimos en las ramas } \\
\text { de un árbol, la señora nos } \\
\text { comentaba que ella viene } \\
\text { desde Huánuco y que fue } \\
\text { referida desde su centro } \\
\text { de salud, nos hizo saber } \\
\text { el proceso que siguió y el } \\
\text { tiempo en que se } \\
\text { demoraron en atender a su } \\
\text { esposo para que sea } \\
\text { intervenido } \\
\text { quirúrgicamente, Por otro } \\
\text { lado nos comentó que su } \\
\text { esposo aun no recupera la } \\
\text { conciencia y que sigue } \\
\text { Hospitalizado, la señora } \\
\text { se mostró tranquila pero a } \\
\text { la vez nos recalcó que la } \\
\text { demora en la atención de } \\
\text { la operación a su esposo } \\
\text { fue porque en el Hospital } \\
\text { se había detectado un } \\
\text { virus lo que hizo que } \\
\text { cierren esas salas y por } \\
\text { una semana no se puedo } \\
\text { operar eso los retrasó pese } \\
\text { a que su esposo entró por } \\
\text { emergencia y no estuvo } \\
\text { en la lista de espera por la } \\
\text { complejidad de su caso. } \\
\text { Pese a todo lo ocurrido la } \\
\text { señora nos comentó que } \\
\text { recibió un buen trato del } \\
\text { personal médico y } \\
\text { administrativo ya que } \\
\text { ellos le informaban y } \\
\text { daban detalles del caso de } \\
\text { su esposo. }\end{array}$ \\
\hline
\end{tabular}




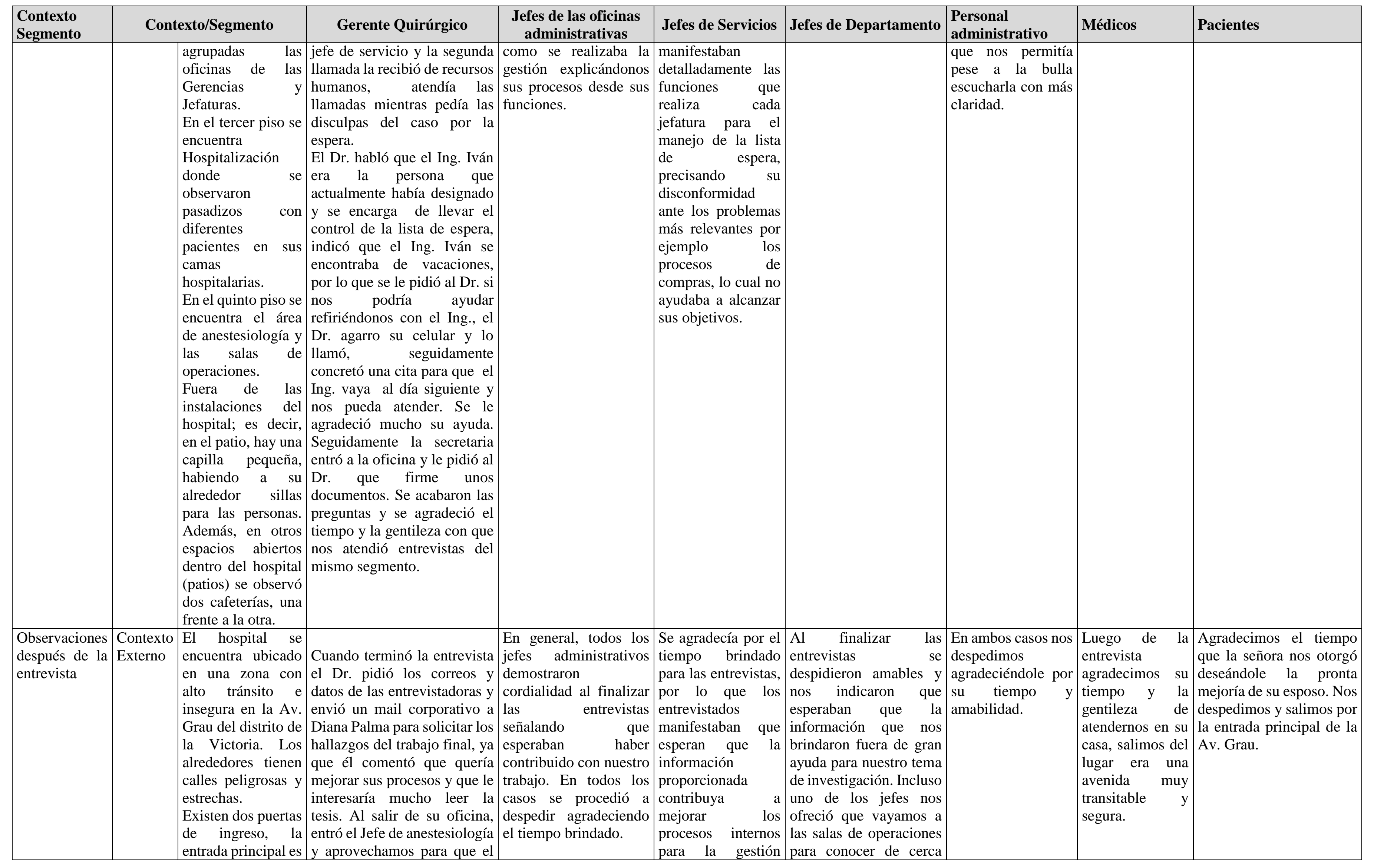




\begin{tabular}{|c|c|c|c|c|c|c|c|c|}
\hline \begin{tabular}{|l|} 
Contexto \\
Segmento \\
\end{tabular} & Contexto/Segmento & Gerente Quirúrgico & $\begin{array}{l}\text { Jefes de las oficinas } \\
\text { administrativas } \\
\end{array}$ & Jefes de Servicios & Jefes de Departamento & \begin{tabular}{|l|l|}
$\begin{array}{l}\text { Personal } \\
\text { administrativo }\end{array}$ \\
\end{tabular} & Médicos & Pacientes \\
\hline & 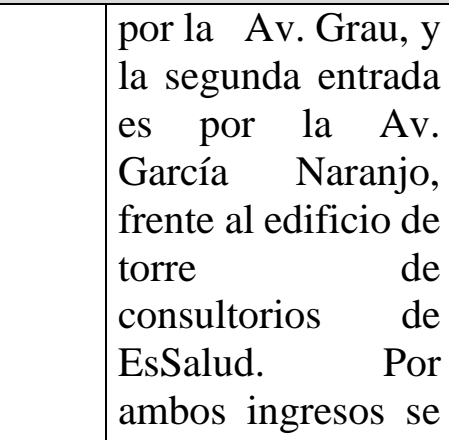 & $\begin{array}{l}\text { Gerente Quirúrgico pueda } \\
\text { referir a las entrevistadoras a } \\
\text { fin que el Jefe de } \\
\text { anestesiología acepte una } \\
\text { entrevista, a lo cual este } \\
\text { último indicó que se le } \\
\text { llamara para coordinar, } \\
\text { seguidamente ambos se } \\
\text { despidieron. }\end{array}$ & & $\begin{array}{l}\text { administrativa del } \\
\text { hospital. }\end{array}$ & $\begin{array}{l}\text { como es que se lleva el } \\
\text { trabajo que realizan. }\end{array}$ & & & \\
\hline $\begin{array}{l}\text { Conclusiones } \\
\text { del segmento }\end{array}$ & $\begin{array}{l}\text { observaron taxis } \\
\text { estacionados a la } \\
\text { espera } \\
\text { pasajeros, no de } \\
\text { observa } \\
\text { estacionamientos } \\
\text { ni ambulantes } \\
\text { alrededor de la } \\
\text { zona externa del } \\
\text { hospital, tampoco } \\
\text { es visible el } \\
\text { estacionamiento } \\
\text { del mismo hospital. }\end{array}$ & $\begin{array}{l}\text { La percepción de la entrevista } \\
\text { fue bastante buena, se } \\
\text { agradeció por la información } \\
\text { brindada de uno de los actores } \\
\text { más importantes del tema de } \\
\text { investigación y por las } \\
\text { referencias para conseguir } \\
\text { dos piezas importantes en la } \\
\text { investigación. Se notó la la } \\
\text { inteligencia y calidad humana } \\
\text { del Gerente Quirúrgico, pues } \\
\text { conocía los temas que } \\
\text { implican toda su gestión y } \\
\text { está muy al pendiente de } \\
\text { mejorar los procesos internos } \\
\text { del hospital. } \\
\text { El trato del Dr. Caballero fue } \\
\text { muy amable y se mostró muy } \\
\text { empático. Fue muy servicial } \\
\text { en todos los aspectos y brindó } \\
\text { información sumamente } \\
\text { valiosa para la investigación, } \\
\text { y fue motivador que muestre } \\
\text { mucho interés en los } \\
\text { hallazgos, recomendaciones } \\
\text { y conclusiones, producto del } \\
\text { trabajo de investigación. }\end{array}$ & 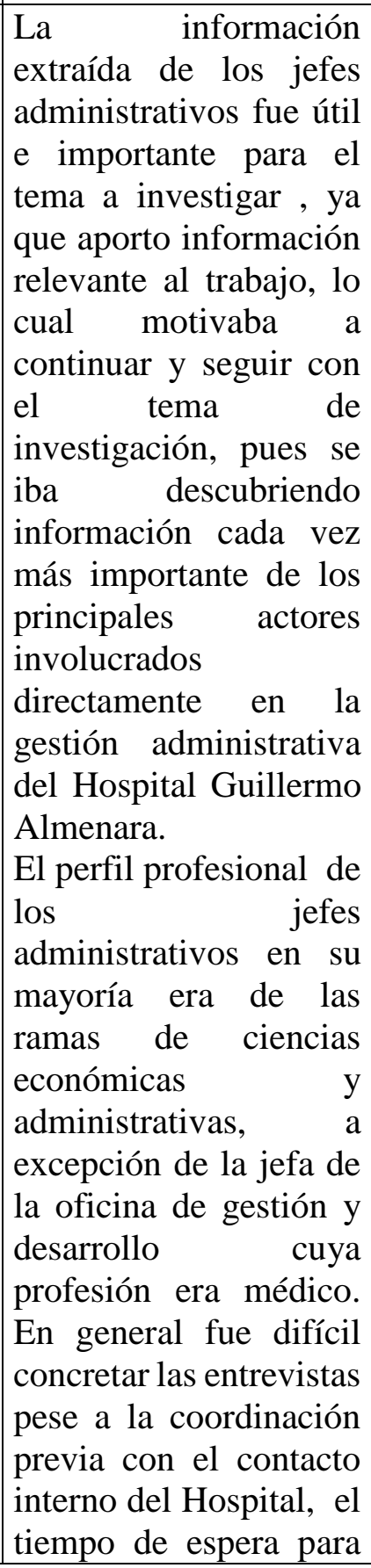 & 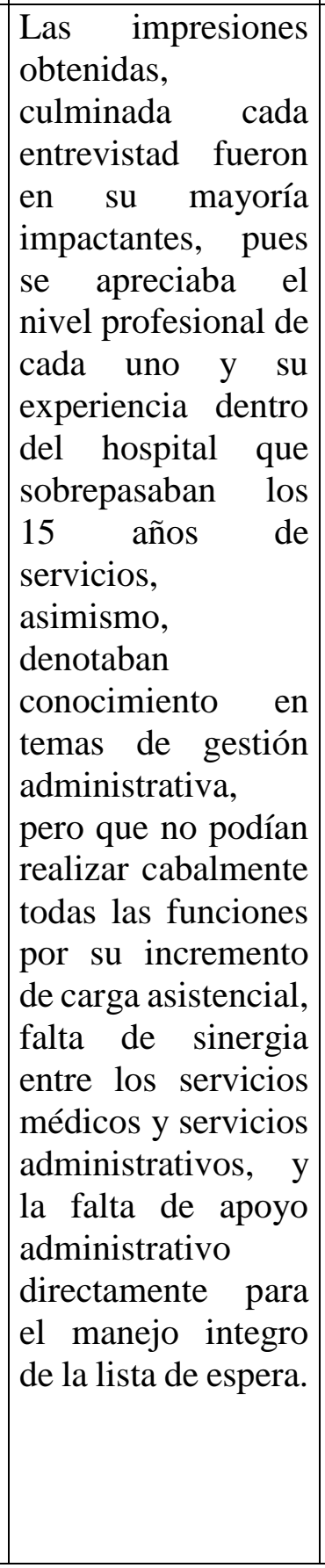 & $\begin{array}{l}\text { Lo doctores accedieron a } \\
\text { las entrevistas pero fue } \\
\text { muy complicado llegar a } \\
\text { ellos y obtener las } \\
\text { entrevistas, debido a su } \\
\text { carga laboral, en ambos } \\
\text { casos nos } \\
\text { proporcionaron revan } \\
\text { información relevante, } \\
\text { en el caso del jefe de } \\
\text { anestesiología por ser } \\
\text { una pieza fundamental } \\
\text { en el hospital nos } \\
\text { explicó minuciosamente } \\
\text { como está compuesto los } \\
\text { servicios que el manejan } \\
\text { y el proceso que hacen } \\
\text { para dar soporte a toda la } \\
\text { gerencia quirúrgica, } \\
\text { también nos brindó } \\
\text { datos e información } \\
\text { sumamente relevante } \\
\text { como las brechas que } \\
\text { tienen y como lo } \\
\text { manejan. En cuanto al } \\
\text { otro jefe de } \\
\text { departamento también } \\
\text { nos brindó información } \\
\text { muy interesante ya que } \\
\text { nos pudimos dar cuenta } \\
\text { que manejan la lista de } \\
\text { espera de manera } \\
\text { diferente y se rigen bajo } \\
\text { otras normativas, sin } \\
\text { embargo, también } \\
\text { reportan a la gerencia } \\
\text { quirúrgica. Nuestra } \\
\end{array}$ & 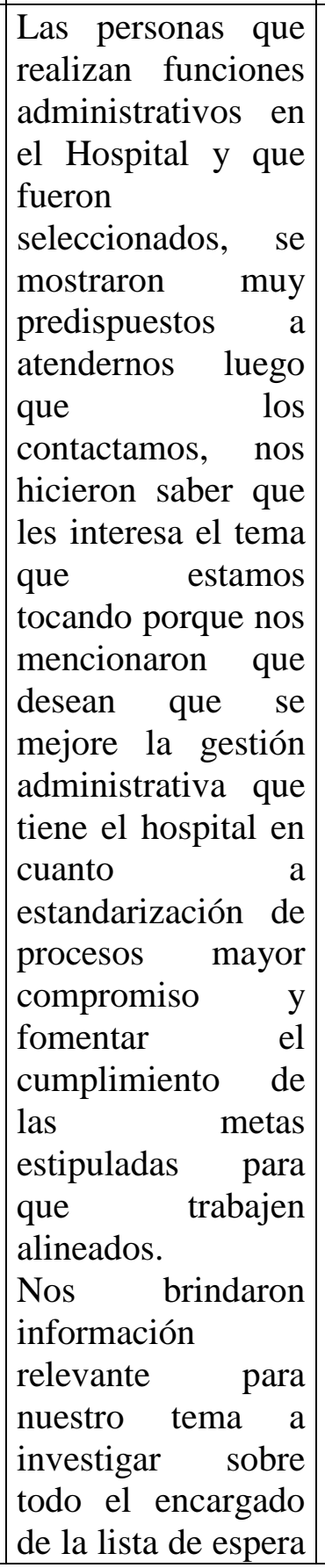 & $\begin{array}{l}\text { La Dra., al } \\
\text { principio se } \\
\text { mostró temerosa } \\
\text { al contenido de } \\
\text { las preguntas. } \\
\text { Luego cuando } \\
\text { las vio nos } \\
\text { proporcionó } \\
\text { mucha } \\
\text { información de } \\
\text { su día como } \\
\text { anestesióloga, } \\
\text { durante la } \\
\text { entrevista se } \\
\text { mostró empática } \\
\text { y atenta a las } \\
\text { preguntas que le } \\
\text { realizábamos. }\end{array}$ & $\begin{array}{l}\text { La señora Ana como } \\
\text { asegurada y esposa del } \\
\text { paciente que fue } \\
\text { intervenido } \\
\text { quirúrgicamente en el } \\
\text { Hospital Guillermo } \\
\text { Almenara Irigoyen en la } \\
\text { especialidad rad de } \\
\text { neurocirugía, refirió el } \\
\text { proceso que realizó para } \\
\text { que su esposo sea } \\
\text { intervenido } \\
\text { quirúrgicamente, } \\
\text { tomando en cuenta que } \\
\text { fue un paciente referido y } \\
\text { que se encontraba en } \\
\text { provincia (Huánuco) y su } \\
\text { ingreso fue por } \\
\text { emergencia, por lo cual } \\
\text { no fue ingresado a la lista } \\
\text { de espera; sin embargo el } \\
\text { paciente esperó treinta y } \\
\text { ocho días para la } \\
\text { intervención programada. } \\
\text { Así mismo refirió que su } \\
\text { esposo lleva treinta días } \\
\text { en cuidados intensivos a } \\
\text { la espera de una mejoría. } \\
\text { Al abordar a la señora } \\
\text { Ana se tuvo que } \\
\text { improvisar en las } \\
\text { preguntas orientándolas a } \\
\text { su caso, tratando de } \\
\text { extraer la mayor } \\
\text { información en cuanto al } \\
\text { tema a investigar, por lo } \\
\text { cual no se siguió el }\end{array}$ \\
\hline
\end{tabular}




\begin{tabular}{|c|c|c|c|c|c|c|c|c|}
\hline \begin{tabular}{|l|} 
Contexto \\
Segmento
\end{tabular} & Contexto/Segmento & Gerente Quirúrgico & $\begin{array}{l}\text { Jefes de las oficinas } \\
\text { administrativas }\end{array}$ & Jefes de Servicios & Jefes de Departamento & $\begin{array}{l}\text { Personal } \\
\text { administrativo }\end{array}$ & Médicos & Pacientes \\
\hline & & & $\begin{array}{l}\text { entrevistar a los jefes } \\
\text { administrativos fue en } \\
\text { promedió de dos a tres } \\
\text { horas por cada uno. }\end{array}$ & & \begin{tabular}{llrr|} 
percepción fue bastante \\
buena ya \\
placer & conocer & de \\
personas & que & tienen \\
muchos & años & de \\
experiencia & en & el \\
hospital. & & \\
\end{tabular} & $\begin{array}{l}\text { a nivel de todo el } \\
\text { hospital nos brindó } \\
\text { más claridad de } \\
\text { todo el proceso y } \\
\text { las mejoras que } \\
\text { están tratando e } \\
\text { implementar para } \\
\text { que la lista } \\
\text { sincea } \\
\text { actualizada. }\end{array}$ & & $\begin{array}{l}\text { protocolo habitual. } \\
\text { Ahora bien, al seguir con } \\
\text { las entrevistas se advirtió } \\
\text { que la información que se } \\
\text { iba a recoger seria } \\
\text { repetitiva y no aportaría al } \\
\text { tema de investigación. }\end{array}$ \\
\hline
\end{tabular}

Elaboración propia 


\subsection{La muestra}

\subsubsection{Descripción de la muestra}

El lugar seleccionado fue el Hospital Almenara, se determinó que su contexto era el lugar apropiado; para encontrar los participantes necesarios para cumplir el objetivo de nuestro tema de investigación.

Por eso, se revisó el funcionamiento administrativo interno del hospital, llegando a la conclusión que los actores elegidos para nuestra investigación debían ser las personas involucradas directamente en la gestión administrativa y del manejo de la lista de espera para la atención del paciente quirúrgico. Decidiendo tomar una muestra 15 personas distribuidas : entre un (1) gerente quirúrgico, tres (3) jefes de servicio médicos, (5) jefes de oficinas administrativas, dos (02) jefes de departamento médicos, dos (02) colaboradores administrativos, un (01) médico y un (01) paciente que fue intervenido quirúrgicamente.

Esta es una muestra no probabilística, porque no buscamos un resultado estadísticamente representativo de la población, pues las unidades de análisis seleccionadas fueron por decisión del investigador, ya que cumplían el perfil para obtener la información y recolección de datos.

\subsection{Diseño o abordaje principal}

\subsubsection{Identificación de la estructura de la entrevista}

Para el presente trabajo se utilizará la técnica de la entrevista a profundidad basándose en una guía de preguntas sema-estructuradas, ya que de esta manera el entrevistador profundizará en los temas a medida que estos se vayan desarrollando durante la entrevista. 


\subsubsection{Guía de preguntas}

Las preguntas diseñadas estuvieron basadas con la finalidad de alcanzar los objetivos específicos del tema de investigación, las cuales se detallan en el Anexo 01.

\subsubsection{Segmentos}

Los segmentos fueron seleccionados de acuerdo a su nivel de responsabilidad, cargo y experiencia, según lo identificado en la Directiva de Gerencia General Nº15-GGESSALUD-2015, aprobado a través de la Resolución de Presidencia Ejecutiva № 545 PE-ESSALUD-2011, y del Reglamento y Organización y Funciones del Hospital Almenara, aprobado mediante Resolución de Presidencia Ejecutiva N ${ }^{\circ} 545$-PEESSALUD-2011, conforme se detallan a continuación:

\section{Segmento I Gerente Quirúrgico:}

La gestión de la oportunidad quirúrgica está a cargo del Gerente Quirúrgico del Hospital Almenara, encargado de generar y consolidar la lista única de oportunidad quirúrgica, por servicios, reportando a la Sede Central el cumplimiento de los indicadores e informes periódicos; a su vez analizar la producción quirúrgica.

\section{Segmento II Jefe de Departamentos:}

Reportan a la Gerencia Quirúrgica el cumplimiento de los indicadores e informes periódicos según se requiera por nivel central, analiza la producción quirúrgica y propone las medidas que se requieran a fin de evitar diferimiento por falta de capacidad operativa.

\section{Segmento III Jefes de las oficinas administrativas:}

Fueron segmentos debido a su vinculación en temas administrativos que infieren en el manejo de la lista de espera de cada servicio, como, por ejemplo:

La jefatura de administración es responsable del cumplimiento de la Directiva de Normas para la gestión de la oportunidad quirúrgica vigente, así como de los resultados por falta de control y seguimiento operativo. 
La jefa de atención al asegurado, quien supervisa y propone estrategias para la atención al asegurado a fin de lograr la satisfacción, atiende y canaliza las quejas y reclamos presentados por los pacientes.

La jefatura de la unidad de referencias y contra referencias proporciona a la jefatura de cada servicio una lista de los pacientes referidos a otras IPRESS para intervención quirúrgica con el fin de verificar la información y hacer la depuración de la lista única de oportunidad quirúrgica en el IPRESS de origen.

La Jefatura de oficina de informática tiene entre sus funciones observar periódicamente, a través de exámenes y visitas inopinadas la gestión de los recursos informáticos administrados por áreas dentro de su ámbito, coordinando las acciones correctivas necesarias a fin de cumplir con las normas objetivos y planes correspondientes.

La Jefatura de gestión y desarrollo es responsable de dirigir el proceso de formulación, priorización y aprobar la iniciativas y propuestas correspondiente a las oficinas a su cargo para los planes de gestión, metas y presupuesto de la Red; hacer seguimiento de su ejecución y resultados y las medidas correctivas.

\section{Segmento IV Jefe de Servicio:}

Los jefes de servicio generan y consolidan su propia lista única de oportunidad quirúrgica, así como, realizan la programación en bases a la lista de pacientes aptos, y responsable registrándolos en el sistema informático vigente, controla las actividades relacionadas con el registro de las intervenciones quirúrgicas y verifica la depuración del paciente en la lista de espera una vez operado o fallecido.

\section{Segmento V Personal Médico Anestesiólogo}

Es responsable de atención de anestesiología, verificando diariamente en el sistema informático institucional vigente la lista de pacientes aptos para intervención quirúrgica Emiten las solicitudes de exámenes y evaluaciones pre quirúrgicas 


\section{Segmento VI Personal Administrativo:}

Colaboradores subordinados inmersos en la gestión administrativa del manejo de la lista de espera.

\section{Segmento VII Paciente de la lista de espera de oportunidad quirúrgica:}

Paciente acreditado, apto para ser programado a una intervención quirúrgica.

Por lo antes expuesto, se presenta el número de personas por segmento:

Segmentos para el desarrollo de las entrevistas

Tabla 2. Segmentos de entrevistados

\begin{tabular}{ll}
\hline SEGMENTOS DE ENTREVISTAS & CANTIDAD \\
\hline Gerentes Quirúrgico & 1 \\
Jefe de Departamentos & 2 \\
Jefe de Oficinas Administrativa & 5 \\
Jefes de Servicios Médicos & 3 \\
Personal Médico Anestesiólogo & 1 \\
Personal Administrativo & 2 \\
Paciente de la lista de espera & 1 \\
& \\
TOTAL, DE ENTREVISTADOS & 15 \\
\hline
\end{tabular}

Elaboración propia

\subsubsection{Categorías}

Los temas que se abordarán en las siguientes entrevistas serán los siguientes, dado que buscan responder a nuestras preguntas de investigación:

- Gestión administrativa vinculada al manejo de la lista de espera del Hospital Almenara.

- Oportunidad de mejora para el manejo de la lista de espera

- Objetivos y metas administrativas asociadas a las herramientas de gestión

- Normas para la gestión de la oportunidad quirúrgica.

- Lista de Espera.

- Herramientas de gestión administrativa 
- Factores que intervienen en el manejo de la Lista de Espera.

- Plan Operativo Institucional.

\subsubsection{El instrumento de Investigación}

El instrumento de investigación utilizado fue la entrevista a profundidad, basada en una guía de preguntas semiestructuradas y fichas de observación, que fue fuente de información para la elaboración de la matriz de codificación (Anexo 03).

El investigador también es instrumento de investigación, pues tiene la libertad de introducir preguntas adicionales para precisar conceptos y comienza a aprender por observación, percepción y descripción que obtiene de los participantes internos (expertos). 


\subsection{Procedimiento}

\subsubsection{Matriz de procesamiento - codificación:}

Tabla 3. Procesamiento de codificación de las entrevistas realizadas

\begin{tabular}{|c|c|c|c|c|c|c|c|}
\hline CATEGORIAS & GERENTES & JEFES ADMINISTRATIVOS & $\begin{array}{c}\text { JEFES DE } \\
\text { DEPARTAMENTO }\end{array}$ & $\begin{array}{l}\text { JEFES DE } \\
\text { SERVICIO }\end{array}$ & $\begin{array}{c}\text { PERSONAL } \\
\text { ADMINISTRATIVO }\end{array}$ & $\begin{array}{l}\text { PERSONAL } \\
\text { MÉDICO }\end{array}$ & PACIENTES \\
\hline \begin{tabular}{|l|} 
OPORTUNIDAD \\
DE MEJORA PARA \\
EL MANEJO DE LA \\
LISTA DE ESPERA \\
DE \\
OPORTUNIDAD \\
QUIRÚRGICA
\end{tabular} & \begin{tabular}{lrr} 
El gerente refirió que un \\
proceso & administrativo \\
eficiente y simplificado en \\
cuanto a los temas de \\
materiales, insumos y \\
recursos & \multicolumn{2}{r}{ humanos } \\
ayudarían a cumplir el \\
manejo de la lista de espera. \\
Por otro lado, indicó que es \\
necesario optimizar los \\
turnos operatorios de \\
personal médico y que las \\
jefaturas de & servicio \\
realicen un control y \\
monitoreo del registro de los \\
pacientes de la lista de \\
espera.
\end{tabular} & $\begin{array}{l}\text { Las oportunidades para mejorar el } \\
\text { manejo de la lista de espera de } \\
\text { operaciones quirúrgicas que } \\
\text { advirtieron los jefes de las oficinas } \\
\text { administrativas en su mayoría fueron } \\
\text { que es necesario el abastecimiento } \\
\text { oportuno de materiales e insumos } \\
\text { médicos y profesionales médicos. } \\
\text { Además, dichos jefes coincidieron en } \\
\text { un mayor compromiso de los jefes de } \\
\text { servicio en el manejo de la lista de } \\
\text { espera, contar con personal en cada } \\
\text { servicio que se encargue de manejar } \\
\text { completamente la lista de espera de } \\
\text { oportunidad quirúrgica desde que el } \\
\text { paciente ingresa hasta que es } \\
\text { operado, así como, mencionaron que } \\
\text { es ineludible un mejor control y } \\
\text { monitoreo del registro de los } \\
\text { pacientes en la lista de espera y } \\
\text { contar con sistemas informáticos } \\
\text { óptimos. Por último, refirieron que } \\
\text { haya mayor programación de turnos } \\
\text { quirúrgicos. }\end{array}$ & 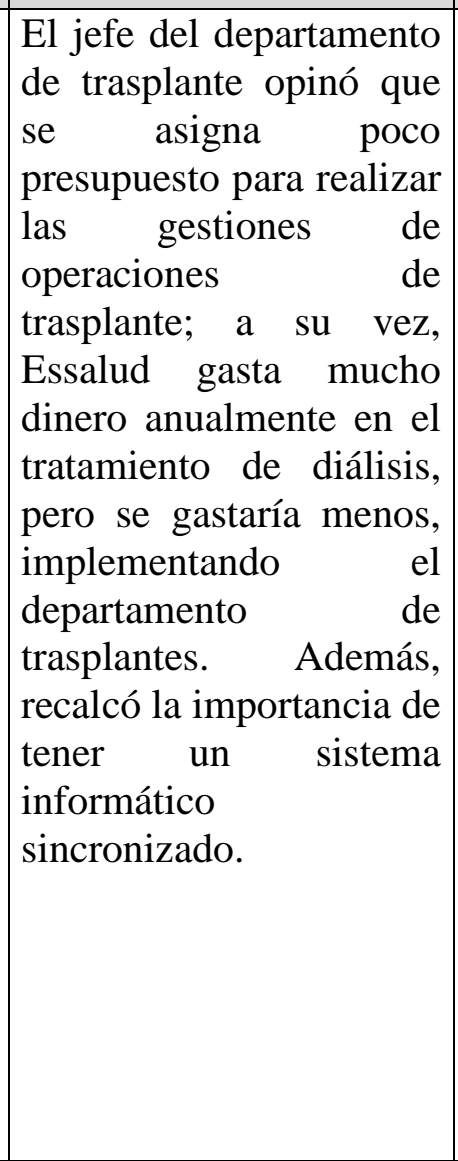 & $\begin{array}{l}\text { Sugieren que es } \\
\text { necesario un personal } \\
\text { administrativo para el } \\
\text { manejo de la lista de } \\
\text { espera, pues el jefe de } \\
\text { servicio y médicos no } \\
\text { se abastecen para } \\
\text { hacerlo. También, } \\
\text { señalan que los } \\
\text { servicios deben ser } \\
\text { abastecidos } \\
\text { oportunamente de } \\
\text { materiales e insumos } \\
\text { médicos. }\end{array}$ & $\begin{array}{l}\text { Refieren que es importante que } \\
\text { cada servicio use el SGH para } \\
\text { tener un proceso estandarizado } \\
\text { del manejo de la lista de espera, } \\
\text { además que es necesario un } \\
\text { mayor compromiso de los jefes } \\
\text { de servicio en el cumplimiento } \\
\text { de la lista de espera, pero se } \\
\text { requiere apoyo administrativo en } \\
\text { cada servicio para el manejo } \\
\text { completo de la lista de espera } \\
\text { desde que el paciente es } \\
\text { registrada en ella hasta que se le } \\
\text { retire porque ya fue intervenido. } \\
\text { También hacen hincapié que el } \\
\text { apoyo debería devenir de los } \\
\text { servicios informáticos para que } \\
\text { haya comunicación directa entre } \\
\text { los servicios quirúrgicos. }\end{array}$ & $\begin{array}{llr}\text { Mencionó } & \text { que } \\
\text { debido } & \text { a } & \text { la } \\
\text { saturación que tiene } \\
\text { el Hospital } & \text { no está } \\
\text { siendo utilizado para } \\
\text { lo que realmente fue } \\
\text { creado } & \text { un } & \text { Hospital } \\
\text { de alta complejidad. } \\
\text { También refirió que } \\
\text { un } & \text { mejor } \\
\text { abastecimiento } & \text { de } \\
\text { insumos y } & \text { recursos } \\
\text { humanos r romo } \\
\text { personal r médico } \\
\text { ayudaría a una mejor } \\
\text { gestión. }\end{array}$ & \\
\hline $\begin{array}{l}\text { OBJETIVOS } \\
\text { METAS }\end{array}$ & $\begin{array}{l}\text { El entrevistado afirmó que } \\
\text { su objetivo principal es } \\
\text { disminuir el número de días } \\
\text { de la lista de espera a menos } \\
\text { de } 45 \text { días. Asimismo, } \\
\text { mencionó que le gustaría } \\
\text { que cada servicio tenga a } \\
\text { visión a futuro para su } \\
\text { desarrollo quirúrgico, por } \\
\text { ello indicó que realiza } \\
\text { reuniones de capacitación y } \\
\text { evaluación de metas. }\end{array}$ & $\begin{array}{l}\text { Los jefes en su mayoría informaron } \\
\text { que realizan reuniones periódicas con } \\
\text { sus subordinados para monitorear el } \\
\text { alcance de sus objetivos. }\end{array}$ & 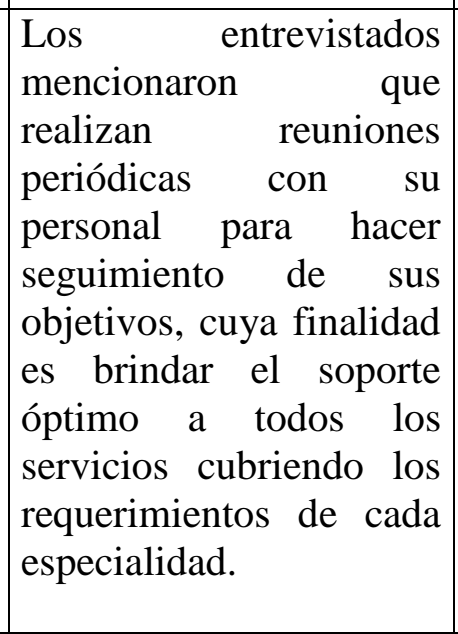 & $\begin{array}{l}\text { Indican que la Oficina } \\
\text { de Estadística procesa } \\
\text { la información del SGH } \\
\text { y reporta a las jefaturas } \\
\text { de servicio y jefaturas } \\
\text { de departamento los } \\
\text { indicadores para que } \\
\text { conozcan ran } \\
\text { producción. Asimismo, } \\
\text { realizan reuniones } \\
\text { periódicas entre jefes y } \\
\text { médicos. }\end{array}$ & $\begin{array}{l}\text { Personal del servicio de } \\
\text { anestesiología hace hincapié que } \\
\text { el jefe de ese servicio es bien } \\
\text { comprometido con el trabajo, } \\
\text { buscando cumplir de la mejor } \\
\text { manera con todos los servicios. }\end{array}$ & $\begin{array}{l}\text { En cuanto a sus } \\
\text { objetivos nos refirió } \\
\text { solo objetivos muy } \\
\text { generales a nivel de } \\
\text { sus funciones ya que } \\
\text { indica que pertenece } \\
\text { netamente a la parte } \\
\text { asistencial r r y } \\
\text { operativa. La Dra. } \\
\text { Refirió que los jefes } \\
\text { realizan reuniones } \\
\text { periódicas rara } \\
\text { hacer seguimiento al }\end{array}$ & \\
\hline
\end{tabular}




\begin{tabular}{|c|c|c|c|c|c|c|c|}
\hline CATEGORIAS & GERENTES & JEFES ADMINISTRATIVOS & $\begin{array}{c}\text { JEFES DE } \\
\text { DEPARTAMENTO }\end{array}$ & $\begin{array}{l}\text { JEFES DE } \\
\text { SERVICIO } \\
\end{array}$ & $\begin{array}{c}\text { PERSONAL } \\
\text { ADMINISTRATIVO } \\
\end{array}$ & $\begin{array}{l}\text { PERSONAL } \\
\text { MÉDICO } \\
\end{array}$ & PACIENTES \\
\hline & & & & & & $\begin{array}{l}\text { cumplimiento de sus } \\
\text { metas. }\end{array}$ & \\
\hline $\begin{array}{l}\text { NORMAS PARA LA } \\
\text { GESTIÓN DE LA } \\
\text { OPORTUNIDAD } \\
\text { QUIRÚRGICA }\end{array}$ & $\begin{array}{l}\text { El gerente menciona la } \\
\text { norma para la gestión de la } \\
\text { oportunidad quirúrgica y } \\
\text { realiza su gestión en función } \\
\text { de dichas normas. }\end{array}$ & $\begin{array}{l}\text { Este segmento indico no conocer el } \\
\text { tiempo de espera determinado para } \\
\text { un paciente de la lista de espera. }\end{array}$ & $\begin{array}{l}\text { Solo uno de los jefes } \\
\text { indicó conocer los } \\
\text { objetivos plasmados en } \\
\text { las normas de la gestión } \\
\text { para la oportunidad } \\
\text { quirúrgica, mencionando } \\
\text { indicadores; no obstante, } \\
\text { otro señalo no aplicarlas, } \\
\text { pero conocerlas. }\end{array}$ & $\begin{array}{l}\text { Uno de los jefes de } \\
\text { servicio indico haber } \\
\text { escuchado las normas } \\
\text { para la oportunidad } \\
\text { quirúrgica, pero no las } \\
\text { detalla. }\end{array}$ & $\begin{array}{l}\text { Conocen la existencia de las } \\
\text { normas de la oportunidad } \\
\text { quirúrgica, pero no las precisan } \\
\text { ni detalla. }\end{array}$ & $\begin{array}{l}\text { Conoce de su } \\
\text { existencia, pero no a } \\
\text { detalle. }\end{array}$ & \\
\hline LISTA DE ESPERA & $\begin{array}{l}\text { Añade que la lista de espera } \\
\text { es una lista oficial donde se } \\
\text { incorporan los pacientes que } \\
\text { han sido diagnosticados con } \\
\text { necesidad quirúrgica y que } \\
\text { han cumplido con todos los } \\
\text { requisitos previos, } \\
\text { asimismo, a esta es } \\
\text { manejada mediante el } \\
\text { Sistema de Gestión } \\
\text { Hospitalaria } \text {-SGH. } \\
\text { También señala que existen } \\
\text { dos tipos de lista de espera, } \\
\text { uno menor a 45 días y otro } \\
\text { mayor a 45 días, esto es en } \\
\text { función a la gravedad de } \\
\text { enfermedad de cada } \\
\text { paciente. Además, comenta } \\
\text { que la lista de espera no se } \\
\text { encuentra sincerada ni } \\
\text { actualizada debido a su } \\
\text { manejo informa por parte } \\
\text { del jefe de servicio; no } \\
\text { obstante, dicho gerente } \\
\text { comentó que se están } \\
\text { tomando medidas para el } \\
\text { uso obligatorio, eficiente y } \\
\text { correcto del SGH, para lo } \\
\text { cual cuenta con un } \\
\text { profesional en sistemas } \\
\text { asignado para todos los } \\
\text { temas que involucra la lista } \\
\text { de espera. }\end{array}$ & 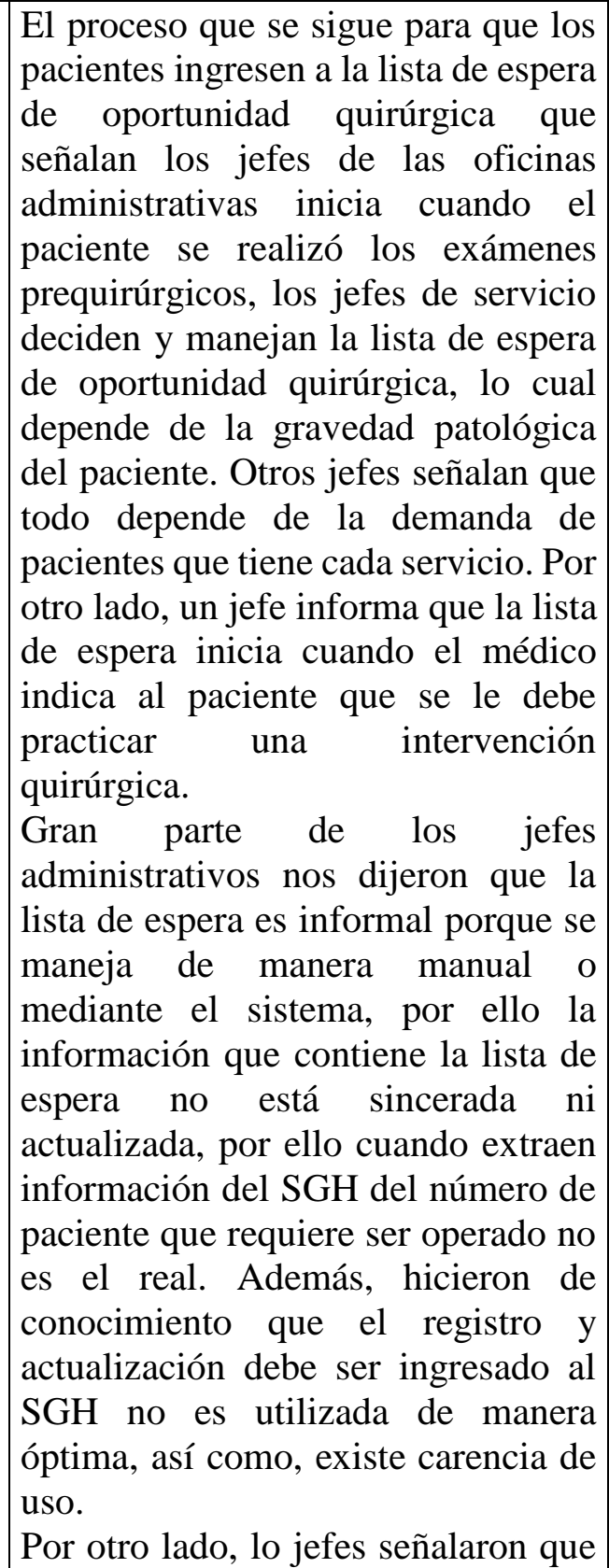 & $\begin{array}{l}\text { Los entrevistados } \\
\text { señalaron que la lista de } \\
\text { espera es informal, ya } \\
\text { que es manual o por } \\
\text { sistema, asimismo, } \\
\text { concordaron que el } \\
\text { proceso del manejo de la } \\
\text { lista de espera inicia } \\
\text { cuando el paciente tiene } \\
\text { sus pre quirúrgicos listos, } \\
\text { ambos aseguraron que } \\
\text { cada jefatura de servicio } \\
\text { maneja su lista de espera; } \\
\text { uno de ellos nos indicó } \\
\text { que se ha implementado } \\
\text { un procedimiento para el } \\
\text { manejo de la lista de } \\
\text { espera donde el médico } \\
\text { cirujano es el } \\
\text { responsable de coordinar } \\
\text { y asegurarse que se } \\
\text { cumplan con los } \\
\text { requerimientos logísticos } \\
\text { antes de dar la fecha de } \\
\text { intervención quirúrgica } \\
\text { al paciente. De igual } \\
\text { manera, señalaron que } \\
\text { los jefes de servicio no se } \\
\text { abastecen para cumplir } \\
\text { con las actividades } \\
\text { administrativas que } \\
\text { conlleva manejar la lista } \\
\text { de espera y recalcaron } \\
\text { que ellos deciden sobre } \\
\text { dicha lista. }\end{array}$ & $\begin{array}{l}\text { Señalan que lo } \\
\text { pacientes ingresan a la } \\
\text { lista de espera después } \\
\text { de sus exámenes } \\
\text { prequirúrgicos, y lista } \\
\text { la realizan en Excel, } \\
\text { pues el sistema } \\
\text { informático no está } \\
\text { implementado ro de } \\
\text { acuerdo con las } \\
\text { necesidades de los } \\
\text { servicios. } \\
\text { Por otro lado, algunos } \\
\text { señalan que la lista de } \\
\text { espera comienza desde } \\
\text { que el médico le dice a } \\
\text { su paciente que } \\
\text { requiere intervención } \\
\text { quirúrgica. } \\
\text { Además, } \\
\text { entrevistados indican } \\
\text { que el turno de paciente } \\
\text { para ser intervenido se } \\
\text { decide mediante una } \\
\text { reunión de junta } \\
\text { médica, y otros, que el } \\
\text { cirujano escoge los } \\
\text { pacientes que va } \\
\text { operar; no obstante, } \\
\text { algunos indican que el } \\
\text { jefe de servicio se } \\
\text { encarga del llenado de } \\
\text { la lista de espera y } \\
\text { decide quien será } \\
\text { intervenido, puesto que }\end{array}$ & $\begin{array}{l}\text { El paciente ingresa a la lista de } \\
\text { espera después de culminado sus } \\
\text { exámenes prequirúrgicos, cada } \\
\text { servicio se encarga de gestionar } \\
\text { y priorizar dicha lista. Sin } \\
\text { embargo, aún se realiza } \\
\text { manualmente. Por ello, la } \\
\text { información que contiene las } \\
\text { listas de espera de cada servicio } \\
\text { no está sincerada ni actualizada. } \\
\text { Además de lo antes mencionado, } \\
\text { mencionan que interfieren las } \\
\text { referencias externas en el } \\
\text { manejo de la lista de espera, } \\
\text { retrasando la ejecución de la lista } \\
\text { de espera que tiene el servicio. } \\
\text { También señalaron que a la } \\
\text { fecha existen algunos proyectos } \\
\text { de propuestas económicas para } \\
\text { los médicos para motivar el } \\
\text { manejo eficiente de la lista de } \\
\text { espera, por ello lo servicios se } \\
\text { están preocupando por dicha } \\
\text { herramienta. }\end{array}$ & $\begin{array}{l}\text { La Dra. Considera } \\
\text { que la lista de espera } \\
\text { empieza luego que } \\
\text { un paciente pasa sus } \\
\text { exámenes } \\
\text { prequirúrgicos, a la } \\
\text { vez nos menciona } \\
\text { que no tiene } \\
\text { conocimiento que } \\
\text { personal maneja la } \\
\text { lista de espera ya que } \\
\text { no se encuentra } \\
\text { dentro del ámbito de } \\
\text { sus funciones, sin } \\
\text { embargo, menciona } \\
\text { que el ingreso para } \\
\text { que un paciente se } \\
\text { encuentre en la lista } \\
\text { de espera depende } \\
\text { de la patología del } \\
\text { mismo del tipo de } \\
\text { enfermedad. } \\
\text { También, mencionó } \\
\text { que la atención de un } \\
\text { paciente en lista de } \\
\text { espera depende } \\
\text { también de la } \\
\text { disponibilidad de } \\
\text { camas y de salas de } \\
\text { operaciones. }\end{array}$ & \\
\hline
\end{tabular}




\begin{tabular}{|c|c|c|c|c|c|c|c|}
\hline CATEGORIAS & GERENTES & JEFES ADMINISTRATIVOS & $\begin{array}{c}\text { JEFES DE } \\
\text { DEPARTAMENTO }\end{array}$ & $\begin{array}{l}\text { JEFES DE } \\
\text { SERVICIO }\end{array}$ & $\begin{array}{c}\text { PERSONAL } \\
\text { ADMINISTRATIVO }\end{array}$ & $\begin{array}{l}\text { PERSONAL } \\
\text { MÉDICO }\end{array}$ & PACIENTES \\
\hline & & $\begin{array}{l}\text { algunos médicos no recuerdan loa } \\
\text { prioridad de los casos debido a la } \\
\text { demanda de pacientes. }\end{array}$ & & $\begin{array}{|lr|}\text { reciben una oferta } & \text { de } \\
\text { turnos quirúrgicos } & \text { del } \\
\text { servicio } & \text { de } \\
\text { anestesiología. }\end{array}$ & & & \\
\hline $\begin{array}{|lr|}\text { HERRAMIENTAS } \\
\text { DE r GESTIÓN } \\
\text { ADMINISTRATIVA }\end{array}$ & $\begin{array}{l}\text { Refiere la importancia del } \\
\text { uso de las herramientas de } \\
\text { gestión, por lo que todo el } \\
\text { personal debería conocer y } \\
\text { alinearse a las metas } \\
\text { establecidas en r las } \\
\text { herramientas de gestión } \\
\text { administrativas }\end{array}$ & $\begin{array}{l}\text { Los jefes administrativos mencionan } \\
\text { que los sistemas informáticos tales } \\
\text { como: Sistema de Gestión } \\
\text { Hospitalaria, Sistema Interno de } \\
\text { Administración Documentaria y } \\
\text { Sistemas Estadísticos son las } \\
\text { herramientas de gestión } \\
\text { administrativa, asimismo algunos } \\
\text { indicaron que sus objetivos están } \\
\text { establecidos en el Reglamento de } \\
\text { Organización y Funciones. Algunos } \\
\text { daban a conocer que, si sabían que } \\
\text { existían, pero no los nombraban; } \\
\text { otros si tenían conocimiento, } \\
\text { nombrándolas y señalan que si } \\
\text { aplicaban dichas herramientas en sus } \\
\text { funciones. No obstante, señalan que } \\
\text { no se difunde ni promueve al } \\
\text { personal el uso, beneficios y } \\
\text { parámetros que marcan las } \\
\text { herramientas de de gestión } \\
\text { administrativa. } \\
\text { Todos los jefes de servicio señalaron } \\
\text { que es importante el uso de las } \\
\text { herramientas de gestión }\end{array}$ & $\begin{array}{lrr}\text { Los } & \text { jefes } & \text { de } \\
\text { departamento } & & \\
\text { mencionaron } & \text { que las } \\
\text { herramientas } & \text { de } & \text { gestión } \\
\text { son importantes } & \text { para el } \\
\text { cumplimiento } & \text { de } \\
\text { objetivos, asimismo, } & \text { otro } \\
\text { mencionó } & \text { conocer } & \text { y } \\
\text { aplicar las } & \text { herramientas } \\
\text { de } & & \text { gestión } \\
\text { administrativas. } & \end{array}$ & $\begin{array}{l}\text { Respecto a las } \\
\text { herramientas de gestión } \\
\text { indicaron que existen, } \\
\text { pero que no se adecuan } \\
\text { a la realidad de cada } \\
\text { servicio, y que es } \\
\text { necesario que la gestión } \\
\text { difunda ras } \\
\text { herramientas para } \\
\text { conocimiento de todo el } \\
\text { personal, pues } \\
\text { indicaron conocerlas, } \\
\text { pero no a precisión. }\end{array}$ & $\begin{array}{l}\text { Señalan que son útiles por } \\
\text { marcan los objetivos, criterios y } \\
\text { requisitos para la } \\
\text { administración, no obstante, no } \\
\text { los conocen bien, por lo que } \\
\text { indican que debería difundirse a } \\
\text { todo el personal. }\end{array}$ & $\begin{array}{l}\text { La Dra. Menciona } \\
\text { que sabe que existen } \\
\text { las herramientas de } \\
\text { gestión, pero no } \\
\text { recuerda nus } \\
\text { nombres, así mismo } \\
\text { indicó que existen } \\
\text { varios indicadores } \\
\text { para establecer las } \\
\text { metas relacionadas a } \\
\text { sus funciones. }\end{array}$ & \\
\hline \begin{tabular}{|lr} 
GESTIÓN & \\
ADMINISTRATIVA \\
PARA & LA \\
ATENCIÓN & DEL \\
PACIENTE & \\
QUIRÚRGICO &
\end{tabular} & $\begin{array}{l}\text { El entrevistado opina que la } \\
\text { gestión administrativa del } \\
\text { hospital es engorrosa y } \\
\text { lenta, por ello una de las } \\
\text { medidas implementadas fue } \\
\text { extender la vigencia de los } \\
\text { resultados de los exámenes } \\
\text { prequirúrgicos } \\
\text { ampliándolos de } 3 \text { a } 6 \\
\text { meses. }\end{array}$ & $\begin{array}{l}\text { La mayoría de los jefes } \\
\text { administrativos opinaron que se debe } \\
\text { mejorar los procesos administrativos } \\
\text { internos haciéndolos más eficientes y } \\
\text { simples, también los jefes } \\
\text { coincidieron en que no se cuenta con } \\
\text { apoyo administrativo para el manejo } \\
\text { de la lista de espera, pues refirieron } \\
\text { que los jefes de servicio no se } \\
\text { abastecen por la carga laboral. Por } \\
\text { otro lado, indicaron que los equipos e } \\
\text { instrumentos médicos se encuentran } \\
\text { en mal estado y que las salas de } \\
\text { operaciones quirúrgica no tienen } \\
\text { oportunamente los materiales } \\
\text { requeridos para iniciar la cirugía. }\end{array}$ & \begin{tabular}{|lrr} 
Los & dos & entrevistados \\
coincidieron & en & que el \\
hospital & Guillermo \\
Almenara & Irigoyen & debe \\
mejorar & los & procesos \\
administrativos & interno \\
haciéndolos & más \\
eficientes y & simple, ya \\
que mencionaron demora \\
en los procesos & de \\
adquisición de & insumos. \\
Por ratro r & lado, \\
mencionaron & que \\
muchas & de & las \\
actividades & & \\
administrativas & son \\
realizadas & por & los
\end{tabular} & 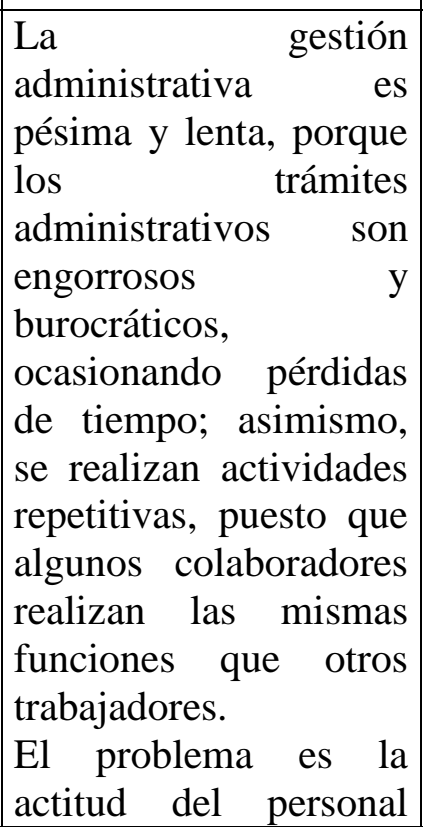 & $\begin{array}{l}\text { Indican que los procedimientos } \\
\text { son muy largos, pues a veces los } \\
\text { medicamentos llegan fuera de } \\
\text { tiempo, cuando el paciente ya no } \\
\text { los necesita. }\end{array}$ & $\begin{array}{l}\text { La Dra. mencionó } \\
\text { que considera buena } \\
\text { la gestión } \\
\text { administrativa del } \\
\text { Hospital Guillermo } \\
\text { Almenara porque } \\
\text { hacen todo lo } \\
\text { posible para tratar de } \\
\text { abastecer toda la } \\
\text { lista de espera que } \\
\text { tienen, pero también } \\
\text { nos recalcó que } \\
\text { podrían mejorar en } \\
\text { sus procesos } \\
\text { internos y } \\
\text { simplificándolos y } \\
\text { haciéndolos mas }\end{array}$ & $\begin{array}{l}\text { La entrevista fue } \\
\text { realizada a la } \\
\text { esposa de un } \\
\text { paciente operado, } \\
\text { la señora indicó } \\
\text { que la gestión a } \\
\text { nivel } \\
\text { administrativa es } \\
\text { buena, porque los } \\
\text { médicos le } \\
\text { explicaron } \\
\text { detalladamente el } \\
\text { proceso que } \\
\text { debía seguir para } \\
\text { que su esposo sea } \\
\text { operado. Al } \\
\text { respecto, señalo }\end{array}$ \\
\hline
\end{tabular}




\begin{tabular}{|c|c|c|c|c|c|c|c|}
\hline CATEGORIAS & GERENTES & JEFES ADMINISTRATIVOS & $\begin{array}{c}\text { JEFES DE } \\
\text { DEPARTAMENTO }\end{array}$ & $\begin{array}{l}\text { JEFES DE } \\
\text { SERVICIO } \\
\end{array}$ & $\begin{array}{c}\text { PERSONAL } \\
\text { ADMINISTRATIVO } \\
\end{array}$ & $\begin{array}{l}\text { PERSONAL } \\
\text { MÉDICO }\end{array}$ & PACIENTES \\
\hline & & & $\begin{array}{l}\text { mismos médicos y q no } \\
\text { cuentan con apoyo } \\
\text { administrativo para el } \\
\text { manejo de la lista de } \\
\text { espera. } \\
\text { También, dieron a } \\
\text { conocer que los jefes de } \\
\text { servicio arman los turnos } \\
\text { del personal médico para } \\
\text { las intervenciones } \\
\text { quirúrgicas. }\end{array}$ & $\begin{array}{l}\text { médico y } \\
\text { administrativo, ya que } \\
\text { la parte administrativa } \\
\text { y la parte asistencial no } \\
\text { trabaja de manera } \\
\text { integrada, aduce una } \\
\text { entrevistada. }\end{array}$ & & $\begin{array}{l}\text { prácticos para que } \\
\text { los mismos médicos } \\
\text { no tengan retraso en } \\
\text { sus actividades. }\end{array}$ & $\begin{array}{l}\text { que su esposo } \\
\text { ingreso por } \\
\text { Emergencia del } \\
\text { Hospital, por lo } \\
\text { que indicó que no } \\
\text { se encontraba en } \\
\text { la lista de espera; } \\
\text { sin embargo, su } \\
\text { programación } \\
\text { quirúrgica } \\
\text { demoro } 38 \text { días } \\
\text { después de haber } \\
\text { cumplido con los } \\
\text { requerimientos } \\
\text { de los exámenes } \\
\text { prequirúrgicos, } \\
\text { pese a la } \\
\text { gravedad de su } \\
\text { enfermedad. }\end{array}$ \\
\hline $\begin{array}{l}\text { FACTORES QUE } \\
\text { INTERVIENEN EN } \\
\text { EL MANEJO DE LA } \\
\text { LISTA DE ESPERA }\end{array}$ & $\begin{array}{l}\text { Señala que existe poca } \\
\text { disponibilidad de turnos } \\
\text { quirúrgicos debido a la } \\
\text { brecha de médicos } \\
\text { anestesiólogos y al al } \\
\text { deficiente, así como la falta } \\
\text { de insumos y materiales } \\
\text { médicos. Esto último } \\
\text { debido a las coordinaciones } \\
\text { complicadas con el área de } \\
\text { logística para el proceso de } \\
\text { compras. } \\
\text { Otro factor mencionado son } \\
\text { los pacientes atendidos } \\
\text { preferentemente por } \\
\text { referencias externas, lo cual } \\
\text { altera la lista de espera. } \\
\text { Por otro lado, hay otros } \\
\text { factores como la } \\
\text { disponibilidad de tiempo de } \\
\text { los médicos cirujanos y de } \\
\text { camas hospitalarias, pues } \\
\text { estas se encuentran } \\
\text { ocupadas mayor tiempo } \\
\text { cuando se dan las } \\
\text { reprogramaciones a a a }\end{array}$ & $\begin{array}{l}\text { Los jefes administrativos consideran } \\
\text { que los factores externos que } \\
\text { influyen al manejo de la lista de } \\
\text { espera son la brecha de camas } \\
\text { hospitalarios existentes y los } \\
\text { pacientes que ingresan por } \\
\text { emergencias. }\end{array}$ & & $\begin{array}{l}\text { Los factores que } \\
\text { influyen en rel } \\
\text { cumplimiento de la lista } \\
\text { de espera son: la } \\
\text { carencia } \\
\text { anestesiólogos y la dalta } \\
\text { de turnos quirúrgicos, } \\
\text { debido que las salas de } \\
\text { operaciones no se dan } \\
\text { abasto, así como, } \\
\text { señalan los } \\
\text { entrevistado, que la } \\
\text { parte administrativa no } \\
\text { toma importancia a los } \\
\text { temas médicos, pues } \\
\text { siempre se presentan } \\
\text { problemas con el área } \\
\text { de logística para el } \\
\text { proceso de compras. }\end{array}$ & 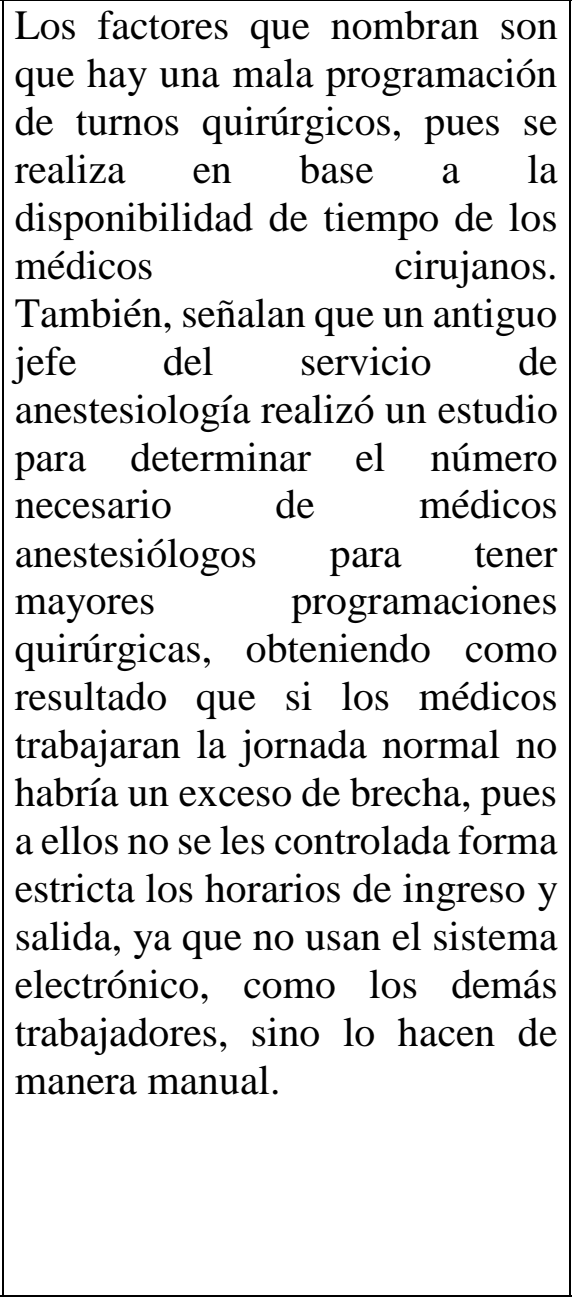 & $\begin{array}{l}\text { Indica que un factor } \\
\text { relevante es que el } \\
\text { Hospital no se da } \\
\text { abasto con la } \\
\text { demanda } r \text { de } \\
\text { pacientes que tiene y } \\
\text { que el problema } \\
\text { tiene como raíz que } \\
\text { las UBAP o centros } \\
\text { de salud a nivel } \\
\text { nacional no se } \\
\text { encuentran bien } \\
\text { equipadas rara } \\
\text { atender a los } \\
\text { pacientes y esto hace } \\
\text { que el Hospital } \\
\text { Guillermo Almenara } \\
\text { se sature por todas } \\
\text { los pacientes que son } \\
\text { referidos al Hospital. } \\
\text { También indicó que } \\
\text { muchas veces los } \\
\text { pacientes no pueden } \\
\text { ser atendidos } \\
\text { oportunamente } \\
\text { porque presentan } \\
\text { otras dolencias y }\end{array}$ & \\
\hline
\end{tabular}




\begin{tabular}{|c|c|c|c|c|c|c|c|}
\hline CATEGORIAS & GERENTES & JEFES ADMINISTRATIVOS & $\begin{array}{c}\text { JEFES DE } \\
\text { DEPARTAMENTO }\end{array}$ & $\begin{array}{l}\text { JEFES DE } \\
\text { SERVICIO }\end{array}$ & $\begin{array}{c}\text { PERSONAL } \\
\text { ADMINISTRATIVO }\end{array}$ & $\begin{array}{l}\text { PERSONAL } \\
\text { MÉDICO }\end{array}$ & PACIENTES \\
\hline & $\begin{array}{l}\text { pacientes que ya están } \\
\text { internados. }\end{array}$ & & & & & 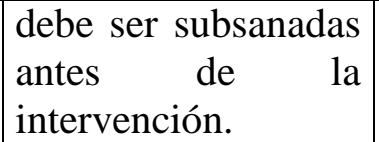 & \\
\hline $\begin{array}{l}\text { PLAN OPERATIVO } \\
\text { INSTITUCIONAL }\end{array}$ & $\begin{array}{l}\text { Indicó que si conoce el Plan } \\
\text { Operativo Institucional y } \\
\text { que su gestión la realiza en } \\
\text { función a las metas } \\
\text { establecidas en el mismo. }\end{array}$ & 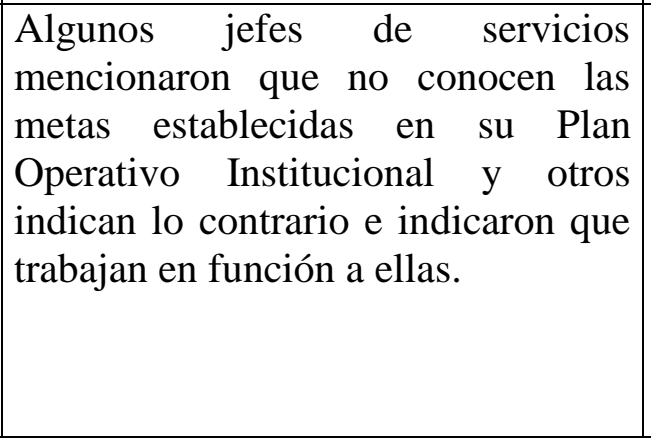 & $\begin{array}{l}\text { Los jefes de } \\
\text { departamento } \\
\text { mencionaron conocer el } \\
\text { POI, pero no conocían } \\
\text { las metas. }\end{array}$ & $\begin{array}{l}\text { Mencionaron el POI, } \\
\text { pero no conocen } \\
\text { detalladamente lo que } \\
\text { este estipula ni las } \\
\text { metas establecidas. }\end{array}$ & $\begin{array}{|lr|}\text { Conocen las metas establecidas } \\
\text { en el POI y un entrevistado del } \\
\text { servicio de anestesiología señala } \\
\text { que informan } & \text { mensualmente } \\
\text { producción, } & \text { operaciones } \\
\text { realizadas, } & \text { operaciones } \\
\text { suspendidas, } & \text { emergencias, } \\
\text { cesarías, } & \text { mortalidad y } \\
\text { morbilidad. } & \end{array}$ & $\begin{array}{l}\text { La Dra. No conoce } \\
\text { las metas estipuladas } \\
\text { en el plan operativo } \\
\text { institucional }\end{array}$ & \\
\hline
\end{tabular}

Elaboración propia 


\subsubsection{Procesamiento de la información}

Tabla 4. Procesamiento de aspectos positivos y negativos de las entrevistas al Gerente Quirúrgico.

\begin{tabular}{|c|c|}
\hline ASPECTOS POSITIVOS & ASPECTOS NEGATIVOS \\
\hline \multicolumn{2}{|c|}{ Gerente Quirúrgico } \\
\hline $\begin{array}{l}\text { Denota amplio conocimiento de la gestión } \\
\text { administrativa del Hospital Almenara, del } \\
\text { POI } 2017 \text { y Normas para la gestión de la } \\
\text { oportunidad quirúrgica del mencionado } \\
\text { hospital. } \\
\begin{array}{l}\text { Proporciona información interesante y } \\
\text { relevante acerca del tema de } \\
\text { investigación. }\end{array}\end{array}$ & $\begin{array}{l}\text { No disponía de tiempo, se le observaba } \\
\text { muy ocupado, a cada momento recibía } \\
\text { constantes llamadas, correos electrónicos } \\
\text { y mensajes instantáneos. } \\
\text { No mencionó difundir el uso, ni } \\
\text { comprometer a su personal con las metas } \\
\text { y objetivos de las herramientas de gestión. }\end{array}$ \\
\hline $\begin{array}{l}\text { Tiene objetivos claros que desea alcanzar } \\
\text { con su gestión. }\end{array}$ & \\
\hline $\begin{array}{l}\text { Conoce las debilidades y aspectos } \\
\text { negativos del hospital en cuanto al } \\
\text { servicio de operaciones quirúrgicas. }\end{array}$ & \\
\hline $\begin{array}{l}\text { Se le observó, gestor de las actividades } \\
\text { internas, vinculadas a su jefatura, } \\
\text { mediante correo y llamadas telefónicas, } \\
\text { durante la entrevista. }\end{array}$ & \\
\hline $\begin{array}{l}\text { Implementó control para el manejo de la } \\
\text { lista de espera a través del apoyo de un } \\
\text { Ing., pues observó deficiencia de los } \\
\text { servicios en la programación de su lista de } \\
\text { espera. }\end{array}$ & \\
\hline $\begin{array}{l}\text { Mostro interés por conocer los resultados } \\
\text { del presente trabajo de investigación. }\end{array}$ & \\
\hline
\end{tabular}

Elaboración propia 
Tabla 5. Procesamiento de aspectos positivos y negativos de las entrevistas a los Jefes Administrativos

\begin{tabular}{|l|l|}
\hline \multicolumn{1}{|c|}{ ASPECTOS POSITIVOS } & \multicolumn{1}{|c|}{ ASPECTOS NEGATIVOS } \\
\hline \multicolumn{1}{|c|}{ Jefes Administrativos } \\
\hline $\begin{array}{l}\text { Indican que el compromiso es el factor } \\
\text { relevante para el manejo de lista de espera. }\end{array}$ & $\begin{array}{l}\text { Señalan que las actividades relacionadas a } \\
\text { las operaciones quirúrgicas no están } \\
\text { dentro del marco de sus competencias. }\end{array}$ \\
$\begin{array}{l}\text { La mayoría de los jefes no conocen los } \\
\text { parámetros normados para el manejo de la } \\
\text { lista de espera. }\end{array}$ & $\begin{array}{l}\text { Nomprometer a su personal con las metas } \\
\text { yobjetivos de las herramientas de gestión. }\end{array}$ \\
$\begin{array}{l}\text { Resaltan la importancia del uso de las } \\
\text { herramientas de gestión. }\end{array}$ & \\
$\begin{array}{l}\text { Los jefes resaltaron la importancia del } \\
\text { presente trabajo de investigación. }\end{array}$ & \\
$\begin{array}{l}\text { Reconocen al Hospital Almenara como } \\
\text { una organización de importancia para el } \\
\text { país. }\end{array}$ &
\end{tabular}

Elaboración propia

Tabla 6. Procesamiento de aspectos positivos y negativos de las entrevistas a los Jefes de Departamento

\begin{tabular}{|l|l|}
\hline \multicolumn{1}{|c|}{ ASPECTOS POSITIVOS } & \multicolumn{1}{|c|}{ ASPECTOS NEGATIVOS } \\
\hline \multicolumn{1}{|c|}{ Jefes de Departamento } \\
\hline $\begin{array}{l}\text { Son médicos profesionales con amplia } \\
\text { experiencia y muchos años de servicio } \\
\text { dentro del Hospital Almenara. }\end{array}$ & $\begin{array}{l}\text { El Departamento de Trasplante tiene una } \\
\text { gestión administrativa de su lista de espera } \\
\text { distinta a la establecida en la Norma 015. }\end{array}$ \\
$\begin{array}{l}\text { Dan a conocer las debilidades desde el } \\
\text { enfoque administrativo del Hospital en } \\
\text { base a su conocimiento en gestión pública. }\end{array}$ & $\begin{array}{l}\text { No mencionaron difundir el uso, ni } \\
\text { comprometer a su personal con las metas } \\
\text { y objetivos de las herramientas de gestión. }\end{array}$ \\
$\begin{array}{l}\text { Implementan procedimientos para } \\
\text { cumplir la atención quirúrgica y evitar o } \\
\text { disminuir problemas administrativos que } \\
\text { impidan la realización de las operaciones } \\
\text { quirúrgicas. }\end{array}$ & \\
$\begin{array}{l}\text { Recalcaron la importancia de los sistemas } \\
\text { informáticos sincronizados. }\end{array}$ & \\
\hline
\end{tabular}

Elaboración propia 
Tabla 7. Procesamiento de aspectos positivos y negativos de las entrevistas a los Jefes de Servicio

\begin{tabular}{|c|c|}
\hline ASPECTOS POSITIVOS & ASPECTOS NEGATIVOS \\
\hline \multicolumn{2}{|c|}{ Jefes de Servicio } \\
\hline $\begin{array}{l}\text { Se percibía el buen profesionalismo y los } \\
\text { amplios conocimientos en sus temas } \\
\text { médicos. } \\
\text { Explayaban sus respuestas durante las } \\
\text { entrevistas para que al entrevistador le } \\
\text { quede clara las respuestas. } \\
\text { Conocían las falencias y debilidades de la } \\
\text { gestión administrativa. } \\
\text { Sustentaban que hacían lo posible para } \\
\text { realizar intervenciones quirúrgicas a los } \\
\text { pacientes, en la medida de lo posible y con } \\
\text { los recursos que tenían a su alcance. }\end{array}$ & $\begin{array}{l}\text { Es difícil concretar una entrevista con } \\
\text { ellos, debido al tiempo que les conlleva } \\
\text { cumplir sus funciones administrativas y } \\
\text { asistenciales. } \\
\text { No mencionaron difundir el uso, ni } \\
\text { comprometer a su personal con las metas } \\
\text { y objetivos de las herramientas de gestión. } \\
\text { No daban una respuesta clara en cuanto al } \\
\text { manejo de la lista de espera, acorde a la } \\
\text { Norma } 015 \text {. } \\
\text { No se ubicó a los jefes de servicio en las } \\
\text { tardes de los días hábiles, tampoco lo días } \\
\text { sábados, ni feriados } \\
\text { No conocen las metas se establecidas en el } \\
\text { POI } 2017 \text { respecto a operaciones } \\
\text { quirúrgicas. }\end{array}$ \\
\hline
\end{tabular}

Elaboración propia

Tabla 8. Procesamiento de aspectos positivos y negativos de las entrevistas al personal Personal Administrativo

\begin{tabular}{|c|c|}
\hline ASPECTOS POSITIVOS & ASPECTOS NEGATIVOS \\
\hline \multicolumn{2}{|c|}{ Personal Administrativo } \\
\hline $\begin{array}{l}\text { Tienen conocimiento de la importancia } \\
\text { del sistema informático para el manejo de } \\
\text { la lista de espera. } \\
\text { Reconocen que los jefes de servicio no se } \\
\text { abastecen para cumplir actividades } \\
\text { asistenciales y administrativas. }\end{array}$ & $\begin{array}{l}\text { No conocen las metas y objetivos de las } \\
\text { herramientas de gestión. } \\
\text { No trabajan en función un mismo } \\
\text { objetivo. }\end{array}$ \\
\hline $\begin{array}{l}\text { Amables y sinceros al responder las } \\
\text { preguntas de las entrevistas. }\end{array}$ & \\
\hline $\begin{array}{l}\text { Mencionaban algunas situaciones } \\
\text { laborales; es decir, se quejaban por }\end{array}$ & \\
\hline
\end{tabular}


situaciones que sucedían al interior del Hospital, por ejemplo: "los médicos no marcan horario de entrada ni salida".

Señalan que las herramientas de gestión son útiles por marcan los objetivos, criterios y requisitos para la administración, no obstante, no las conocen bien.

Elaboración propia

Tabla 9. Procesamiento de aspectos positivos y negativos de las entrevistas al personal Personal Médico

\begin{tabular}{|l|l|l|}
\hline \multicolumn{1}{|c|}{ ASPECTOS POSITIVOS Personal Médico } \\
\hline \multicolumn{2}{|c|}{ ASPECTOS NEGATIVOS } \\
\hline $\begin{array}{l}\text { Tienen conocimiento de la importancia } \\
\text { del sistema informático para el manejo de }\end{array}$ & No conocen las metas y objetivos de las \\
la lista de espera. & No trabajan en función un mismo \\
Reconocen que los jefes de servicio no se & objetivo. & \\
abastecen para cumplir actividades & No conocen el POI 2017. & \\
asistenciales y administrativas. & No conocen la Norma 015. & \\
Amables y sinceros al responder las & No desean involucrarse en temas \\
preguntas de las entrevistas. & administrativos. \\
\hline
\end{tabular}

Elaboración propia 
Tabla 10. Procesamiento de aspectos positivos y negativos de las entrevistas al personal Personal Administrativo

\begin{tabular}{|c|c|}
\hline ASPECTOS POSITIVOS & ASPECTOS NEGATIVOS \\
\hline \multicolumn{2}{|c|}{ Pacientes } \\
\hline $\begin{array}{l}\text { Reconocen el nivel de importancia del } \\
\text { Hospital Almenara. }\end{array}$ & $\begin{array}{l}\text { No conocen las metas y objetivos de las } \\
\text { herramientas de gestión. }\end{array}$ \\
\hline \multirow[t]{3}{*}{ Gentiles y amables durante la entrevista. } & No conocen la gestión administrativa. \\
\hline & No conocen la Norma 015. \\
\hline & No conocen el POI 2017. \\
\hline
\end{tabular}

Elaboración propia 


\section{CAPÍTULO III}

\section{ANÁLISIS DE DATOS Y RESULTADOS}

\subsection{Análisis y resultados de las entrevistas}

El siguiente capítulo tiene como finalidad analizar e interpretar la información extraída de los segmentos seleccionados: Gerente quirúrgico, jefes de las oficinas administrativas, Jefes de departamentos, Jefes de servicios, personal administrativo, personal médico y asegurados, cuyo fin es responder a las preguntas de investigación y verificar la hipótesis de investigación planteada.

1. ¿Cuál es el proceso que sigue el Hospital Almenara para el manejo de la lista de espera en la atención del paciente quirúrgico?

Según el marco teórico existe un procedimiento establecido en la Directiva de Gerencia General $N^{\circ}$ 015-GG-ESSALUD-2015 "Normas para la gestión de la oportunidad Quirúrgica en el Seguro Social de Salud -ESSALUD”, la cual indica el procedimiento de intervenciones quirúrgicas.

- El médico cirujano especialista determina la necesidad de intervención quirúrgica, revisa la lista de espera y determina la prioridad del paciente en base a la lista de pacientes aptos y registra la información en el Sistema Informático Institucional Vigente - SIIV.

- Cada jefatura de servicio administra la lista única de oportunidad quirúrgica en el SIIV, comunica al paciente la fecha probable de su intervención quirúrgica y brinda información al mismo de los pasos a seguir.

- El Jefe de Servicio programa la disponibilidad de sala de operaciones y recursos necesarios para la intervención quirúrgica. 
- Los pacientes que no han sido programados o los que habiéndolo sido, no hubieran sido operados en su oportunidad, tienen prioridad en la programación subsiguiente.

- El cirujano especialista determina el alta definitiva del paciente luego de los controles post-quirúrgicos y de ser el caso se realiza la contrarreferencia (lo contrarrefiere para que sea atendido en su Centro de Salud origen).

- El SIIV permite la depuración en la lista única de oportunidad quirúrgica, una vez operado al paciente, que es verificado permanentemente por el Jefe de Servicio o Departamento Quirúrgico.

Ahora bien, de acuerdo a lo extraído de las entrevistas, todos los entrevistados concordaron que los jefes de cada servicio manejan y deciden sobre la lista de espera de su servicio, tomando en consideración aspectos como: la gravedad patológica del paciente, tiempo de espera, demanda de pacientes y referencias externas, así como, pacientes que ingresan por emergencia.

En las entrevistas realizadas a los diferentes segmentos, la mayoría indicó que la lista de espera comienza cuando se incorporan en ella a los pacientes que han cumplido con todos sus exámenes pre-quirúrgicos, resultando aptos para ser intervenidos quirúrgicamente.

Al respecto, el gerente quirúrgico señaló lo siguiente:

(...) La lista de espera es aquella lista en la cual oficialmente se incorporan los pacientes que han sido diagnosticados como de necesidad quirúrgica y que han cumplido con todos los requisitos previos para poder ser considerado aptos a ser incluidos en la lista de espera (...) (Segmento I: Gerente Quirúrgico del Hospital Guillermo Almenara Irigoyen).

(...) el último mes, marzo 2018, se ha sacado registro de 3200 pacientes que se encuentran en lista de espera (...) (Segmento VI: Profesional Ingeniero - encargado de controlar la lista de espera de todos los servicios). 
Por otro lado, una jefa de servicio mencionó:

La lista de espera empieza desde que el médico le dice al paciente que tiene que operarse (...) (Segmento IV: Jefe del servicio Oftalmología).

Un jefe mencionó que lo médicos tratantes eligen al paciente que será intervenido.

En nuestro caso decide el médico cirujano, cada médico dispone que paciente se opera

(...) (Segmento IV: Jefe del servicio Oftalmología).

(...) La lista se ve alterada por los referidos de los mismos trabajadores (...) (Segmento

\section{I: Gerente Quirúrgico).}

(...) La lista de pacientes se maneja de acuerdo a la patología del paciente (...) (Segmento IV: Jefe del servicio Oftalmología).

(...) Tenemos una lista de espera por tiempo, vemos cual es el paciente que tiene más tiempo de espera (...) (Segmento IV: Jefe del servicio Oftalmología).

(...) El problema del día a día es que los pacientes de lista de espera son reemplazados por los pacientes que ingresan por emergencia (...) (Segmento I: Gerente Quirúrgico). Del mismo modo, algunas jefaturas de servicio deciden la prioridad de atención mediante una junta médica, donde analizan la complejidad de la enfermedad del paciente.

Se decide que paciente entra a la lista de espera, mediante junta médica (...) (Segmento IV: Jefe de servicio de Neurocirugía).

No obstante, al realizar las entrevistas, la mayoría considera que la lista de espera no está sincerada; pues algunos jefes de servicio registran y llevan el control manualmente o mediante hoja de cálculo Excel, y otros lo realizan mediante el sistema informático, sistema de gestión hospitalaria-SGH, pese a los lineamientos y disposiciones del Gerente Quirúrgico basados en la Norma 015. 
(...) Se ha implementado de manera estricta el uso del SGH y se monitorea diariamente, ya que el día 5 de cada mes se debe elevar a la Gerencia de Operaciones de la SEDE CENTRAL (...) (Segmento I: Gerente Quirúrgico).

(...) Todos tienen habilitado el SGH (...) (Segmento III: Jefa de la Oficina de Soporte Informático).

(...) El registro y actualización de la lista de espera debe ser ingresado en el sistema de gestión hospitalaria pero aún se usa de manera manual (...) (Segmento VI: Profesional Ingeniero - encargado de controlar la lista de espera de todos los servicios)

Los diferentes segmentos entrevistados tenían conocimiento del uso estricto del SGH para registro, actualización y seguimiento de la lista de espera, pero adujeron que el mencionado sistema no está implementado de acuerdo a la necesidad de los servicios, por ello aún lo realizan de manera manual.

(...) Existe un software llamado SGH, y nos han dado charlas para poder estandarizar el proceso de la lista de espera (...) (Segmento IV: Jefe de servicio de Neurocirugía).

(...) El SGH no tiene para tal cosa (...) has visto cómo hacemos nuestras órdenes de sala, lo hacemos a mano, porque no se pone en el sistema, no hay programación para cirugía ambulatoria, no tiene esa opción; como no tiene muchas otras (...) (Segmento IV: Jefe del servicio Oftalmología).

(...) Hemos hecho saber a la jefatura de informática del hospital los problemas que presenta el SGH; sin embargo la respuesta que recibimos siempre es que el SGH no puede ser alterado; porque viene de la Sede Central (...) (Segmento IV: Jefe del servicio

\section{Oftalmología).}

Además, los entrevistados manifestaron que no se abastecen para cumplir con las actividades administrativas que conlleva manejar la lista de espera. 
(...) Tenemos un software, pero muchas especialidades no la utilizan, porque tienen mucha carga laboral (...) (Segmento III: Jefe de la Oficina de Administración).

En consecuencia, se logró identificar que cada servicio del Hospital Almenara, maneja y decide su lista de espera de diferente manera; pues en las respuestas obtenidas por lo diferentes segmentos se logró identificar que no es de total cumplimiento el procedimiento estandarizado en la herramienta de gestión Norma 015, además se reconoció que el control y supervisión que tiene la Gerencia Quirúrgica no es suficiente, ya que cada jefatura de servicio y personal administrativo opta por procedimientos distintos, en parte por la resistencia al uso del instrumento sistematizado.

\section{2. ¿Cuál es la gestión administrativa que se realiza dentro del Hospital Almenara con respecto al manejo de la lista de espera de oportunidad quirúrgica?}

Si bien la Norma 015 brinda detalladamente los lineamientos para el manejo de la lista de la oportunidad quirúrgica, respecto a le gestión administrativa detalla lo siguiente:

"El jefe de Servicio/ Departamento Quirúrgico, determina sus necesidades de personal, bienes, servicios y presupuesto y solicita oportunamente a la Unidad de Gestión de Oportunidad Quirúrgica la atención de su requerimiento".

La Gerencia Central de Logística I Central de Abastecimientos de Bienes estratégicos (según corresponda) gestiona oportunamente la atención de los requerimientos formulados por la Unidad de Gestión de Oportunidad Quirúrgica de acuerdo a la normatividad vigente que permita cumplir el logro de los objetivos institucionales.

"La Unidad Central de Gestión de Oportunidad Quirúrgica consolida, evalúa y gestiona la dotación oportuna del personal asistencial comunicando a la Gerencia Central de gestión de las personas". 
La Gerencia Central de Gestión de las Personas - GCGP evalúa y dota oportunamente del personal administrativo que solicite la GCO solicitado por la Unidad Central de Gestión de Oportunidad Quirúrgica.

Sin embargo, el 100\% de los entrevistados opinó que la gestión administrativa en general es engorrosa y lenta, porque lo trámites administrativos para todos los procedimientos dilatan el tiempo. Además, reportaron la demora en los procesos internos en el área de Adquisiciones - Logística, para las compras de los instrumentales quirúrgicos.

(...) Demora en procesos de adquisición de insumo (...) (Segmento II: Jefes de

\section{Departamento).}

(..) Si hay algo que no funciona es el sistema de compras, decir que no funciona es una exageración, (..), estamos tan mal, que el instrumental lo compran los mismos médicos.

\section{(...) (Segmento IV: Jefe del servicio Oftalmología).}

No obstante, la jefa de la Oficina de Administración, encargada del área de compras de medicamentos e insumos, señalo:

(...) Hay que cumplir muchos procesos para efectuar las compras, para cumplirlo los médicos deberían conocer la "LEY DE CONTRATACIONES DEL ESTADO” a fin que puedan hacer sus requerimientos (...) (Segmento III: Jefe de la Oficina

\section{Administración).}

Por otro lado, gran parte de los jefes de los diferentes segmentos mencionaron que muchas de las actividades administrativas son realizadas por los mismos jefes de servicio, y que estos no cuentan con apoyo administrativo para el manejo de la lista de espera.

(...) No tenemos todos los procesos claros, algunos colaboradores realizan funciones que deben cumplir otras personas. (...) (Segmento IV: Jefe de la Oficina Administración). 
(...) Sería bueno que contemos con un recurso administrativo, porque lo médicos, jefes de servicio, realizamos trabajo asistencial y también trabajo administrativo. (...) (Segmento IV: Jefe de Neurocirugía).

(...) Los jefes de servicios arman los turnos del personal médico para las operaciones quirúrgicas (...) (Segmento II: Jefe de Departamento de Anestesiología).

Ahora bien, pese a que refirieron los argumentos antes señalados; también la gran parte de los entrevistados advirtieron que es necesario lo siguiente:

(...) Mayor compromiso de los jefes de servicio en el cumplimiento del manejo de la lista de espera. (Segmento III: Jefe de Oficina de Gestión y Desarrollo).

Sin embargo, los mismos entrevistados reconocieron, en base a su experiencia adquirida por las funciones desarrolladas durante muchos años dentro del Hospital Almenara, así como el alto nivel profesional de cada uno de ellos, que si bien los problemas administrativos son barreras para desempeñar eficientemente su trabajo, existen oportunidades de mejora que ellos mismos deben desarrollar para un óptimo manejo de la lista de espera.

(...) Es importante que cada servicio use el Sistema de Gestión Hospitalaria para tener un proceso estandarizado de manejo de lista de espera y que refleje la realidad del hospital (...) (Segmento VI: Profesional Ingeniero - encargado de controlar la lista de espera de todos los servicios).

(...) Que cada servicio médico cuente con personal que se encargue de manejar completamente la lista de espera desde el ingreso hasta el retiro del paciente (...) (Segmento VI: Profesional Ingeniero - encargado de controlar la lista de espera de todos los servicios).

(...) Control y monitoreo del registro de los pacientes en la lista de espera (...) (Segmento I: Gerente Quirúrgico). 
(...) Abastecimiento de materiales, insumos en el oportuno de la intervención quirúrgica

\section{(...) (Segmento I: Gerente Quirúrgico).}

(...) Optimizar los turnos operatorios de personal médico (..) (Segmento I: Gerente Quirúrgico).

Respecto a lo último, el servicio de anestesiología programa los turnos operatorios, en base al número de médicos anestesiólogos del servicio, los cuales son ofertados a los distintos servicios médicos, pero hay una brecha de profesionales en medicina con la especialidad en anestesiología.

(...) Actualmente, tenemos una brecha de 30 médicos anestesiólogos, por lo que no podemos cubrir la demanda de todos los servicios de forma oportuna, aunque tratamos (...) (Segmento II: Jefe de Departamento de Anestesiología).

(...) Utilizar las 14 salas de operaciones que tiene el hospital, pues solo funcionan 13 (...) (Segmento II: Jefe de Departamento de Anestesiología).

Por consiguiente, se deduce que existen problemas administrativos internos latentes y permanentes, debido a que los procesos para realizar acciones operativas $y$ administrativas son largas, lo cual impacta negativamente en la gestión interna del hospital, cuyo efecto está ligado al manejo deficiente de la lista de espera de oportunidad quirúrgica; no obstante, también se percibió una fuerte resistencia a los cambios y al compromiso para llegar a los objetivos planteados en la Norma 015.

Asimismo, se determina que el manejo administrativo dentro del hospital difiere a lo estipulado; es decir, el procedimiento que realizan los funcionarios y trabajadores dentro Hospital para canalizar los requerimientos de sus necesidades es diferente a lo que indica la Norma 015.

3. ¿Qué acciones realizan los colaboradores del Hospital Almenara para lograr el cumplimiento de las metas estipuladas en las herramientas de gestión 
administrativas: ¿Plan Operativo Institucional 2017 y Normas para la

\section{Gestión de la Oportunidad Quirúrgica?}

El gerente quirúrgico y la jefa de la oficina de atención al asegurado mencionaron conocer el Plan Operativo Institucional 2017 e indicaron que su gestión la realizan en función a las metas establecidas en el mismo.

Asimismo, la secretaria del servicio anestesiología comentó que su servicio remite estadísticas de productividad asistencial.

(...) el servicio de anestesióloga informa mensualmente a la Gerencia Quirúrgica la producción de operaciones realizadas, operaciones suspendidas, emergencias y mortalidad.

Sin embargo, el resto de los entrevistados mencionaron que el Plan Operativo Institucional es una herramienta de gestión, pero indicaron que no conocían las metas estipuladas en ella; contradictoriamente dijeron que realizaban reuniones periódicas con los trabajadores de sus áreas respectivas, para coordinar el seguimiento de las metas.

(...) Se debería socializar las metas del Plan Operativo Institucional (...), tenemos que empujar el carro para llegar todos a la meta (...) (Segmento IV: Jefe de la Oficina Administración).

(...) No se puede llegar a la meta establecida en el POI, porque no hay presupuesto, todo ello está ligado (...) (Segmento IV: Jefe de la Oficina Administración).

Respecto a las Normas para la Oportunidad Quirúrgica, el Gerente Quirúrgico y el Jefe del Departamento de Anestesiología relataron y explicaron los criterios e indicadores plasmados en la Norma para la Gestión de la Oportunidad Quirúrgica, mencionando que realizan su gestión basándose en dichos documento normativos, de los cuales dieron a conocer que el tiempo de espera normado para que un paciente sea intervenido quirúrgicamente es que no sea mayor a 45 días. 
También, un profesional de la Gerencia Quirúrgico, encargado la lista de espera, demostró conocer las Normas para la gestión de la oportunidad:

(...) Hay una normativa, la 015, esa normativa viene desde la Sede Central y tiene todos los lineamientos sobre el manejo, control de la lista de espera y rangos de responsabilidad de las áreas involucradas (...) (Segmento VI: Profesional Ingeniero encargado de controlar la lista de espera de todos los servicios).

(...) lo ideal sería 45 días pero lamentablemente por el proceso de sinceramiento de la lista de espera que se tiene (...), y hay servicios que no se adecuan tenemos un tiempo de espera aproximado de 250 días en forma general (...) (Segmento VI: Profesional Ingeniero - encargado de controlar la lista de espera de todos los servicios).

Otros entrevistados de las jefaturas administrativas indicaron no conocer el tiempo de espera determinado para un paciente de la lista de espera sea atendido quirúrgicamente.

Se considera que lo establecido en el Plan Operativo Institucional 2017 de ESSALUD no es de conocimiento de todos los colaboradores, pues la gran mayoría no conocía las metas y actividades programadas en ella, así como las metas relacionadas a la lista de espera de oportunidad quirúrgica.

El Plan Operativo Institucional 2017 del Hospital Almenara, tenía como meta realizar 6067 intervenciones quirúrgicas de manera trimestral en el hospital.

Sin embargo, a raíz del análisis de las entrevistas realizadas, apreciamos que el 100\% de los entrevistados no conocía el número de operaciones quirúrgicas que se debió realizar en el hospital en el citado año, por lo que se considera que lo plasmado en esta herramienta de gestión no es de conocimiento de los colaboradores.

Por ello, se determina que no se imparten, ni se dan a conocer las metas relacionadas al manejo de la lista de espera, lo cual impacta en la gestión, ya que no trabajan en función a un objetivo común. 
4. ¿Cuál es la importancia del uso de las herramientas de gestión administrativa normadas por la entidad EsSalud tales como: Norma 015 y Plan Operativo Institucional (POI), vinculadas a la lista de espera de la atención en pacientes quirúrgicos?

De las entrevistas realizadas mencionaron la importancia de las herramientas de gestión, indicando que todo el personal debería conocer y alinearse a las metas establecidas, siendo útiles porque marcan los objetivos, criterios y requisitos, así como el resultado que se desea lograr en tiempos determinados en cuánto a la productividad de atención de los pacientes dentro del hospital.

Si bien, algunos nombraron las herramientas de gestión e indicaron que las aplican como guía para desarrollar sus funciones, se observó que no conocían detalladamente los parámetros necesarios relacionados a los fines que se desea alcanzar.

(...) Todas las herramientas de gestión son importantes, sino no se crearían (...) (Segmento III: Jefe de la oficina de Soporte Informático).

(...) Las herramientas de gestión administrativa son muy generales, no se adecuan a la realidad de cada servicio (...) No se puede comparar una especialidad, con otras que son más compleja (..) (Segmento IV: Jefe de la Neurocirugía).

Además, los jefes de servicio mencionaron que son importantes las herramientas, pero que no se alinean a la realidad del hospital ni de los servicios, pues existen factores internos y externos, ineludibles por los mismos, los cuales han sido explicados en la pregunta 1 y 2 .

(...) Yo creo que algunas normativas pueden ser modificadas, ya que podrían reformularse para hacer más ágil nuestros procesos (...) (Segmento IV: Jefe de la Oficina Administración). 
Por último, se conoció que las metas no son difundidas ni impartidas entre el personal, tanto jefes y subordinados, así como no se promueven el beneficios en el cual incurrirían al involucrarse proactivamente para alcanzar las metas programadas. 


\section{CAPÍTULO IV}

\section{DISCUSIÓN DE RESULTADOS}

\subsection{Hallazgos}

- El tiempo de espera que tiene el hospital actualmente para que un paciente sea atendido quirúrgicamente es de 250 días, pese a que la Norma para la Gestión de la Oportunidad Quirúrgica establece que no debe exceder a 45 días de espera.

- La jefatura del Departamento de Trasplante no aplican las herramientas de gestión administrativa que maneja ESSALUD, puesto que se rigen a normativas estándar reguladas a niveles internacionales. Además, el jefe de departamento de trasplante dio a conocer que actualmente no existe la preocupación por investigar académicamente desde el aspecto administrativo el tema la donación de órganos, por lo que se sugiere la posibilidad de investigar a profundidad sobre este tema, desde el punto de vista administrativo.

- El departamento de trasplante también maneja lista de espera e informa a la Gerencia Quirúrgica, pero tiene una gestión distinta a la lista de espera de operaciones quirúrgicas.

- La carencia más importante de profesionales es de médicos con especialidad en anestesiología.

- Las estadísticas que aparecen en los documentos oficiales de ESSALUD respecto a la lista de espera de oportunidad quirúrgica contienen información no alineada a la realidad del Hospital Almenara, pues según la investigación la lista actualmente no está sincerada.

- El servicio que tiene mayor lista de espera es el servicio de Traumatología 


\subsection{Barreras}

- La dificultad para concretar las citas con los jefes administrativos y de servicios, pues no disponían de tiempo.

- La preocupación que demostraban los entrevistas por brindar mucha información, pues pensaban que los podían perjudicar.

- No se logró entrevistar al jefe de servicio de traumatología, pese a las reiteradas visitas a su oficina, hasta en 10 oportunidades, ya que se conocía que este servicio era el que tenía la mayor lista de espera de todo el hospital.

\subsection{Brechas}

No hemos tenidos brechas en este trabajo de investigación. 


\section{CAPÍTULO V}

\section{CONCLUSIONES}

1. Las herramientas de gestión analizadas marcan los principios, técnicas, prácticas y metas para alcanzar los objetivos respecto a la lista de espera de oportunidad quirúrgica en el Hospital Almenara; sin embargo, la mayoría de los trabajadores no aplican estrictamente los lineamientos estipulados. Por consiguiente, concluimos que actualmente las herramientas de gestión administrativa no aportan para una mejor gestión de la lista única de oportunidad quirúrgica, por lo no se valida la hipótesis planteada.

Es necesario mencionar que la realidad que afronta los servicios médicos del hospital hace que los colaboradores realicen actividades diferentes a las normadas para tratar de atender a pacientes con necesidad quirúrgica.

2. El cumplimiento de la programación de la lista de espera se ve alterada por la preferencia que se brinda a los referidos (pacientes) de los mismos colaboradores; así como por los pacientes que ingresan por Emergencia.

3. Hay un proceso establecido para el manejo de lista de espera estipulado por la Norma 015; sin embargo, dichos procesos no se cumplen en el Hospital Almenara, pues cada jefatura de servicio maneja y decide sobre la lista de su servicio, según su necesidad, por ejemplo: la Jefatura de Neurocirugía, debido a la complejidad de su naturaleza, opta por decidir la prioridad de intervención quirúrgica de un paciente mediante una junta médica. 
4. Pese a los lineamientos establecidos en la Norma 015 y las disposiciones del Gerente Quirúrgico respecto al uso obligatorio del sistema informático vigenteSIIV para el registro y control de la lista de espera, algunos jefes de servicio siguen usando Excel (Office) y otros lo hacen de forma manual (papel), porque adujeron que el sistema informático vigente no se encuentra implementado de acuerdo con la necesidad de cada servicio.

5. El 100\% de los entrevistados opinó que la administración del Hospital Almenara en general es engorrosa y lenta, porque los procedimientos a seguir internamente, dilatan el tiempo de solución a los problemas, como sucede con el proceso de compra para materiales médicos, los cuales se enmarcan en normativas legales, y estos no son del todo conocidos por el personal médico, dificultándose el tramite entre el área médica y el área administrativa para la realización de las compras de los materiales e insumos médicos.

6. Muchos de los jefes de servicio no se abastecen para realizar actividades administrativas que implica el manejo de la lista de espera, excusándose en que no cuentan con apoyo administrativo para el manejo de esta.

7. La necesidad más importante que tiene el hospital en cuanto a profesionales en medicina, son los médicos con especialidad en anestesiología, pues existe una brecha de 30 anestesiólogos para cubrir los turnos quirúrgicos demandados por los diferentes servicios.

8. Las herramientas de gestión administrativa no se difunden para conocimiento de todo el personal involucrado; es decir, el personal no conocía las metas establecidas para las operaciones quirúrgicas en el POI 2017, así como, no conocen los lineamientos de la Norma 015. 
9. Las metas y objetivos planteadas en las herramientas de gestión no son difundidas al personal y éste no lo conoce.

10. No se utiliza en su máxima capacidad las 13 salas de operaciones disponibles, porque no se puede programar más turnos quirúrgicos, debido a los escases de médicos anestesiólogos en el hospital y a la disponibilidad de tiempo de los médicos cirujanos.

11. El número de pacientes de la lista única de oportunidad quirúrgica asciende a tres mil doscientos (3200) pacientes y el tiempo de espera aproximado es de 250 días, al mes de abril 2018, dicha información no se puede confirmar debido a que los jefes de cada de servicio no estandarizan el manejo de su lista de espera en el sistema informático, esto afecta en los resultados cuantitativos del número de pacientes de la lista de espera y en los indicadores que presenta el Hospital Almenara.

12. Los profesionales médicos no tienen un control de entrada y salida de la jornada laboral; se notó ausentismo de jefes de servicio en el horario de la tarde y fines de semana.

13. Todas las personas entrevistadas de los distintos segmentos son profesionales con mucha experiencia dentro del Hospital Almenara, la mayoría refirió tener más de 20 años laborando en el mismo hospital, por lo que los consideramos expertos en el fenómeno estudiado.

14. En cuanto a acciones de mejora para la lista de espera, la Gerencia Quirúrgica designó un profesional informático como encargado de todo lo que involucra al seguimiento y control de la lista de espera de todos los servicios, acorde a la Norma 015; además, ha dispuesto que el médico cirujano coordine y se asegure de tener 
todo el material e insumos quirúrgicos, así como la disponibilidad de sala antes de programar la fecha de la intervención quirúrgica.

15. Se identificó que los pacientes no tienen conocimiento de la gestión administrativa que existe detrás de la lista de espera que maneja el Hospital Almenara, estimamos que la información extraída del segmento no era potencial para alcanzar nuestros objetivos de investigación. 


\section{RECOMENDACIONES}

1. Se recomienda a las jefaturas de todos los niveles difundir a todo el personal los objetivos y lineamientos enmarcados en las herramientas de gestión POI 2017 y Norma 015, a su vez se realice seguimiento y control de los avances antes del cierre en cada trimestre, de esta manera los colaboradores trabajarían en equipo orientados a cumplir un objetivo en común. Además, se simplificarían las actividades internas rigiéndose a lo señalado en las herramientas de gestión.

2. Se sugiere organizar, programar y supervisar un cronograma de actividades donde se establezcan fechas límites para que cada jefatura de servicio presente el estado situacional de su lista de espera, con ello programar reuniones con el personal involucrado para establecer las metas a corto plazo con el fin de aplicar los lineamientos de la Norma 015 que ayude a mejorar la administración de la lista única de oportunidad quirúrgica.

3. Se aconseja renovar el aplicativo sistema informático vigente, implementándolo con más opciones según necesidades de cada servicio mejorando su contenido, de esta manera los colaboradores podrán tener un mejor registro, control y depuración de la información que se ingresa en la lista única de oportunidad quirúrgica.

4. Se recomienda a la Dirección del Hospital destacar un profesional con perfil administrativo, para que coordine, controle y reporte la lista única de oportunidad quirúrgica de todos los servicios.

5. Se recomienda a los gerentes y jefes aplicar las técnicas de la administración, basadas en planear, dirigir, integrar personal, controlar y coordinar, detalladas en el marco teórico de la presente investigación. 
6. Se recomienda profundizar mediante investigaciones académicas en temas de gestión en los campos de atención al paciente en el Hospital Almenara, aplicando métodos que puedan resolver problemas administrativos. 


\section{BIBLIOGRAFÍA}

Centrángolo, O., Bertranou, F., Casanova, L. \& Casalí, P. (2013). El sistema de salud del Perú: situación actual y estrategias para orientar la extensión de la cobertura contributiva. LIMA: OIT/Oficina de la OIT para los Países Andinos, 2013.

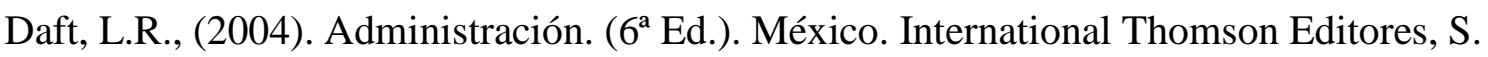
A.

Gutiérrez, Walter (Dir.).(2005). La Constitución Comentada. Análisis artículo por artículo. Obra colectiva por 117 juristas del país (p. 432). Recuperado de https://andrescusi.files.wordpress.com/2014/03/constittucion-politica-comentadagaceta-juridica-tomo-i.pdf

Seguro Social de Salud (ESSALUD). (2015). Directiva "Normas para la Gestión de la Oportunidad Quirúrgica en el Seguro Social de Salud- ESSALUD”. Lima: ESSALUD Recuperado de http://www.essalud.gob.pe/downloads/normat_super_plan_conf/RES_1518_GG_ESSA LUD_2015_Super_Plan_Confianza.pdf

Seguro Social de Salud (ESSALUD). (2017). Plan Estratégico Institucional 2017 - 2021. Lima: ESSALUD Recuperado de http://www.essalud.gob.pe/transparencia/pdf/planes/plan_estrategico_institucional_201 7_2021.pdf 
Koontz H., -Weihrich H., \& Cannice M. (2012). Administración: Una Perspectiva Global y Empresarial. México. McGRAW-HILL/INTERAMERICANA EDITORES S.A. DE C.V

Lazo, O., Alcalde, J. \& Espinoza, O. (2016). El sistema de salud en Perú. Situación y desafíos. LIMA. REP S.A.C.

MINSA (2011). Portal de MINSA. Perú. Recuperado de http://www.digemid.minsa.gob.pe/UpLoad/UpLoaded/PDF/AtencionFarmaceutica/Cate gorizacion-UPSS_Farmacia.pdf

Seguro Social de Salud (ESSALUD). (2017). Plan Operativo Institucional 2017 Desagregado por dependencias. Lima: ESSALUD. Recuperado de http://www.essalud.gob.pe/transparencia/poi/POIDESAGREGADO2017.pdf

Seguro Social de Salud (ESSALUD). (2017). Reglamento de Organización y Funciones. Recuperado de http://www.essalud.gob.pe/reglamento_de_organizacion_y_funciones/ [Consulta: 10 de diciembre 2017]

Seguro Social de Salud (ESSALUD).(2012). Plan Estratégico Institucional 2012-2016. Lima: $\quad$ ESSALUD. $\quad$ Recuperado de http://www.essalud.gob.pe/transparencia/pdf/planes/plan_2012_2016.pdf

Seguro Social de Salud (ESSALUD). (2014). Essalud atenderá embalse de cirugías atrasadas por huelgas a través del Plan Confianza. Recuperado de 
http://www.essalud.gob.pe/essalud-atendera-embalse-de-cirugias-atrasadas-por-huelgasa-traves-de-plan-confianza/ [Consulta: 10 de Noviembre de 2017].

Seguro Social de Salud (ESSALUD, 2017), Información Gerencial de principales prestaciones de salud setiembre 2017, Lima: ESSALUD.

Super Intendencia Nacional de Administración Tributaria (SUNAT). (s.f). Essalud$\begin{array}{llll}\text { Contribuciones } & y & \text { Aportaciones-Personas. Recuperado de }\end{array}$ http://orientacion.sunat.gob.pe/index.php/personas-menu/contribuciones-yaportaciones-personas/essalud-contribuciones-y-aportaciones-personas/3082-tasa-ycalculo-del-aporte-al-essalud-personas [Consulta: 15 de Enero de 2017]. 


\section{ANEXOS}

\section{ANEXO 01}

\section{Guía de preguntas}

Preguntas por categorías.

Categoría 1- Gestión administrativa para atención del paciente quirúrgico Hospital Guillermo Almenara I

1. ¿Cuál es el proceso administrativo que sigue el hospital para que un paciente sea atendido quirúrgicamente?

2. ¿Cómo considera la gestión administrativa que se realiza en el hospital para la atención del paciente quirúrgico? ¿Por qué?

3. ¿Qué acciones realizan para evaluar el proceso administrativo de la oportunidad quirúrgica?

4. ¿Qué oportunidades de mejora en los procesos internos impulsarían una mejor gestión con calidad?

5. ¿Existe algún tipo de factores internos o externes que intervienen en los procesos administrativos del hospital?

6. ¿Cuál es el apoyo administrativo que reciben para ejecutar su trabajo?

7. ¿Cuáles son los requerimientos administrativos más frecuentes que reciben?

8. ¿Cuáles son los requerimientos administrativos más frecuentes que realizan?

Categoría 2- Lista de espera Hospital Almenara.

1. ¿Qué es la lista de espera?

2. ¿Cómo funciona el manejo de la lista de espera en el hospital? y ¿Cuál es su percepción? 
3. ¿Qué factores relevantes considera usted que intervienen en el manejo de la lista de espera?

4. ¿Cómo es el soporte técnico de la lista de espera?

5. ¿Cuáles son sus tiempos de respuesta?

6. ¿Qué formatos o procesos se debe seguir ante un requerimiento de la lista de espera?

7. ¿Cómo es la comunicación al paciente sobre la lista de espera?

8. ¿Qué sistema de evaluación maneja actualmente el hospital para llevar la lista de espera?

9. ¿Qué debilidades o deficiencias encuentra en la gestión de la lista de espera que maneja el hospital?

10. ¿Desde cuándo existe la lista de espera? y cuando fue su último cambio?

Categoría 3- Objetivos y metas.

1. ¿Qué es para usted objetivos y metas?

2. ¿Cuáles son los objetivos más importantes en su área?

3. ¿Qué acciones realizan para llegar a dichos objetivos?

4. ¿Considera Usted que los objetivos Institucionales se encuentran alineados a la realidad de la Institución?

5. ¿Que dificulta o impide cumplir los objetivos de su área?

6. ¿Cómo se comunican los objetivos y metas en las diferentes gerencias o jefaturas?

7. ¿Realiza Usted un feed back o retroalimentación de sus objetivos Institucionales?

8. ¿Recibe Usted un feed back o retroalimentación de sus objetivos Institucionales?

Categoría 4 - Herramientas de gestión administrativa.

1. ¿Sabe usted cuales con las herramientas de gestión administrativa que tiene EsSalud?

2. ¿Cómo se enteró que existen estas herramientas de gestión? 
3. ¿De todas las herramientas de gestión cual es para usted la más importante o relevante?

4. ¿Conoce Usted el Plan Operativo Institucional 2017, las normas para la gestión de la oportunidad quirúrgica y las normas de referencias y contrarreferencias?

5. ¿Considera Usted importante las herramientas de gestión administrativa para el manejo de la lista de espera de oportunidad quirúrgica? ¿Por qué?

6. ¿Cómo se comunica al personal los cambios de dichas herramientas?

7. ¿Desde su punto de vista son útiles para usted las herramientas de gestión?

8. ¿Para usted cual es la finalidad del Plan Operativo Institucional?

9. ¿Considera usted que las normas para la gestión de la oportunidad quirúrgica de la Institución se alinean a la realidad que afronta el hospital?

10. ¿Existe alguna evaluación de las herramientas de gestión administrativas? ¿Cómo es?

11. ¿Qué beneficios considera que tienen las herramientas de gestión administrativa?

12. ¿Qué otra herramienta de gestión administrativa le gustaría que se implemente?

Categoría 5 -Tiempo de espera para la atención del paciente quirúrgico.

1. ¿Cuál es el tiempo de espera aproximado para la atención de un paciente quirúrgico en el hospital?

2. ¿Cuál es el proceso para determinar el tiempo de espera para un paciente que necesita ser intervenido quirúrgicamente?

3. ¿Cuál cree usted que es el factor más relevante que impacta en el tiempo de espera para que un paciente sea atendido quirúrgicamente?

4. A su criterio ¿Cómo ve los tiempos de espera para la oportunidad quirúrgica que tiene el hospital? 
5. ¿Qué factor o factores podrían mejorar los tiempos de espera para la atención de pacientes quirúrgicos?

6. ¿Ha encontrado usted alguna oportunidad de mejora para contrarrestar el tiempo de espera que tiene el hospital?

7. ¿Cree usted que un mejor apoyo administrativo mejoraría los tiempos de espera? y? ¿Cuál sería?

8. Para la programación quirúrgica ¿el tiempo de espera que tiene un paciente es el elemento más importante?

9. ¿Quién es el personal a cargo de llevar el control de los tiempos de espera en el área?

10. ¿Cómo y qué persona comunica al paciente el tiempo de espera?

Preguntas por segmentos

Categoría 1- Gestión administrativa para atención del paciente quirúrgico Hospital Guillermo Almenara

Segmento Gerente Quirúrgico

1. ¿Cuál es el proceso administrativo que sigue el hospital para que un paciente sea atendido quirúrgicamente?

2. ¿Cómo considera la gestión administrativa que se realiza en el hospital para la atención del paciente quirúrgico? ¿Por qué?

3. ¿Qué acciones realizan para evaluar el proceso administrativo de la oportunidad quirúrgica?

4. ¿Qué oportunidades de mejora en los procesos internos impulsarían una mejor gestión con calidad?

5. ¿Existe algún tipo de barrera en los procesos administrativos del hospital?

6. ¿Cuál es el apoyo administrativo que reciben para ejecutar su trabajo? 
7. ¿Cuáles son los requerimientos administrativos más frecuentes que reciben?

Segmento jefes Administrativos

1. ¿Cuál es el proceso administrativo que sigue el hospital para que un paciente sea atendido quirúrgicamente?

2. ¿Cómo considera la gestión administrativa que se realiza en el hospital para la atención del paciente quirúrgico? ¿Por qué?

3. ¿Qué acciones realizan para evaluar el proceso administrativo de la oportunidad quirúrgica?

4. ¿Qué oportunidades de mejora en los procesos internos impulsarían una mejor gestión con calidad?

5. ¿Existe algún tipo de barrera en los procesos administrativos del hospital?

6. ¿Cuál es el apoyo administrativo que reciben para ejecutar su trabajo?

7. ¿Cuáles son los requerimientos administrativos más frecuentes que reciben?

Segmentos jefes de departamentos.

1. ¿Cuál es el proceso administrativo que sigue el hospital para que un paciente sea atendido quirúrgicamente?

2. ¿Cómo considera la gestión administrativa que se realiza en el hospital para la atención del paciente quirúrgico? ¿Por qué?

3. ¿Qué acciones realizan para evaluar el proceso administrativo de la oportunidad quirúrgica?

4. ¿Qué oportunidades de mejora en los procesos internos impulsarían una mejor gestión con calidad?

5. ¿Existe algún tipo de barrera en los procesos administrativos del hospital?

6. ¿Cuál es el apoyo administrativo que reciben para ejecutar su trabajo?

7. ¿Cuáles son los requerimientos administrativos más frecuentes que reciben? 
Segmento personal medico

1. ¿Cuál es el proceso administrativo que sigue el hospital para que un paciente sea atendido quirúrgicamente?

2. ¿Cómo considera la gestión administrativa que se realiza en el hospital para la atención del paciente quirúrgico? ¿Por qué?

3. ¿Qué acciones realizan para evaluar el proceso administrativo de la oportunidad quirúrgica?

4. ¿Qué oportunidades de mejora en los procesos internos impulsarían una mejor gestión con calidad?

5. ¿Existe algún tipo de barrera en los procesos administrativos del hospital?

6. ¿Cuál es el apoyo administrativo que reciben para ejecutar su trabajo?

7. ¿Cuáles son los requerimientos administrativos más frecuentes que reciben?

8. ¿Cuáles son los requerimientos administrativos más frecuentes que realizan?

Segmento personal administrativo

1. ¿Cuál es el proceso administrativo que sigue el hospital para que un paciente sea atendido quirúrgicamente?

2. ¿Cómo considera la gestión administrativa que se realiza en el hospital para la atención del paciente quirúrgico? ¿Por qué?

3. ¿Qué acciones realizan para evaluar el proceso administrativo de la oportunidad quirúrgica?

4. ¿Qué oportunidades de mejora en los procesos internos impulsarían una mejor gestión con calidad?

5. ¿Existe algún tipo de barrera en los procesos administrativos del hospital?

6. ¿Cuál es el apoyo administrativo que reciben para ejecutar su trabajo?

7. ¿Cuáles son los requerimientos administrativos más frecuentes que realizan? 
Segmento personal asegurado

1. ¿Cuál es el proceso administrativo que sigue el hospital para que un paciente sea atendido quirúrgicamente?

2. ¿Cómo considera la gestión administrativa que se realiza en el hospital para la atención del paciente quirúrgico? ¿Por qué?

3. Categoría 2- Lista de espera Hospital Guillermo Almenara Irigoyen

Segmento Gerente Quirúrgico.

1. ¿Qué es la lista de espera?

2. ¿Cómo funciona el manejo de la lista de espera en el Hospital? y ¿Cuál es su percepción?

3. ¿Qué factores relevantes considera usted que intervienen en el manejo de la lista de espera?

4. ¿Cómo es el soporte técnico de la lista de espera?

5. ¿Cuáles son sus tiempos de respuesta?

6. ¿Qué formatos o procesos se debe seguir ante un requerimiento de la lista de espera?

7. ¿Cómo es la comunicación al paciente sobre la lista de espera?

8. ¿Qué sistema de evaluación maneja actualmente el hospital para llevar la lista de espera?

9. ¿Desde cuándo existe la lista de espera? y cuando fue su último cambio?

10. ¿Qué debilidades o deficiencias encuentra en la gestión de la lista de espera que maneja el hospital?

Segmento Jefes Administrativos

1. ¿Qué es la lista de espera?

2. ¿Cómo funciona el manejo de la lista de espera en el hospital? y ¿Cuál es su percepción? 
3. ¿Qué factores relevantes considera usted que intervienen en el manejo de la lista de espera?

4. ¿Cómo es el soporte técnico de la lista de espera?

5. ¿Cuáles son sus tiempos de respuesta?

6. ¿Qué formatos o procesos se debe seguir ante un requerimiento de la lista de espera?

7. ¿Cómo es la comunicación al paciente sobre la lista de espera?

8. ¿Qué sistema de evaluación maneja actualmente el hospital para llevar la lista de espera?

9. ¿Desde cuándo existe la lista de espera? y cuando fue su último cambio?

Segmento Personal Médico.

1. ¿Qué es la lista de espera?

2. ¿Cómo funciona el manejo de la lista de espera en el hospital? y ¿Cuál es su percepción?

3. ¿Qué factores relevantes considera usted que intervienen en el manejo de la lista de espera?

4. ¿Cómo es el soporte técnico de la lista de espera?

5. ¿Cuáles son sus tiempos de respuesta?

6. ¿Qué formatos o procesos se debe seguir ante un requerimiento de la lista de espera?

7. ¿Cómo es la comunicación al paciente sobre la lista de espera?

8. ¿Qué sistema de evaluación maneja actualmente el hospital para llevar la lista de espera?

9. ¿Qué debilidades o deficiencias encuentra en la gestión de la lista de espera que maneja el hospital?

10. ¿Desde cuándo existe la lista de espera? y cuando fue su último cambio?

Segmento Personal Administrativo 
1. ¿Qué es la lista de espera?

2. ¿Cómo funciona el manejo de la lista de espera en el hospital? y ¿Cuál es su percepción?

3. ¿Qué factores relevantes considera usted que intervienen en el manejo de la lista de espera?

4. ¿Cómo es el soporte técnico de la lista de espera?

5. ¿Cuáles son sus tiempos de respuesta?

6. ¿Qué formatos o procesos se debe seguir ante un requerimiento de la lista de espera?

7. ¿Cómo es la comunicación al paciente sobre la lista de espera?

8. ¿Qué sistema de evaluación maneja actualmente el hospital para llevar la lista de espera?

9. ¿Qué debilidades o deficiencias encuentra en la gestión de la lista de espera que maneja el hospital?

10. ¿Desde cuándo existe la lista de espera? y cuando fue su último cambio?

Segmento Asegurado

1. ¿Cuál fue el proceso que Usted siguió para que sea atendido quirúrgicamente en el Hospital?

2. ¿Cómo funciona el manejo de la lista de espera en el hospital? y ¿Cuál es su percepción?

3. ¿Qué factores relevantes considera usted que intervienen en el manejo de la lista de espera?

4. ¿Qué formatos o procesos se debe seguir ante un requerimiento de la lista de espera?

5. ¿Cómo es la comunicación al paciente sobre la lista de espera?

6. ¿Qué debilidades o deficiencias encuentra en la gestión de la lista de espera que maneja el hospital? 
7. ¿Qué tan conforme se siente Usted con el tiempo de espera para la atención quirúrgica que tiene el hospital?

Categoría 3- Objetivos y metas.

Segmento Gerente Quirúrgico

1. ¿Cuáles son los objetivos más importantes en su área?

2. ¿Qué acciones realizan para llegar a dichos objetivos?

3. ¿Considera Usted que los objetivos Institucionales se encuentran alineados a la realidad de la Institución?

4. ¿Que dificulta o impide realizar los objetivos de su área?

5. ¿Cómo se comunican los objetivos y metas en las diferentes gerencias o jefaturas?

6. ¿Realiza Usted un feed back o retroalimentación de sus objetivos Institucionales?

7. ¿Recibe Usted un feed back o retroalimentación de sus objetivos Institucionales?

Segmento Jefes Administrativos.

1. ¿Qué es para usted objetivos y metas?

2. ¿Cuáles son los objetivos más importantes en su área?

3. ¿Qué acciones realizan para llegar a dichos objetivos?

4. ¿Considera Usted que los objetivos Institucionales se encuentran alineados a la realidad de la Institución?

5. ¿Que dificulta o impide realizar los objetivos de su área?

6. ¿Cómo se comunican los objetivos y metas en las diferentes gerencias o jefaturas?

7. ¿Realiza Usted un feed back o retroalimentación de sus objetivos Institucionales?

8. ¿Recibe Usted un feed back o retroalimentación de sus objetivos Institucionales?

Segmento Personal medico

1. ¿Qué es para usted objetivos y metas?

2. ¿Cuáles son los objetivos más importantes en su área? 
3. ¿Qué acciones realizan para llegar a dichos objetivos?

4. ¿Considera Usted que los objetivos Institucionales se encuentran alineados a la realidad de la Institución?

5. ¿Que dificulta o impide realizar los objetivos de su área?

6. ¿Cómo se comunican los objetivos y metas en las diferentes gerencias o jefaturas?

7. ¿Recibe Usted un feed back o retroalimentación de sus objetivos Institucionales?

Segmento Personal administrativo

1. ¿Qué es para usted objetivos y metas?

2. ¿Cuáles son los objetivos más importantes en su área?

3. ¿Qué acciones realizan para llegar a dichos objetivos?

4. ¿Considera Usted que los objetivos Institucionales se encuentran alineados a la realidad de la Institución?

5. ¿Que dificulta o impide realizar los objetivos de su área?

6. ¿Cómo se comunican los objetivos y metas en las diferentes gerencias o jefaturas?

7. ¿Recibe Usted un feed back o retroalimentación de sus objetivos Institucionales?

Segmento Asegurado

No aplica

Categoría 4 - Herramientas de gestión administrativa.

Segmento Gerente Quirúrgico

1. ¿De todas las herramientas de gestión cual es para usted la más importante o relevante?

2. ¿Conoce Usted el Plan Operativo Institucional 2017, las normas para la gestión de la oportunidad quirúrgica y las normas de referencias y contrarreferencias?

3. ¿Considera Usted importante las herramientas de gestión administrativa para el manejo de la lista de espera de oportunidad quirúrgica? ¿Por qué? 
4. ¿Cómo se comunica al personal los cambios de dichas herramientas?

5. ¿Desde su punto de vista son útiles para usted las herramientas de gestión?

6. ¿Para usted cual es la finalidad del Plan Operativo Institucional?

7. ¿Considera usted que las normas para la gestión de la oportunidad quirúrgica de la Institución se alinean a la realidad que afronta el Hospital?

8. ¿Existe alguna evaluación de las herramientas de gestión administrativas? ¿Cómo es?

9. ¿Qué beneficios considera que tienen las herramientas de gestión administrativa?

10. ¿Qué otra herramienta de gestión administrativa le gustaría que se implemente?

Segmento Jefes Administrativos.

1. ¿Sabe usted cuales con las herramientas de gestión administrativa que tiene EsSalud?

2. ¿Cómo se enteró que existen estas herramientas de gestión?

3. ¿De todas las herramientas de gestión cual es para usted la más importante o relevante?

4. ¿Conoce Usted el Plan Operativo Institucional 2017, las normas para la gestión de la oportunidad quirúrgica y las normas de referencias y contrarreferencias?

5. ¿Considera Usted importante las herramientas de gestión administrativa para el manejo de la lista de espera de oportunidad quirúrgica? ¿Por qué?

6. ¿Cómo se comunica al personal los cambios de dichas herramientas?

7. ¿Desde su punto de vista son útiles para usted las herramientas de gestión?

8. ¿Para usted cual es la finalidad del Plan Operativo Institucional?

9. ¿Considera usted que las normas para la gestión de la oportunidad quirúrgica de la Institución se alinean a la realidad que afronta el hospital? 
10. ¿Existe alguna evaluación de las herramientas de gestión administrativas? ¿Cómo es?

11. ¿Qué beneficios considera que tienen las herramientas de gestión administrativa?

12. ¿Qué otra herramienta de gestión administrativa le gustaría que se implemente?

Personal medico

1. ¿Sabe usted cuales con las herramientas de gestión administrativa que tiene EsSalud?

2. ¿Cómo se enteró que existen estas herramientas de gestión?

3. ¿De todas las herramientas de gestión cual es para usted la más importante o relevante?

4. ¿Conoce Usted el Plan Operativo Institucional 2017, las normas para la gestión de la oportunidad quirúrgica y las normas de referencias y contrarreferencias?

5. ¿Considera Usted importante las herramientas de gestión administrativa para el manejo de la lista de espera de oportunidad quirúrgica? ¿Por qué?

6. ¿Cómo se comunica al personal los cambios de dichas herramientas?

7. ¿Desde su punto de vista son útiles para usted las herramientas de gestión?

8. ¿Para usted cual es la finalidad del Plan Operativo Institucional?

9. ¿Considera usted que las normas para la gestión de la oportunidad quirúrgica de la Institución se alinean a la realidad que afronta el hospital?

10. ¿Existe alguna evaluación de las herramientas de gestión administrativas? ¿Cómo es?

11. ¿Qué beneficios considera que tienen las herramientas de gestión administrativa?

12. ¿Qué otra herramienta de gestión administrativa le gustaría que se implemente?

Personal administrativo 
1. ¿Sabe usted cuales con las herramientas de gestión administrativa que tiene EsSalud?

2. ¿Cómo se enteró que existen estas herramientas de gestión?

3. ¿De todas las herramientas de gestión cual es para usted la más importante o relevante?

4. ¿Conoce Usted el Plan Operativo Institucional 2017, las normas para la gestión de la oportunidad quirúrgica y las normas de referencias y contrarreferencias?

5. ¿Considera Usted importante las herramientas de gestión administrativa para el manejo de la lista de espera de oportunidad quirúrgica? ¿Por qué?

6. ¿Cómo se comunica al personal los cambios de dichas herramientas?

7. ¿Desde su punto de vista son útiles para usted las herramientas de gestión?

8. ¿Para usted cual es la finalidad del Plan Operativo Institucional?

9. ¿Considera usted que las normas para la gestión de la oportunidad quirúrgica de la Institución se alinean a la realidad que afronta el hospital?

10. ¿Existe alguna evaluación de las herramientas de gestión administrativas? ¿Cómo es?

11. ¿Qué beneficios considera que tienen las herramientas de gestión administrativa?

12. ¿Qué otra herramienta de gestión administrativa le gustaría que se implemente?

Segmento asegurado

No aplica

Categoría 5 -Tiempo de espera para la atención del paciente quirúrgico.

\section{Segmento Gerente Quirúrgico}

1. ¿Cuál es el tiempo de espera aproximado para la atención de un paciente quirúrgico en el hospital? 
2. ¿Cuál es el proceso para determinar el tiempo de espera para un paciente que necesita ser intervenido quirúrgicamente?

3. ¿Cuál cree usted que es el factor más relevante que impacta en el tiempo de espera para que un paciente sea atendido quirúrgicamente?

4. A su criterio ¿Cómo ve los tiempos de espera para la oportunidad quirúrgica que tiene el hospital?

5. ¿Qué factor o factores podrían mejorar los tiempos de espera para la atención de pacientes quirúrgicos?

6. ¿Ha encontrado usted alguna oportunidad de mejora para contrarrestar el tiempo de espera que tiene el hospital?

7. ¿Cree usted que un mejor apoyo administrativo mejoraría los tiempos de espera? y ¿Cuál sería?

8. Para la programación quirúrgica ¿el tiempo de espera que tiene un paciente es el elemento más importante?

9. ¿Quién es el personal a cargo de llevar el control de los tiempos de espera en el área?

10. ¿Cómo y qué persona comunica al paciente el tiempo de espera?

Segmento Jefes

1. ¿Cuál es el tiempo de espera aproximado para la atención de un paciente quirúrgico en el hospital?

2. ¿Cuál es el proceso para determinar el tiempo de espera para un paciente que necesita ser intervenido quirúrgicamente?

3. ¿Cuál cree usted que es el factor más relevante que impacta en el tiempo de espera para que un paciente sea atendido quirúrgicamente? 
4. A su criterio ¿Cómo ve los tiempos de espera para la oportunidad quirúrgica que tiene el hospital?

5. ¿Qué factor o factores podrían mejorar los tiempos de espera para la atención de pacientes quirúrgicos?

6. ¿Ha encontrado usted alguna oportunidad de mejora para contrarrestar el tiempo de espera que tiene el hospital?

7. ¿Cree usted que un mejor apoyo administrativo mejoraría los tiempos de espera? y ¿Cuál sería?

8. Para la programación quirúrgica ¿el tiempo de espera que tiene un paciente es el elemento más importante?

9. ¿Quién es el personal a cargo de llevar el control de los tiempos de espera en el área?

10. ¿Cómo y qué persona comunica al paciente el tiempo de espera?

\section{Personal Médico}

1. ¿Cuál es el tiempo de espera aproximado para la atención de un paciente quirúrgico en el hospital?

2. ¿Cuál es el proceso para determinar el tiempo de espera para un paciente que necesita ser intervenido quirúrgicamente?

3. ¿Cuál cree usted que es el factor más relevante que impacta en el tiempo de espera para que un paciente sea atendido quirúrgicamente?

4. A su criterio ¿Cómo ve los tiempos de espera para la oportunidad quirúrgica que tiene el hospital?

5. ¿Qué factor o factores podrían mejorar los tiempos de espera para la atención de pacientes quirúrgicos? 
6. ¿Ha encontrado usted alguna oportunidad de mejora para contrarrestar el tiempo de espera que tiene el hospital?

7. ¿Cree usted que un mejor apoyo administrativo mejoraría los tiempos de espera? y cuál sería?

8. Para la programación quirúrgica ¿el tiempo de espera que tiene un paciente es el elemento más importante?

9. ¿Quién es el personal a cargo de llevar el control de los tiempos de espera en el área?

10. ¿Cómo y qué persona comunica al paciente el tiempo de espera?

Personal Administrativo

1. ¿Cuál es el tiempo de espera aproximado para la atención de un paciente quirúrgico en el hospital?

2. ¿Cuál es el proceso para determinar el tiempo de espera para un paciente que necesita ser intervenido quirúrgicamente?

3. ¿Cuál cree usted que es el factor más relevante que impacta en el tiempo de espera para que un paciente sea atendido quirúrgicamente?

4. A su criterio ¿Cómo ve los tiempos de espera para la oportunidad quirúrgica que tiene el hospital?

5. ¿Qué factor o factores podrían mejorar los tiempos de espera para la atención de pacientes quirúrgicos?

6. ¿Ha encontrado usted alguna oportunidad de mejora para contrarrestar el tiempo de espera que tiene el hospital?

7. ¿Cree usted que un mejor apoyo administrativo mejoraría los tiempos de espera? y ¿Cuál sería? 
8. Para la programación quirúrgica ¿el tiempo de espera que tiene un paciente es el elemento más importante?

9. ¿Quién es el personal a cargo de llevar el control de los tiempos de espera en el área?

10. ¿Cómo y qué persona comunica al paciente el tiempo de espera?

Segmento Asegurado

1. ¿Cuál es el tiempo de espera aproximado para la atención de un paciente quirúrgico en el hospital?

2. ¿Cuál cree usted que es el factor más relevante que impacta en el tiempo de espera para que un paciente sea atendido quirúrgicamente?

3. A su criterio ¿Cómo ve los tiempos de espera para la oportunidad quirúrgica que tiene el hospital?

4. ¿Qué factor o factores podrían mejorar los tiempos de espera para la atención de pacientes quirúrgicos? 
ANEXO 02

\begin{tabular}{|c|c|c|}
\hline CATEGORIAS & TEMAS & CÓDIGO \\
\hline \multirow{5}{*}{$\begin{array}{l}\text { OPORTUNIDAD } \\
\text { DE MEJORA PARA } \\
\text { EL MANEJO DE LA } \\
\text { LISTA DE ESPERA } \\
\text { DE } \\
\text { OPORTUNIDAD } \\
\text { QUIRÚRGICA }\end{array}$} & $\begin{array}{l}\text { Mejorar en los procesos } \\
\text { administrativos } \\
\text { haciéndolos más eficientes y } \\
\text { simplificarlos }\end{array}$ & MPAIHMES \\
\hline & $\begin{array}{l}\text { Optimizar los turnos operatorios } \\
\text { de personal médico }\end{array}$ & OTO \\
\hline & $\begin{array}{l}\text { Abastecimiento de materiales, } \\
\text { insumos y recursos humanos } \\
\text { (médicos) }\end{array}$ & AMIRH \\
\hline & $\begin{array}{l}\text { Control y monitoreo del registro } \\
\text { de los pacientes en la lista de } \\
\text { espera }\end{array}$ & CMRPLE \\
\hline & $\begin{array}{l}\text { Que cuente con los insumos y } \\
\text { materiales específicos para entrar } \\
\text { a la cirugía. }\end{array}$ & QCIMEC \\
\hline \multirow{4}{*}{$\begin{array}{l}\text { OBJETIVOS } \\
\text { METAS }\end{array}$} & $\begin{array}{l}\text { Que cada servicio tenga visión a } \\
\text { futuro para su desarrollo } \\
\text { quirúrgico }\end{array}$ & QCSTVFDQ \\
\hline & $\begin{array}{l}\text { Imparte los objetivos como parte } \\
\text { de su gestión }\end{array}$ & IOREM \\
\hline & $\begin{array}{l}\text { Reuniones de capacitación y } \\
\text { reuniones de evaluación de metas }\end{array}$ & RCREM \\
\hline & $\begin{array}{l}\text { La meta es disminuir el número } \\
\text { de días de la lista de espera en } \\
\text { menos de } 45 \text { días }\end{array}$ & LMDNDLE \\
\hline \multirow{2}{*}{$\begin{array}{l}\text { NORMAS PARA LA } \\
\text { GESTIÓN DE LA } \\
\text { OPORTUNIDAD } \\
\text { QUIRÚRGICA }\end{array}$} & $\begin{array}{l}\text { Conoce le las normas de la } \\
\text { oportunidad quirúrgica }\end{array}$ & CLNOQ \\
\hline & Estípula 45 días de espera & E45D \\
\hline \multirow{4}{*}{ LISTA DE ESPERA } & $\begin{array}{l}\text { Los jefes de servicios arman los } \\
\text { turnos del personal médico para } \\
\text { las operaciones }\end{array}$ & LJSATPMO \\
\hline & \begin{tabular}{|l} 
Existen dos tipos de lista de \\
espera uno menor o igual a 45 \\
días y otro mayor a 45 días \\
\end{tabular} & EDLEM45M45 \\
\hline & \begin{tabular}{|lll}
\multicolumn{4}{l}{ Los pacientes de la lista de espera } \\
son reemplazados por los \\
pacientes que ingresan por \\
emergencia
\end{tabular} & PLERPE \\
\hline & $\begin{array}{l}\text { La lista de espera incorpora los } \\
\text { pacientes que han sido } \\
\text { diagnosticados con necesidad } \\
\text { quirúrgica y que han cumplidos } \\
\text { con todos los requisitos previos } \\
\end{array}$ & LEIPDNQCRP \\
\hline
\end{tabular}




\begin{tabular}{|c|c|c|}
\hline CATEGORIAS & TEMAS & CÓDIGO \\
\hline & $\begin{array}{l}\text { Un paciente de la lista de espera } \\
\text { es un paciente para una } \\
\text { programación electiva } \\
\text { (oportunidad quirúrgica) }\end{array}$ & PLEPPE \\
\hline & $\begin{array}{l}\text { La lista de espera se maneja } \\
\text { mediante el Sistema de Gestión } \\
\text { Hospitalaria-SGH }\end{array}$ & LEMMSGH \\
\hline & $\begin{array}{l}\text { Las operaciones quirúrgicas } \\
\text { deben llevarse a cabo respetando } \\
\text { la lista de espera }\end{array}$ & OQDRLE \\
\hline & $\begin{array}{l}\text { La información que contiene la } \\
\text { lista de espera no está sincerada ni } \\
\text { actualizada }\end{array}$ & ICLENSNA \\
\hline \multirow{3}{*}{$\begin{array}{ll}\text { HERRAMIENTAS } \\
\text { DE r GESTIÓN } \\
\text { ADMINISTRATIVA }\end{array}$} & \begin{tabular}{|l}
\multicolumn{3}{l}{ Todo el personal debe conocer las } \\
metas establecidas en las \\
herramientas de gestión \\
administrativa
\end{tabular} & TPDCMEHG \\
\hline & $\begin{array}{l}\text { Son útiles porque marcan los } \\
\text { objetivos, criterios y requisitos } \\
\text { para que el paciente se atienda en } \\
\text { alguna de las áreas }\end{array}$ & SUOCPAA \\
\hline & \begin{tabular}{|lrrr} 
Establecen & los & \multicolumn{2}{c}{ indicadores } \\
Permite conocer & las & metas \\
alcanzadas & y & \multicolumn{2}{c}{ realizar } \\
comparaciones entre períodos
\end{tabular} & EIPCMARCEP \\
\hline \multirow{2}{*}{$\begin{array}{lr}\text { GESTIÓN } \\
\text { ADMINISTRATIVA } \\
\text { PARA } \\
\text { ATENCIÓN } \\
\text { PACIENTE } \\
\text { QUIRÚRGICO }\end{array}$} & $\begin{array}{l}\text { La gestión administrativa es } \\
\text { engorrosa y lenta }\end{array}$ & GAEL \\
\hline & $\begin{array}{l}\text { Actualmente la vigencia de los } \\
\text { resultados de los exámenes } \\
\text { prequirúrgicos se ha ampliado de } \\
3 \text { a } 6 \text { meses }\end{array}$ & AVREPA6M \\
\hline \multirow{6}{*}{$\begin{array}{l}\text { FACTORES QUE } \\
\text { INTERVIENEN EN } \\
\text { EL MANEJO DE LA } \\
\text { LISTA DE ESPERA }\end{array}$} & $\begin{array}{l}\text { Si el servicio de anestesiología } \\
\text { falla o para todas las operaciones } \\
\text { quirúrgicas de los servicios se } \\
\text { paralizan ofallan }\end{array}$ & SSDAFPOQ \\
\hline & $\begin{array}{l}\text { Poca disponibilidad de turnos } \\
\text { quirúrgicos, debido a la brecha de } \\
\text { médico anestesiólogo }\end{array}$ & PDTQDBA \\
\hline & $\begin{array}{l}\text { Brecha de insumos y materiales } \\
\text { médicos }\end{array}$ & BIMM \\
\hline & $\begin{array}{l}\text { Coordinaciones complicadas con } \\
\text { el área de Logística para el } \\
\text { proceso de compras }\end{array}$ & CCALPPC \\
\hline & $\begin{array}{l}\text { Los médicos cirujano a veces no } \\
\text { tienen turnos disponibles }\end{array}$ & MCNTD \\
\hline & $\begin{array}{l}\text { Los pacientes son atendidos } \\
\text { preferentemente por referencias } \\
\text { externas, lo cual altera la lista de } \\
\text { espera oficial. }\end{array}$ & PAPREALE \\
\hline
\end{tabular}




\begin{tabular}{|c|c|c|}
\hline CATEGORIAS & TEMAS & CÓDIGO \\
\hline & $\begin{array}{l}\text { Camas ocupadas mayor tiempo } \\
\text { por reprogramaciones quirúrgicas }\end{array}$ & COMTPPQ \\
\hline \multirow{2}{*}{$\begin{array}{l}\text { PLAN OPERATIVO } \\
\text { INSTITUCIONAL }\end{array}$} & $\begin{array}{l}\text { No conoce las metas establecidas } \\
\text { en POI }\end{array}$ & NCMPOI \\
\hline & $\begin{array}{l}\text { Si conocen y trabajan en función } \\
\text { a sus metas establecidas en su POI }\end{array}$ & SCTFMPOI \\
\hline
\end{tabular}

